\title{
Advanced Fuels Campaign 2013 Accomplishments
}

October 2013

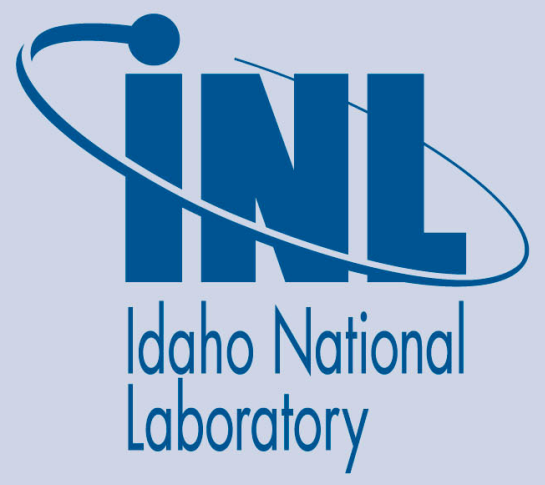

The INL is a U.S. Department of Energy National Laboratory operated by Battelle Energy Alliance 
INL/EXT-13-30520

FCRD-FUEL-2013-000269

\title{
Advanced Fuels Campaign 2013 Accomplishments
}

\author{
Compiled and Edited By: \\ Lori Braase \\ Doug Hamelin \\ INL Systems Analyses
}

October 2013

\section{Idaho National Laboratory \\ Fuel Cycle Research and Development Idaho Falls, Idaho 83415}

http://www.inl.gov

Prepared for the

U.S. Department of Energy

Office of Nuclear Energy

Under DOE Idaho Operations Office

Contract DE-AC07-05ID14517 


\section{ADVANCED FUELS CAMPAIGN 2013 Accomplishments}
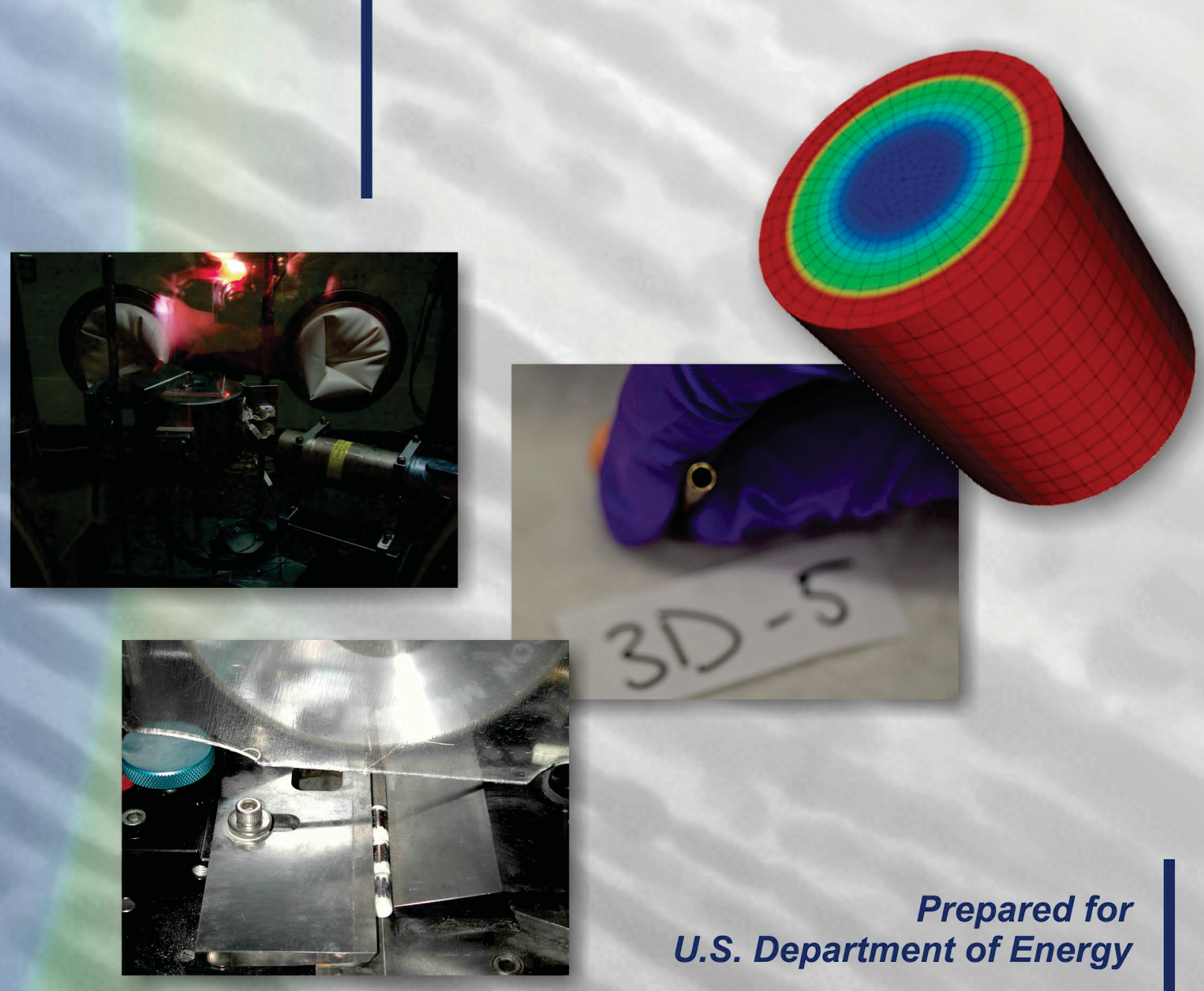

Prepared for U.S. Department of Energy Advanced Fuels Campaign

Revision 0 October 2013 FCRD-FUEL-2013-000269

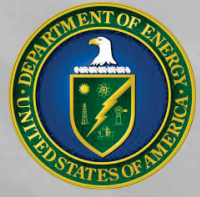




DISCLAIMER
This information was prepared as an account of work sponsored by an
agency of the U.S. Government. Neither the U.S. Government nor any
agency thereof, nor any of their employees, makes any warranty,
expressed or implied, or assumes any legal liability or responsibility for
the accuracy, completeness, or usefulness, of any information, apparatus,
product, or process disclosed, or represents that its use would not infringe
privately owned rights. References herein to any specific commercial
product, process, or service by trade name, trade mark, manufacturer, or
otherwise, does not necessarily constitute or imply its endorsement,
recommendation, or favoring by the U.S. Government or any agency
thereof. The views and opinions of authors expressed herein do not
necessarily state or reflect those of the U.S. Government or any agency
thereof.




\title{
ADVANCED FUELS CAMPAIGN FY 2013 ACCOMPLISHMENTS REPORT
}

\author{
FCRD-FUEL-2013-000269 \\ INL/EXT-13-30520 \\ Revision 0
}

October 2013

Compiled and edited by:

Lori Braase (lori.braase@inl.gov)

Doug Hamelin (douglas.hamelin@inl.gov)

INL Systems Analyses

\section{Approved by:}

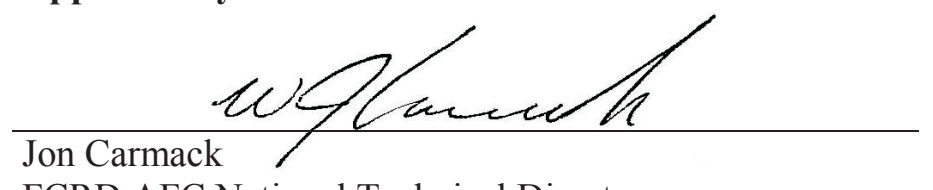

October 30, 2013

FCRD AFC National Technical Director 
This page intentionally left blank. 


\section{CONTENTS}

ACRONYMS. viii

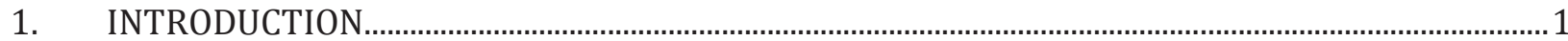

2. CAMPAIGN MANAGEMENT AND ORGANIZATION ….......................................................................

2.1 AFC Integration Meetings and Technical Workshops .............................................................. 6

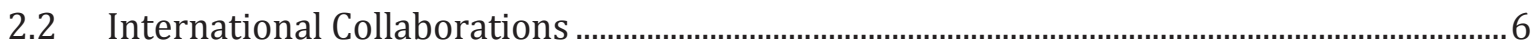

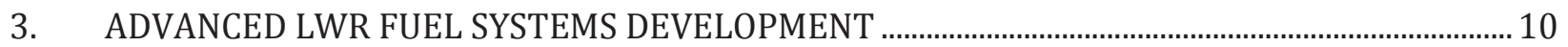

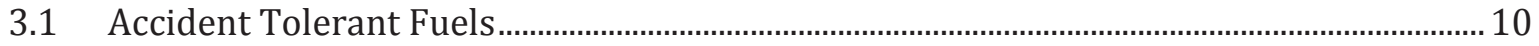

3.2 Industry and University Led Accident Tolerant Fuel Projects ...............................................12

3.3 Core Level Advanced LWR Fuel Concept Analysis ................................................................... 12

3.4 DOE/JAEA Collaboration on Accident Behavior of Oxide Fuels.............................................. 14

3.5 Severe Accident Test Facility ……..................................................................................... 15

3.6 Thermochemical Experiment and Modeling of U-RE-O Systems .......................................... 16

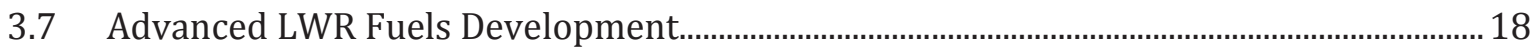

3.7.1 Ceramic Fuel Technologies.......................................................................................... 18

3.7.2 High Density Fuels Glovebox ..................................................................................... 19

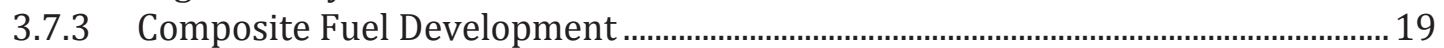

3.7.4 Fabrication of Enriched Ceramic Fuels ......................................................................... 21

3.7.5 Field Assisted Sintering Technique (FAST) ................................................................ 22

3.7.6 Particulate Based Fuels........................................................................................................ 23

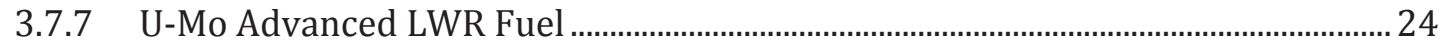

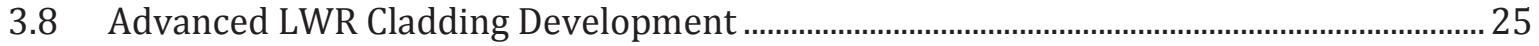

3.8.1 Advanced FeCrAl Alloy Development .........................................................................25

3.8.2 Molybdenum LWR Clad Development through CVD Processing...............................26

3.8.3 SiC Gap Analysis and Feasibility Study for LWR Application...................................... 26

3.8.4 Neutron Irradiation Testing of ATF Cladding Materials ............................................. 27

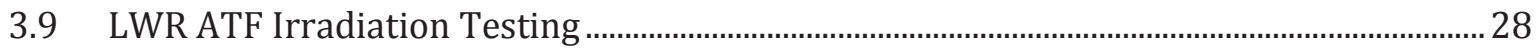

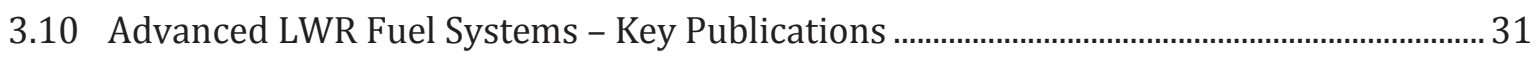

4. METALLIC TRANSMUTATION FUELS TECHNOLOGIES ..................................................................... 34

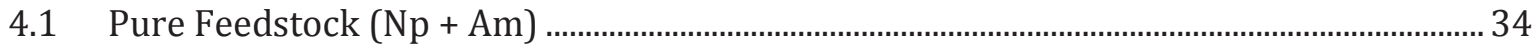

4.2 Advanced Transmutation Fuel Fabrication Technique Development ................................. 35

4.3 Fabrication of Metal Fuel Samples for Irradiation Testing ……................................................. 37

4.4 Transmission Electron Microscopy Analysis of U-Pu-Zr Alloys.............................................. 38

4.5 Performance modeling of the AFC-2A, 2B irradiation experiments ..................................... 40

4.6 Metal Fuel Performance Sensitivity Assessment .......................................................................... 42

4.7 PIE Report on Legacy EBR-II Metallic Fuels................................................................................. 44

4.8 Fast Reactor Cladding Development............................................................................................ 45

4.9 FFTF/MOTA Irradiation Results on Tempered Ferritic/Martensitic Steels....................... 46

4.10 High Dose Irradiation Results on MA957 Advanced ODS Ferritic Alloy …........................... 47

FCRD-FUEL-2013-000269 iii 
4.11 Radiation Resistance of a Large NQA-1 Heat of HT-9 ............................................................. 48

4.12 Metallic Transmutation Fuels Technologies - Key Publications ............................................ 48

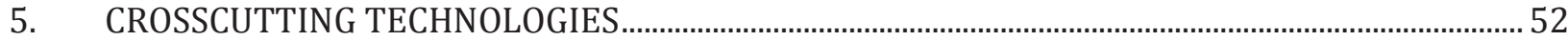

5.1 Advanced Non-Destructive Post Irradiation Examination.....................................................5 52

5.2 Laser-based Characterization/PIE Technique Development ................................................. 53

5.3 Atom Probe Tomography on U-Pu-Zr fuel .................................................................................. 55

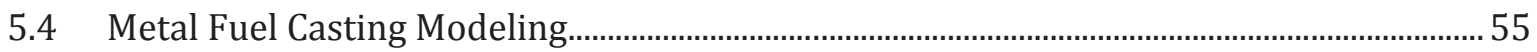

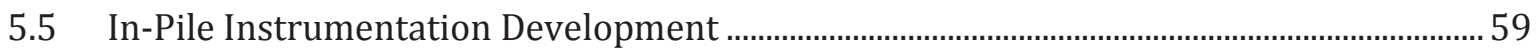

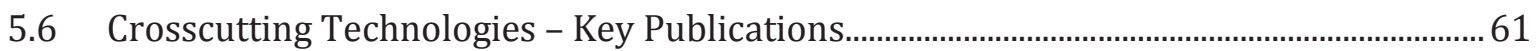

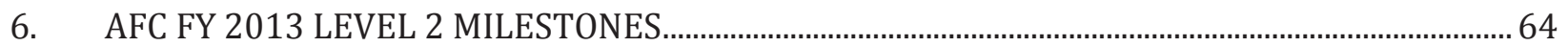

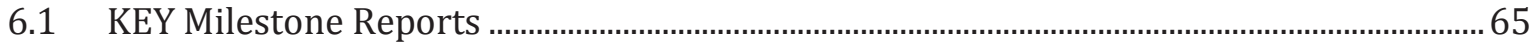

\section{FIGURES}

Figure 1. AFC Organization with NEAMS Interface ……................................................................................ 5

Figure 2. Proposed Accident Tolerant Fuel evaluation methodology. Preliminary concept down-selection would occur within Step 1, with secondary down-selection occurring at the end of Phase 1 prior to detailed tests and behavior model

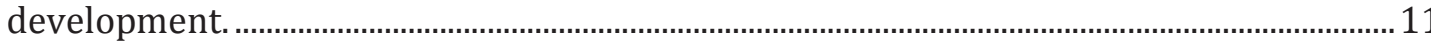

Figure 3. Explicit Serpent (Monte Carlo) model of Reference Reactor .........................................................13

Figure 4. Impact of the UN fuel porosity on the cycle length assuming a constant linear heat rate per pin

Figure 5. Oxidation rate constants developed for UO2 exposed to various partial pressures of water vapor as required for kinetic rate studies illustrating the impact of temperature on oxidation and degradation of $\mathrm{UO}_{2}$ at elevated temperatures. Sample families of oxidation curves are shown at left.

Figure 6. Severe Accident Test Station and Associated CVD-SiC Exposure Test Results 16

Figure 7. ATF FeCrAl LOCA Test 16

Figure 8. Oxygen Distribution in Irradiated Fuel Pellet 17

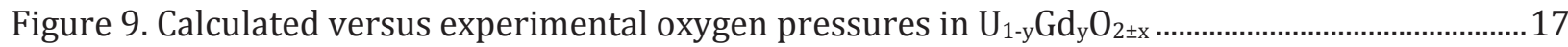

Figure 10. High Density Fuels Glovebox in EFF.

Figure 11. Thermal conductivity of $\mathrm{U}_{3} \mathrm{Si}$ and $\mathrm{U}_{3} \mathrm{Si}_{2}$ as a function of temperature compared to that of $\mathrm{UO}_{2}$. (a) Oxidation of $\mathrm{U}_{3} \mathrm{Si}_{2}$ and $\mathrm{U}_{3} \mathrm{Si}_{5}$ in synthetic air compared to $\mathrm{UN}$ and $\mathrm{UO}_{2} \cdot(\mathrm{b})$

Figure 12. Centerless grinder preparing to grind three alumina surrogate pellets. Pellets before and after grinding

Figure 13. UF $_{6}$ Deconversion Lab-scale Reactor Vessel 
Figure 14. Comparison of the sintering rates of conventional versus field assisted sintering for $\mathrm{UO}_{2}$ pellets

Figure 15. High density $U(C, N)$ kernels have been fabricated and characterized via electron microscopy and X-ray diffractometry.

Figure 16. Examination of surrogate fully ceramic micro encapsulated fuel irradiated to LWR-lifetime conditions has revealed excellent performance of both fuel matrix and constituent layers of the TRISO fuel. 24

Figure 17. U-Mo Extrusion Press................................................................................................................................ 24

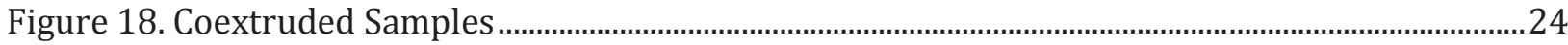

Figure 19. PVD Coated U-Mo Disk Ready for Corrosion Testing.....................................................................25

Figure 20. Radiography and metallographic images of a prototype irradiation capsule ........................25

Figure 21. 1x1 $\mu \mathrm{m}$ atomic force microscopy (AFM) image from FBCVD Mo film, showing grain size ranging from 10 to $130 \mathrm{~nm}$

Figure 22. Comparison of MELCOR-predicted maximum cladding temperature during a TMI2 accident sequence for Zircaloy and SiC cladding and structural components.

Figure 23. Optical image showing tensile specimen of 14YWT (ferritic oxide dispersion strengthened steel) after irradiation in ATR to $6 \mathrm{dpa}$ at a temperature of $290^{\circ} \mathrm{C}$ 27

Figure 24. ATF-1 Experiment Component Cross Sections. 29

Figure 25. ATF-1 Capsule and Rodlet Design 30

Figure 26. LWR Basket Design. 30

Figure 27. Left: design drawing of the Americium Distillation Furnace including tantalum tube (olive color) containing molten Americium (plum color) and special gamma detector (upper left of picture). Right: actual Americium Distillation Furnace assembled in glovebox showing the special gamma detector (tube with yellow tape at right) that accurately measures movement of radioactive metal from hot distillation zone to cold condensation zone.

Figure 28. Photo of purified Am chips obtained using Americium Distillation/Condensation apparatus at INL. A total of 4.1 grams were recovered.

Figure 29. Glovebox Advanced Casting System installed and assembled in the Casting Laboratory glovebox.

Figure 30. Temperature log of typical test casting run of the GACS performed as validation test in the CL glovebox

Figure 31. Right: example showing outside surface of as machined fuel slug product. Left: same as machined fuel slug showing annulus. .38

Figure 32. Finished AFC-3C irradiation test capsules.

Figure 33. TEM micrograph obtained from an as-cast 52U-20Pu-3Am-2Np-8.0Ln-15Zr sample showing nano-sized light and dark contrast grain structure.

Figure 34. Electron diffraction pattern from a Zr rich inclusion along the [110] axis revealing it to be in the, to date, unreported face-centered-cubic structure. 39 
Figure 35. Left: high Am content RE inclusion surrounded by high $\mathrm{Zr}$ content inclusion.

Right: combined high Zr content and high Am content inclusion.

Figure 36. Effect of a breach in rodlet 4 on the cladding temperature during the AFC-2A

(left) and AFC-2B (right) irradiation.

Figure 37. Comparison of the calculated location of the $1700 \mathrm{C}$ isotherm and peak temperature with the post irradiation examination image

Figure 38. Case 1 - Literature values for phase diagram transition temperatures, adjust rod power and boundary condition

Figure 39. Case 2 - Operator data for power and temperature boundary condition, adjust the phase transition temperatures

Figure 40. Full T179 Model 44

Figure 41. Fission gas release from X496 pins compared to higher smeared density (75\%) U-10Zr irradiations in EBR-II

Figure 42. Optical micrograph of top axial section (X/L = 0.95) of X496 pin CL14. White colored areas are the fuel; dark is epoxy-impregnated porosity.

Figure 43. Tubes fabricated from 14YWT (FCRD-NFA1 heat) for irradiation in the BOR-60 reactor (a) Tubes L101-L104 and (c) Tubes L105-L116 will be irradiated at 380C. Tubes (b) L201-L204 and (d) Tubes L205-L216 will be irradiated at 410C.

Figure 44. Fracture toughness of HT-9, GA3X and F82H after $5-7$ dpa at $375^{\circ} \mathrm{C}$ and resulting matrix precipitates that form as viewed by atom probe tomography.

Figure 45. Fracture surface of an MA957 tensile specimen irradiated to $412^{\circ} \mathrm{C}$ at $109 \mathrm{dpa}$ and tested at room temperature.

Figure 46. Stress/Strain curves plotted for ferritic/martensitic steels before and after irradiation in ATR to $6 \mathrm{dpa}$ at 290C. Tests performed at room temperature.

Figure 47. Illustration of a) the series of energy-specific radiographic images acquired for a single LANSCE neutron pulse for the first generation of $\mathrm{UO}_{2}$ mockup assemblies, and b) a single radiographic image at a specific energy with the associated nresonance patterns.

Figure 48. Left: Photograph of MPM, Left-middle: Elastic constants of UZr system vs. composition (values reported in GPa), Right-middle: Elastic constants of HT9 vs. temperature (inset: heating furnace), Right: Sample loading capsule.

Figure 49. APT reconstruction of oxidized U-55Pu-20Zr sample showing the different oxidation depths of the components. Only the metallic ions of $\mathrm{Zr}, \mathrm{U}$, and $\mathrm{Pu}$ are displayed to highlight different oxidation behavior

Figure 50. Reconstruction of U-55Pu-20Zr samples showing the $\mathrm{Pu} / \mathrm{U}$ rich and $\mathrm{Zr}$ depleted region at the edge of the samples that is hypothesized to be a former grain boundary region. .55

Figure 51. Two alternative mold geometries that show promise in reducing rod breakage. .57

Figure 52. Phase diagram representations for simple, linear alloys, and complex uraniumplutonium alloys .58

Figure 53. Simple fuel rod geometry and preliminary U-Pu segregation simulation results. 59 


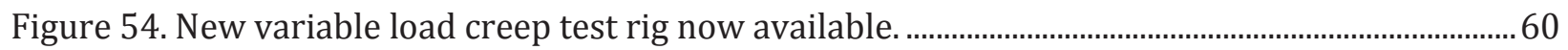

Figure 55. INL-developed magnetostrictive transducer design...................................................................60

Figure 56. Laboratory evaluations initiated for enhancing fiber optics based elongation probe.

\section{TABLES}

Table 1. Calculated cycle length for various fuel options at $5 \%{ }^{235} \mathrm{U}$ enrichment with a soluble boron concentration of 500 ppm.................................................................................. 20

Table 2. ATF Irradiation Testing and Qualification Test Series (Planning)................................................28

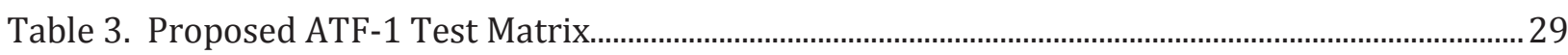

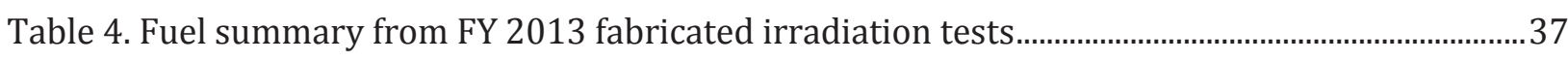

Table 5. $\mathrm{UO}_{2}$ mockup assemblies for advanced NDE assessments at LANSCE.........................................53 


\section{ACRONYMS}

AFC

AMBB

ANL

A00

APT

ASU

ATF

ATR

BDBA

BNL

CAES

CEA

CNC

CRADA

CVD

DFEM

DOE

dpa

EBR

EFPD

EPRI

EURATOM

FAST

FBCVD

FCF

FCM

FCRD

FFTF

FIB

FOA

FS

FY

GACID
Advanced Fuels Campaign

Americium Bearing Blankets

Argonne National Laboratory

Anticipated Operational Occurrence

Atom Probe Tomography

Arizona State University

Accident Tolerant Fuel

Advanced Test Reactor

Beyond Design Basis Accident

Brookhaven National Laboratory

Center for Advanced Energy Studies

Atomic Energy Commission (France)

Computer Numerical Control

Cooperative Research and Development Agreement

Chemical Vapor Deposition

Densification-Based Finite-Element Model

Department of Energy

Displacements Per Atom

Experimental Breeder Reactor

Effective Full-Power Day

Electric Power Research Institute

European Atomic Energy Community

Field Assisted Sintering Technique

Fluidized Bed Chemical Vapor Deposition

Fuel Conditioning Facility

Fully Ceramic Microencapsulated

Fuel Cycle Research and Development

Fast Flux Test Facility

Focused Ion Beam

Funding Opportunity Announcement

Flash Sintering

Fiscal Year

Global Actinide Cycle International Demonstration 
GACS

HFEF

HFIR

IAEA

INERI

INL

IRP

ITU

JAEA

JFCS

KAERI

LANL

LANSCE

LEAP

LLNL

LOCA

LTA

LTR

LWR

LWRS

MA

MBM

MFC

Mo

MOTA

MOX

MPM

MSC

NDE

NE

NEAMS

NEUP

NFA

NRAD

NRC
Glovebox Advanced Casting System

Hot Fuel Examination Facility

High-Flux Isotope Reactor

International Atomic Energy Agency

International Nuclear Energy Research Initiative

Idaho National Laboratory

Integrated Research Project

Institute for Transuranium Elements

Japan Atomic Energy Agency

Joint Fuel Cycle Studies

Korean Atomic Energy Research Institute

Los Alamos National Laboratory

Los Alamos Neutron Science Center

Local Electrode Atom Probe

Lawrence Livermore National Laboratory

Loss of Coolant Accident

Lead Test Assembly

Lead Test Rod

Light Water Reactor

Light Water Reactor Sustainability Program

Minor Actinide

MOOSE-BISON-MARMOT

Materials and Fuels Complex

Molybdenum

Materials Open Test Assembly

Mixed Oxide

Mechanical Properties Microscope

Master Sintering Curve

Non-Destructive Examination

Office of Nuclear Energy

Nuclear Energy Advanced Modeling and Simulation

Nuclear Energy University Program

Nano-Strengthened Ferritic Alloy

Neutron Radiography Reactor

Nuclear Regulatory Commission 
ODS

OECD-NEA

ORNL

PIE

PNNL

PWR

$\mathrm{R} \& \mathrm{D}$

RD\&D

RIAR

SATS

SEM

SET

$\mathrm{SiC}$

SFR

SPS

SRNL

TCM

TD

TEM

TMI

TRISO

TRL

TRU

UNF

USC

XRD
Oxide Dispersion Strengthened

Org for Economic Cooperation and Development-Nuclear Energy Agency

Oak Ridge National Laboratory

Post-irradiation Examination

Pacific Northwest National Laboratory

Pressurized Water Reactor

Research and Development

Research, Development, and Demonstration

Research Institute of Atomic Reactors (Russia)

Severe Accident Test Station

Scanning Electron Microscope

Separate Effects Test

Silicon Carbide

Sodium Fast Reactor

Spark Plasma Sintering

Savannah River National Laboratory

Thermal Conductivity Microscope

Theoretical Density

Transmission Electron Microscope

Three Mile Island

Tristructural Isotropic

Technology Readiness Level

Transuranic

Used Nuclear Fuel

University of South Carolina

$\mathrm{X}$-Ray Diffraction 


\section{ADVANCED FUELS CAMPAIGN FY 2013 ACCOMPLISHMENTS REPORT}

\section{INTRODUCTION}

The mission of the Advanced Fuels Campaign (AFC) is to perform Research, Development, and Demonstration (RD\&D) activities for advanced fuel forms (including cladding) to enhance the performance and safety of the nation's current and future reactors; enhance proliferation resistance of nuclear fuel; effectively utilize nuclear energy resources; and address the longer-term waste management challenges. This includes development of a state-of-the art Research and Development (R\&D) infrastructure to support the use of "goal-oriented science-based approach."

In support of the Fuel Cycle Research and Development (FCRD) program, AFC is responsible for developing advanced fuels technologies to support the various fuel cycle options defined in the Department of Energy (DOE) Nuclear Energy Research and Development Roadmap, Report to Congress, April 2010.

AFC uses a "goal-oriented science-based approach" aimed at a fundamental understanding of fuel fabrication methods and fuel and cladding performance under irradiation, enabling the pursuit of multiple fuel forms for future fuel cycle options. This approach includes fundamental experiments, theory, and advanced modeling and simulation. The modeling and simulation activities for fuel performance are carried out under the Nuclear Energy Advanced Modeling and Simulation (NEAMS) program, which is closely coordinated with AFC.

Also included is research and development (R\&D) of light water reactor (LWR) fuels with enhanced accident tolerance to improve the fuel system's ability to achieve significantly higher fuel and plant performance, and to developed innovations that provide major increases in burn-up and performance. The goal is advanced nuclear fuels and materials that are robust, have high performance capability, and are more tolerant to accident conditions than traditional fuel systems. In this report the word "fuel" is used generically to include fuels, targets, and their associated cladding materials.

AFC management and integration activities included continued support for international collaborations, primarily with France, Japan, European Union, Republic of Korea, and China, as well as various working group and expert group activities in the Organization for Economic Cooperation and Development Nuclear Energy Agency (OECD-NEA) and the International Atomic Energy Agency (IAEA). Three industry-led Funding Opportunity Announcements (FOAs) and two university-led Integrated Research Projects (IRPs) were funding in 2013. All are closely integrated with AFC and Accident Tolerant Fuels (ATF) research.

AFC successfully organized and conducted a meeting to initiate development of the attributes and metrics characterizing accident tolerant fuel performance and behavior. It was followed by an international meeting co-organized with OECD/NEA to bring together the international community for the same purpose. The proposed ATF evaluation process was developed and documented in the August AFC LWR ATF Performance Metrics Report Executive Summary.

The FCRD Relevancy Review on AFC was held in Idaho Falls, Idaho on November 5-8, 2012. The report not only covers the entire scope of $\mathrm{AFC}$, but also includes the individual inputs from the panel members. It provides the overall relevancy assessment of the major R\&D activities, responses to panel questions, observations, conclusions, and recommendations. The final report was issued in December. 
Accomplishments made during fiscal year (FY) 2013 are highlighted in this report, which focuses on completed work and results. The process details leading up to the results are not included; however, the technical contact is provided for each section. The key FY 2013 technical area outcomes are highlighted below.

\section{ACCIDENT TOLERANT FUELS (ATF)}

- A high-temperature furnace capable of $1700^{\circ} \mathrm{C}$ was developed and moved into a hot-cell to perform Beyond Design Basis Accident (BDBA) testing of advanced fuel forms. This furnace is part of the Severe Accident Test Station, which will be available to the international community of standard and BDBA testing.

- High temperature steam exposure was performed on a suite of advanced fuel forms to determine kinetics of attack. Results were analyzed and provided to reactor core accident modelers to determine whether improvement in performance or coping time of the reactor is achieved.

- A new enhanced accident tolerant steel alloy has been developed in the FeCrAl composition with exceptional resistance to steam attack at conditions that would consume Zircaloy alloys. Within the defined nuclear compositional range, alloys exhibit good mechanical properties, ease of welding, and are formable into thin walled tubes. Neutron irradiation studies are underway.

- Uranium nitride kernels, assumed critical to achieve normal cycle length in the application of fully ceramic microencapsulated fuels, have been demonstrated to $>92 \%$ theoretical density.

- Examination of surrogate fully ceramic micro encapsulated fuel irradiated to LWR-lifetime conditions has revealed excellent performance of both fuel matrix and constituent layers of the Tristructural Isotropic (TRISO) fuel.

- In a close collaboration between Los Alamos National Laboratory (LANL) and the Japan Atomic Energy Agency (JAEA) researchers, the oxidation behavior of oxide UO2 fuels under breach-of-cladding conditions was determined in new detail. This data will help improve understanding of fuel degradation under severe accident conditions and the associated ability to predict and assess fuel dispersal. These experiments also provide insight and guidance for development of advanced fuel systems which can have improved performance under accident conditions.

- In collaboration between LANL and Brookhaven National Laboratory (BNL), initial screening and assessment of new, advanced ceramic fuels was performed with a specific goal of achieving enhanced accident tolerance while maintaining economic and performance characteristics necessary for near-term deployment in existing LWR reactors. By coupling material compatibility screening experiments with assembly level neutronics analysis, several candidate systems were rapidly discarded allowing a more detailed assessment of remaining candidates. It should be noted that this activity compliments the industry-lead FOA projects on accident tolerant fuel development.

- Capabilities have been established at LANL for fabrication of ceramic fuels with tailored enrichment for testing ATF concepts in the Advanced Test Reactor (ATR) at the Idaho National Laboratory (INL). Enriched feedstock synthesis was demonstrated on a gram scale sample starting from UF6 precursor, which is essential for industrial process compatibly. The feedstock and fuel pellet fabrication glovebox capabilities are specifically targeted at ceramic fuel fabrication. This capability can be available for fuel pellet fabrication to 
support ATF system irradiations for the industry-lead FOAs and the university-lead IRPs, or the national lab-designed concepts. Note that this line cannot produce particle fuel as that special fuel capability is located at Oak Ridge National Laboratory (ORNL).

- Accurate thermodynamic representations of urania-rare earth systems are important for the development of predictive fuel performance models of solid fission product behavior in UO2 and advanced oxide nuclear fuels. In FY 2013, the oxide thermodynamics, and phase equilibria of the U- Ce-O, U-Gd-O, and U-Nd-O systems were studied by researchers at ORNL and papers on the U- Ce-O and U-Gd-O systems were submitted to the Journal of Nuclear Materials. In addition, a paper on the U-La-O system was published in the journal in FY 2013.

- $\quad$ Rapid, low temperature field assisted sintering has been demonstrated for UO2-based fuels. The techniques compliment work done under a University of Florida Nuclear Energy University Program (NEUP) on spark plasma sintering and provide potential for commercially viable pellet fabrication of composite fuels that cannot be made by conventional routes.

- INL and LANL researchers demonstrated neutron beam and proton beam-based advanced, non-destructive post-irradiation examination (PIE) of fuel rods. Initial experiments have shown that these capabilities can allow more rapid development and qualification of new fuel systems by providing 3-D imaging of the fuel microstructure, defects and chemistry. A set of $\mathrm{UO}_{2}$ ceramic and $\mathrm{U}-10 \mathrm{Zr}$ metal fuel rodlet mockups have been fabricated for nondestructive examination at the Los Alamos Neutron Science Center (LANSCE) facilities at LANL and at the Neutron Radiography Reactor (NRAD) facility at INL in order to further defined the spatial resolutions of the various techniques and to establish experience in sample transfer and handling which will be necessary as this new paradigm of PIE is implemented.

- Two new alloys of Fe-Cr-Al Accident Tolerant Cladding were produced by ORNL, called ORNL-A and ORNL-B. Initial materials were sent to INL for weld technique development and LANL for ion irradiation and mechanical testing.

- Thin-walled molybdenum tubing was produced at LANL using the fluidized bed chemical vapor deposition (CVD) process.

- Specimens of candidate ATF engineering alloys that were irradiated in ATR to doses up to 6 dpa at $290^{\circ} \mathrm{C}$ were shipped from INL to LANL hot cells. Tensile testing is underway at LANL and samples have been shipped to ORNL for fracture toughness testing.

- The design of a new irradiation test vehicle for conducting irradiations of accident tolerant fuel concepts in ATR (ATF-1) was completed.

\section{METALLIC TRANSMUTATION FUELS}

- Researchers at INL successfully reduced Americium Oxide (AmOx) to Americium metal. Americium feedstock is in short supply in the United States and Americium in metallic form is ultra-rare. The ability to reduce small quantities of AmOx to Am metal supports the continued R\&D of metallic transmutation fuels.

- The Glovebox Advanced Casting System (GACS) furnace was installed and americium bearing uranium zirconium alloy fuel was used to initiate testing with minor actinide. Installation of the GACS furnace into this glovebox is a very important accomplishment that will enable the casting of plutonium and minor actinide bearing fuels at either near 
atmospheric or increased pressure using gravity casting into a re-usable mold on the 100300 gram scale.

- A total of four drop in style metallic alloy fuel irradiation tests were fabricated in FY 2013 including the AFC-3C, AFC-3D, AFC- 4A, and AFC-4B tests. These tests include both advanced composition as well as fuel structural design concepts. The fuel concepts that are part of the AFC-3C/D and AFC-4A tests include advanced fuel alloys that are both solid sodium bonded fuel and well as annular helium bonded fuels. AFC-4B is a cooperative test between the FCRD program and TerraPower wherein fuel compositions relevant to TerraPower and cladding liners of interest to both programs are included.

- Transmission Electron Microscopy (TEM) studies were conducted on various fuel compositions to better understand the nature of metallic transmutation fuels and to better integrate experiments with computation and modeling with respect to the scientific approach. These studies are the first of their kind with regard to use of the focused ion beam (FIB) for sample preparation of metallic transmutation fuels (TRU bearing fuel type materials) and the use of the TEM and its associated techniques (electron diffraction for single phase crystallite structure determination, energy dispersive spectroscopy for microchemical analysis) to investigate specific microstructural features of the fuel materials.

- Previously irradiated specimens cut from the ACO-3 duct and tubing of an advanced Oxide Dispersion-Strengthened (ODS) alloy (FCRD-NFA1) were successfully shipped to Russia for irradiation in the BOR-60 reactor through a Cooperative Research and Development Agreement (CRADA) with TerraPower.

- Tubing was produced from the consolidated heat of advanced ODS steel, FCRD-NFA1, for inclusion in an irradiation at BOR-60 through a CRADA with TerraPower.

- An irradiation was initiated in ATR for two new advanced metallic fuels experiments.

- A major PIE Report was issued on the examination of relevant legacy fuels from the Experimental Breeder Reactor II (EBR-II).

\title{
CROSSCUTTING CAPABILITIES
}

- The first ever atom probe tomography (APT) studies of AFC transmutation fuel (U-Pu-Zr) were recently performed at the Center for Advanced Energy Studies (CAES) facility at INL. Samples for APT were prepared using the hot FIB at the Materials and Fuels Complex (MFC) and then transferred to CAES for analysis using the cutting edge Local Electrode Atom Probe (LEAP) 4000x HR atom probe.

- A sample loading and heating apparatus was designed and construction initiated for measurement of mechanical and thermal properties. This device will allow for measurement of higher temperature properties using the advanced measurement methods.

\section{CAMPAIGN MANAGEMENT AND ORGANIZATION}

\author{
J. Carmack (INL)
}

One of the most challenging aspects of AFC is the management, integration, and coordination of major R\&D activities across multiple organizations. AFC interfaces and collaborates with FCRD campaigns, universities, industry, various DOE programs and laboratories, federal agencies (e.g., Nuclear Regulatory Commission [NRC]), and international organizations. Key challenges are the development of fuel technologies to enable major increases in fuel performance (safety, reliability, 
power and burnup) beyond current technologies, and development of characterization methods and predictive fuel performance models to enable more efficient development and licensing of advanced fuels. Challenged with the research and development of fuels for two different reactor technology platforms, the AFC program has targeted transmutation fuel development on metal fuel only and focused ceramic fuel development solely on Advanced Light Water Reactor (LWR) Fuels.

AFC is organized into three technical areas and is integrated with NEAMS for fuels modeling and simulation. The technical areas are 1) Advanced LWR Fuels, 2) Metallic Transmutation Fuels, and 3) Crosscutting Capability development. The technical highlights in this report are organized in these three categories shown in Figure 1.

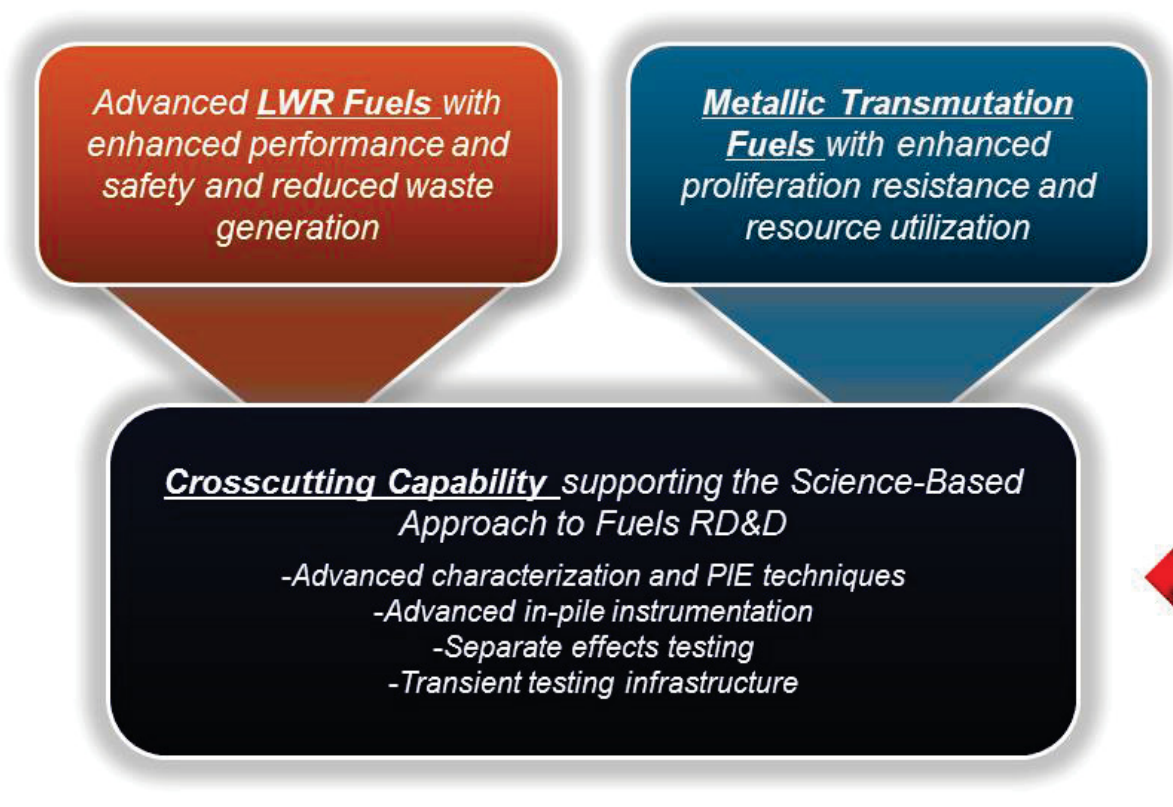

ADVANCED FUELS CAMPAIGN

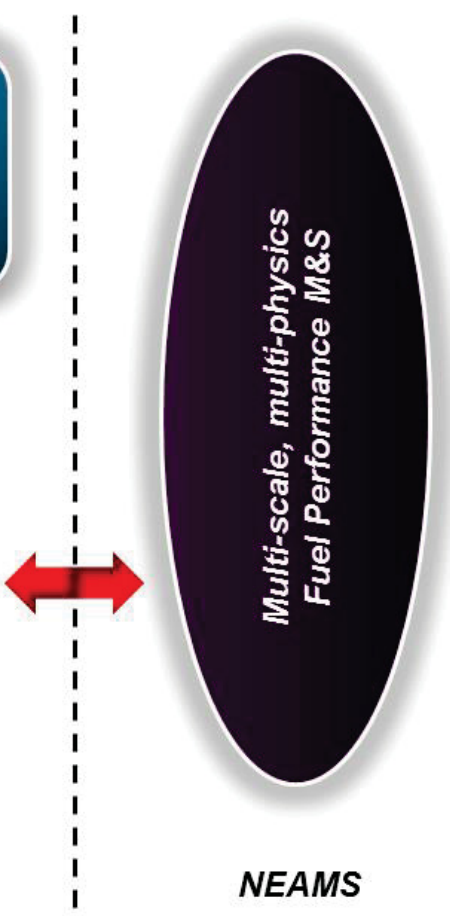

Figure 1. AFC Organization with NEAMS Interface

The AFC leadership team consists of the following technical area leads:

\section{ADVANCED LWR FUELS}

- Ceramic-based Fuels Technologies, K. McClellan, LANL

- Microencapsulated Fuels Technologies, L. Snead, ORNL

- Accident Tolerant Fuels Technologies, S. Bragg-Sitton, INL

\section{METALLIC TRANSMUTATION FUELS}

- Metallic-based Fuels Technologies, J. R. Kennedy, INL

\section{CROSSCUTTING CAPABILITY}

- Core Materials Technologies, S. Maloy, LANL

- Irradiation Testing Technologies, S. Hayes, INL

- Analytic Support, C. Unal, LANL 


\section{CAMPAIGN MANAGEMENT}

- National Technical Director, J. Carmack, INL

- Systems Integrator, L. Braase, INL

\subsection{AFC Integration Meetings and Technical Workshops} L. Braase (INL)

Two AFC integration meetings were conducted during FY 2013. In general, the meetings consisted of DOE-NE guidance, industry partner's needs and insights, and technical presentations that provided the status of R\&D efforts. The meeting locations and dates are listed below.

- Las Vegas, Nevada, March 26-28, 2013. Many of the technical discussions focused on Accident Tolerant Fuel and the associated industry-led FOAs and university-led IRPs. Requirements and expectations for FY 2014 irradiation and steam tests were provided.

- $\quad$ Salt Lake City, UT, August 27-29, 2013. This was an integrated meeting with NEAMS to demonstrated applied use of modeling and simulation to fuel development activities. FY 2014 planning and expectations were discussed.

\subsection{International Collaborations J. Carmack (INL)}

AFC researchers are very active in international collaborations with Korea, France, Japan, China, Russia, and EURATOM. These interactions and collaborations are managed through a combination of participation in Generation IV Global International Forum projects, International Nuclear Energy Research Initiative (INERI) projects, and participation in bilateral and trilateral government-togovernment agreements.

The Global Actinide Cycle International Demonstration (GACID) project seeks to demonstrate the irradiation and performance of minor actinide-bearing mixed oxide (MOX) fuel in the Monju reactor in Japan. The Gen-IV Sodium Fast Reactor (SFR) project provides the means for collaboration on the development of advanced fuels including metallic, ceramic, nitride, carbide, and advanced cladding systems. France's Atomic Energy Commission (CEA) and DOE have a joint bilateral to pursue the assessment of the UO2-Am system as a transmutation system for americium. Significant progress was made this year in the U.S. on this subject in the design of an AMBB (Americium Bearing Blanket) irradiation experiment to be conducted in the INL Advanced Test Reactor. CEA efforts have demonstrated the capability to fabricate high concentration Americium bearing ceramic fuel pellets for this irradiation.

Following the Fukushima event, the AFC ceramic fuels team and the Japan Atomic Energy Agency (JAEA) Tokai fuel property team began looking at opportunities for increased bilateral collaboration on accident behavior of oxide fuels. A number of areas for collaboration were identified and provided to the respective program management for potential inclusion in the DOE/JAEA bilateral and DOE/JAEA/CEA multilateral arrangements. This activity is highlighted below in the Advanced LWR technical section of accomplishments and has been productive in the area of oxidation kinetics of the uranium oxide fuel system.

OECD-NEA supports several collaborations with the US, including organizing international workshops on Accident Tolerant Fuels. A specific international workshop on enhanced accident tolerant fuel attributes and metrics was organized by the OECD-NEA in December 2012 and included significant participation by U.S. nuclear industry and research institutions, including technical staff from the Advanced Fuel Campaign. A follow-on meeting is planned for October 2013. 
EURATOM-DOE collaborative fuel R\&D focused on specific technical staff exchanges on fabrication and characterization methods with the Joint Research Center-Institute of Transuranium Elements.

US-Russia Civil Nuclear Bilateral Collaboration focused primarily on joint materials irradiation in B0R60, metallic alloy fuel development, characterization and PIE methods, in-pile instrumentation, and advanced LWR fuels. A subcontract is in place between DOE and the Russian Research Institute of Atomic Reactors (RIAR) institute to design the materials irradiation apparatus for BOR60. Additional topics for collaboration of mutual interest are also under discussion including fuels irradiation testing in B0R60.

The 2011 Cooperative Research and Development Agreement (CRADA), between INL and the Korean Atomic Energy Research Institute (KAERI), is focused on joint R\&D on recycle, fabrication, and materials irradiated in a light water reactor. After processing and recycling used nuclear fuel (UNF) at the INL Fuel Conditioning Facility (FCF), new fuel pins will be fabricated and irradiated in ATR. Primary efforts in the fuels portion of this collaboration are design, construction, and installation of the needed fuel fabrication equipment in a hot cell for remote fabrication of small quantities of recycle metallic fuels. 
This page intentionally left blank. 


\section{ADVANCED \\ LIGHT WATER REACTOR \\ FUEL SYSTEMS DEVELOPMENT}

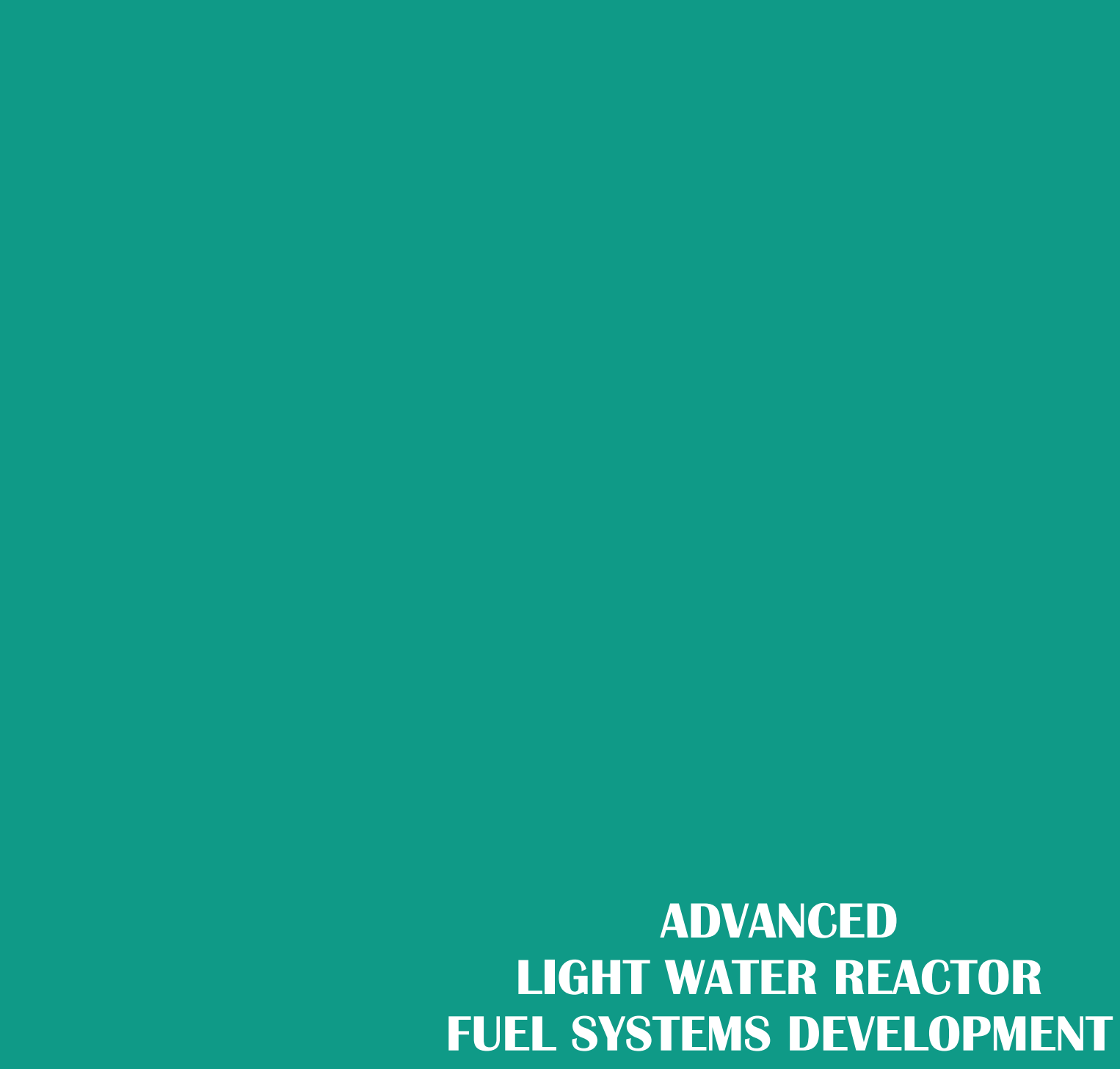




\section{ADVANCED LWR FUEL SYSTEMS DEVELOPMENT}

Researchers across the AFC have been investigating a number of potential fuels and cladding technologies to improve fuel system performance in both normal and accident conditions. Significant progress has been made on establishing oxidation, corrosion, and materials property characterization capabilities and techniques that can be used to assess the performance of potential advanced LWR fuel technologies. In addition, AFC has been preparing for the first irradiation of ATF technologies in the ATR in FY 2014, consistent with the ATF Roadmap.

\subsection{Accident Tolerant Fuels}

S. Bragg-Sitton (INL)

The draft Accident Tolerant Fuels (ATF) roadmap focuses on the development of advanced LWR fuels with enhanced accident tolerance. Fuels with enhanced accident tolerance are those that, in comparison with the standard $\mathrm{UO}_{2}$-zirconium alloy system currently used by the nuclear industry, can tolerate loss of active cooling in the reactor core for a considerably longer time period during design-basis and beyond design-basis events (depending on the LWR system and accident scenario) while maintaining or improving the fuel performance during normal operations and operational transients.

A series of national and international meetings were held in FY2013 to begin establishing a broad consensus on how to approach ATF design, optimization and evaluation for down-selection. Each of these meetings provided qualitative direction on an appropriate set of enhanced accident tolerant fuel attributes, metrics and associated screening evaluations for different classes of fuel and cladding material.

A small team from across the DOE laboratories has begun to define a technical evaluation approach for accident tolerant LWR fuels that will enable down-selection of the various fuel design concepts at multiple points along the development path. A draft of the technical evaluation metrics for ATF was developed and submitted to the advanced fuel development community for review.

The proposed development and evaluation path is shown in Figure 2, where each expert panel review will assess the relative benefits and vulnerabilities of candidate designs across the various operational regimes: Fabrication / Manufacturability; Normal Operation and Anticipated Operational Occurrences (AOOs); Postulated Accidents (Design Basis); Severe Accidents (Beyond Design Basis); Used Fuel Storage / Disposition. The proposed technical evaluation methodology will be applied to gauge the ability of each of these concepts to meet performance and safety goals relative to the current $\mathrm{UO}_{2}$ - zirconium alloy system and relative to one another. This ranked evaluation will be used to enable the continued development of the most promising ATF design options given budget and time constraints, with a goal of inserting one (or possible two) concepts as an LTR or LTA in a commercial LWR by 2022. Note that we are currently in Phase I of development, which include the feasibility assessment and preliminary down-selection and essentially corresponds to technology readiness level (TRL) 1 to 3. 


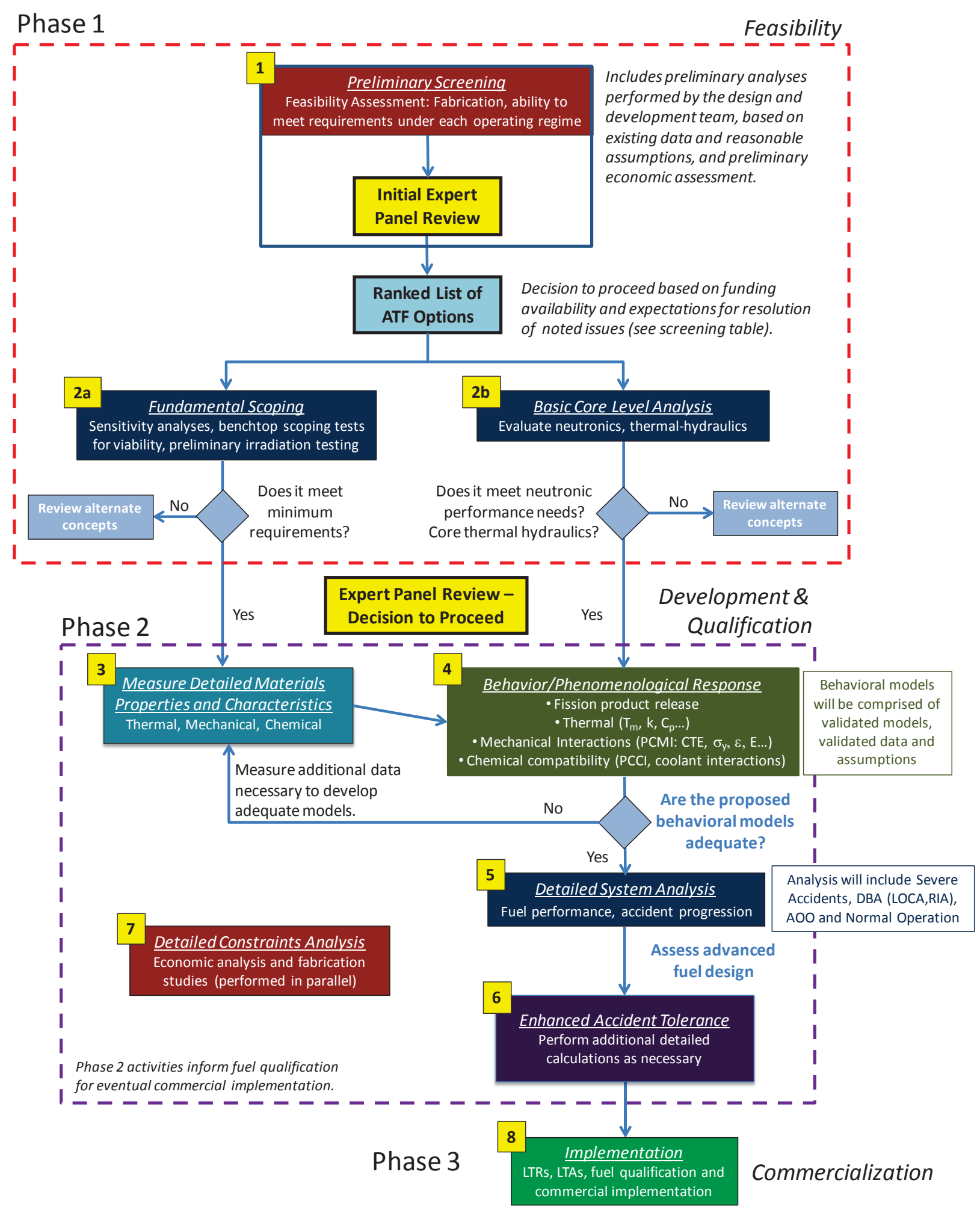

Figure 2. Proposed Accident Tolerant Fuel evaluation methodology. Preliminary concept down-selection would occur within Step 1, with secondary down-selection occurring at the end of Phase 1 prior to detailed tests and behavior model development. 


\subsection{Industry and University Led Accident Tolerant Fuel Projects \\ S. Bragg-Sitton, (INL)}

Three DOE FOA industry-led projects were funded late in FY 2012. They are closely coordinated with AFC through directly funded DOE laboratory participation, as well as industry participation in AFC-led characterization and irradiation testing activities. It is expected that these three industry projects, which include participation by national laboratories and universities, will successfully identify potential accident tolerant fuel designs and concepts.

- Westinghouse Electric Corporation will investigate advanced cladding concepts coupled with advanced fuel pellet design.

- General Electric Corporation will investigate advanced cladding for enhanced accident tolerance.

- AREVA will investigate a number of fuel and cladding options ultimately choosing one for testing and development.

Two university-led IRPs were also funded late in FY 2012, to specifically develop accident tolerant fuel concepts. The University of Illinois Urbana-Champaign project will investigate modified zirconium cladding technology and the University of Tennessee project will investigate ceramic cladding coating technologies. They both support AFC's goal for R\&D in accident tolerant fuels.

NEUP, under the direction of DOE's Office of Nuclear Energy (NE-4), funds multiple projects related to AFC. These projects are ongoing and range from the development of enhanced thermal conductivity fuel compositions to the development of advanced in-pile fuel testing methods and instrumentation. University programs and AFC continue to effectively collaborate to meet DOE's nuclear energy R\&D goals.

\subsection{Core Level Advanced LWR Fuel Concept Analysis}

M. Todosow and N.R. Brown (BNL); K.J. McClellan (LANL)

An assessment of the viability and potential attractiveness of advanced nuclear fuels must include consideration of how proposed concepts will impact the nominal reactor performance and safety characteristics. This assessment includes neutronics analyses to evaluate the impact on performance parameters (e.g., cycle length/burnup, etc.) and safety-related characteristics (e.g., reactivity and control coefficients, kinetics parameters, etc.).

In FY 2012, BNL developed a methodology to perform an initial screening of performance and safety of candidate fuel concepts based on assembly and full three-dimensional reactor analyses. In FY 2013, the methodology was refined and expanded to allow a more complete analysis of performance under a wide spectrum of potential transients and accidents, up to but not including, Beyond Design Basis Accidents (BDBA). The resultant methodology provides the capability to screen candidate fuel concepts to address the desired objective of ensuring that a proposed concept has at least equivalent performance to current uranium dioxide $\left(\mathrm{UO}_{2}\right)$-Zirc fuel.

The key elements of the methodology are:

- Initial Screening Analyses. Infinite lattice calculations for an explicit model of a fuel assembly with the TRITON deterministic code, and the Serpent Monte Carlo code to provide an initial estimate of the impact of the new fuel relative to the reference $\left(\mathrm{UO}_{2}\right)$-Zirc fuel on cycle length/burnup (Figure 3), reactivity and control coefficients, etc.

- Three-Dimensional Core Analyses. Three-dimensional core analyses are performed with the Serpent Monte Carlo neutron transport tool that allows an extremely detailed modeling of 
the geometry and the nuclear data (Figure 4), and the PARCS deterministic nodal neutron diffusion code. The PARCS model uses nuclear data generated by Serpent or TRITON in a full three-dimensional model of the reactor core including thermal-hydraulic/fuel temperature reactivity feedback. PARCS is used for fuel cycle analyses (cycle-by-cycle or equilibrium cycle) and time-dependent analyses such as for a rod ejection accident.

- Transient Analyses. The analysis of selected transients is performed with the TRACE systems analysis code using point kinetics to represent the reactor, or coupled to PARCS if a detailed core model is required.

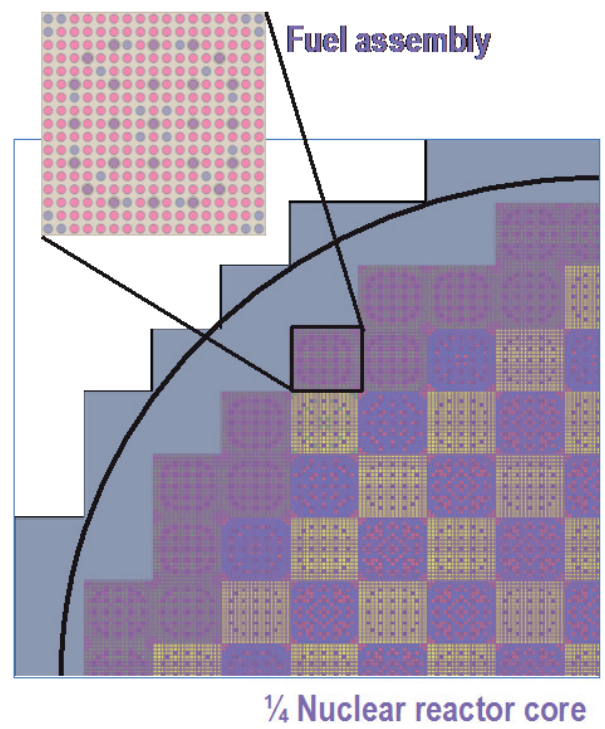

Figure 3. Explicit Serpent (Monte Carlo) model of Reference Reactor

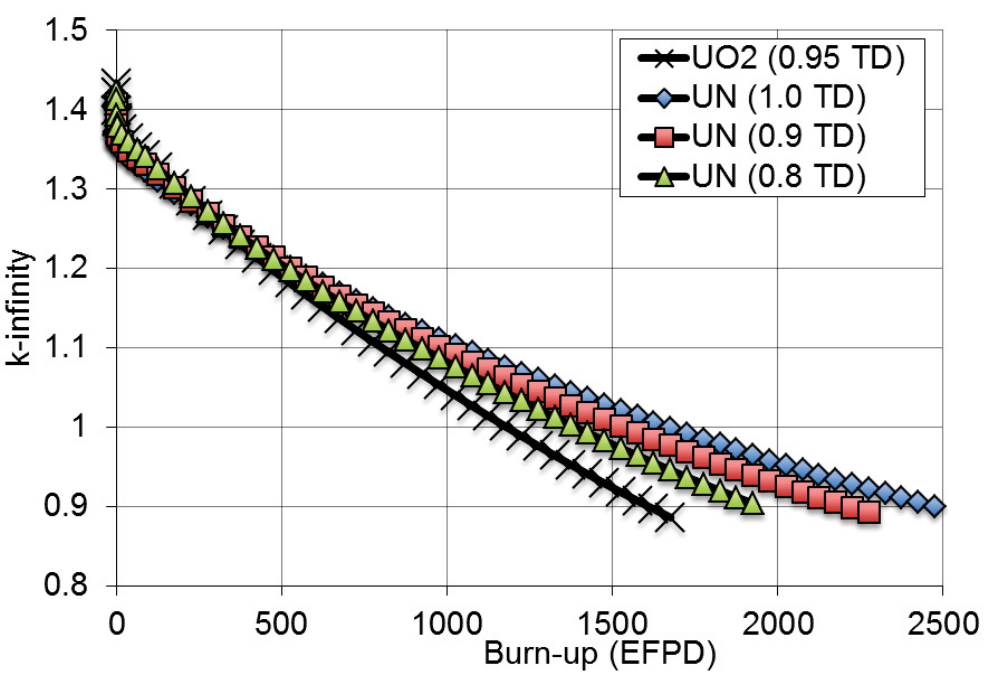

Figure 4. Impact of the UN fuel porosity on the cycle length assuming a constant linear heat rate per pin

The FY 2013 study encompassed several advanced composite fuel concepts with uranium nitride as a primary phase in collaboration with experimental studies at LANL. The primary nitride phase is "shielded" from water by a secondary phase, which would allow the potential benefits of nitride fuels to be realized in an LWR. The objective of these studies was a preliminary assessment of nitride fuels in Pressurized Water Reactors (PWR) from an operational perspective. The key objective of these analyses was to assess the potential impacts of the implementation of these fuels on operational performance and safety characteristics.

We considered uranium dioxide $\left(\mathrm{UO}_{2}\right)$ and $\mathrm{UN}$ base cases with varying porosity, and compared them with the candidate composite UN-based fuels. The comparison was performed for nominal conditions in a reference PWR with Zr-based cladding. As composite fuels, we studied UN/U $\mathrm{U}_{3} \mathrm{Si}_{5}$, $\mathrm{UN} / \mathrm{U}_{3} \mathrm{Si}_{2}, \mathrm{UN} / \mathrm{UB}_{4}$, and $\mathrm{UN} / \mathrm{ZrO}_{2}$. In the case of $\mathrm{UB}_{4}$, the boron content is $100 \%$ enriched in ${ }^{11} \mathrm{~B}$. The proposed zirconium dioxide $\left(\mathrm{ZrO}_{2}\right)$ phase is cubic and yttria-stabilized. In all cases $\mathrm{UN}$ is the primary phase, with small fractions of $\mathrm{U}_{3} \mathrm{Si}_{5}, \mathrm{U}_{3} \mathrm{Si}_{5}, \mathrm{UB}_{4}$, or $\mathrm{ZrO}_{2}$ as a secondary phase. In this analysis we showed that two baseline nitride cases at different fractions of theoretical density $(0.8$ and 0.95 ) generally bound the neutronic performance of the candidate composite fuels.

Performance was comparable with $\mathrm{UO}_{2}$. One notable difference observed was longer cycle lengths with the composite fuels (due to increased fuel loading). Another significant finding is that the nitride composites exhibited a harder neutron spectrum, which decreased the reactivity worth of typical burnable absorbers, soluble boron, and control rod materials relative to the $\mathrm{UO}_{2} \mathrm{case}$. In general, the full-core reactivity coefficients for the nitride and nitride composite fuels were within the design limits for the reference PWR. The baseline UN and UN/Z $\mathrm{ZO}_{2}$ cases, both with relatively 
high porosity in the nitride phase (20\%), exhibited the strongest similarity to the reference $\mathrm{UO}_{2}$ case.

\subsection{DOE/JAEA Collaboration on Accident Behavior of Oxide Fuels A.T. Nelson, K.J. McClellan (LANL); K. Suzuki and M. Kato (JAEA-Tokai)}

Following the Fukushima Daiichi disaster, AFC and JAEA-Tokai fuel property team began looking at opportunities for increased bilateral collaboration on accident behavior of oxide fuels. Starting in 2011, JAEA assigned one visiting scientist per year to be stationed at LANL to participate in collaborative research related to fuel behavior under accident conditions. One key area of immediate mutual interest was oxidation behavior of oxide fuels as a function of atmosphere and temperature.

Previous exploration of the response of $\mathrm{UO}_{2}$ fuel pellets to oxidizing atmospheres has been focused on temperatures well below those that an LWR fuel experiences during normal operation, not to mention the extremes encountered under accident scenarios. This gap in the knowledge base is understandable for the reference system employed to date. Exposure of zirconium cladding to water vapor will result in significant hydrogen production, exposing the fuel to a principally reducing environment that significantly retards mechanical degradation. However, efforts within AFC are focused on qualifying and deploying new cladding alloys that are largely unaffected by water vapor until much higher temperatures in order to provide longer coping times in the event of a Loss of Coolant Accident (LOCA). Companion experimental studies are essential to understand the effect of changes in the cladding on LWR fuel performance during all stages of operation.

- New ceramic fuel compositions were screened for accident tolerant characteristics \& neutronic performance

- Ceramic fuel fabrication capabilities were brought online to make ATF tests with enrichments tailored for ATR irradiations

- Field assisted sintering was demonstrated as a route to fabricate fuels that cannot be synthesized using conventional processes

Measurement of the oxidation of $\mathrm{UO}_{2}$ under a range of atmospheres was performed at LANL in order to better understand consequences of oxidation-resistant cladding as well as provide comprehensive data sets to inform accident modeling efforts. Thermogravimetric analysis provided in situ measurement of the oxidation of $\mathrm{UO}_{2}$ samples during exposure to atmospheres containing up to $100 \%$ water vapor at temperatures as high as $1200^{\circ} \mathrm{C}$. Isothermal studies executed over six hour time intervals were performed over a range of steam partial pressures in order to probe the impact of atmosphere and temperature on oxidation. Families of oxidation curves were constructed (Figure 5a) and fit to various conventional models. Sample results of this study are shown in Figure 5b, where the rate constants obtained for a wide range of atmospheres and temperatures are plotted. 


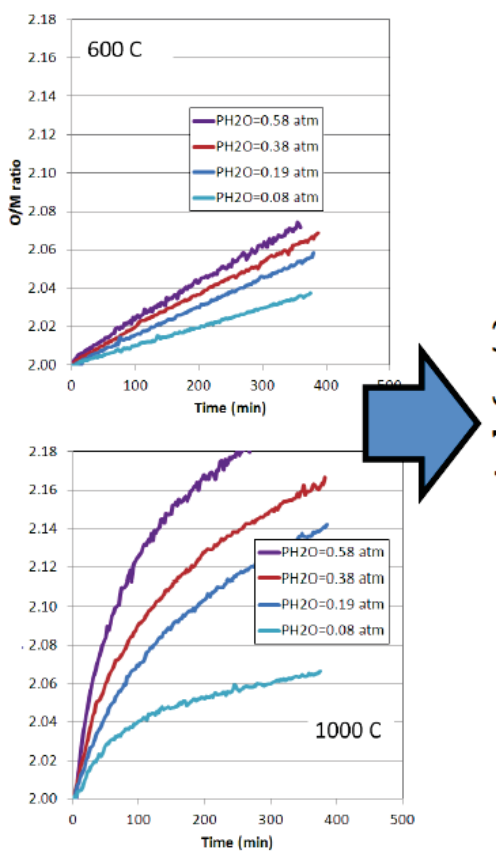

a)

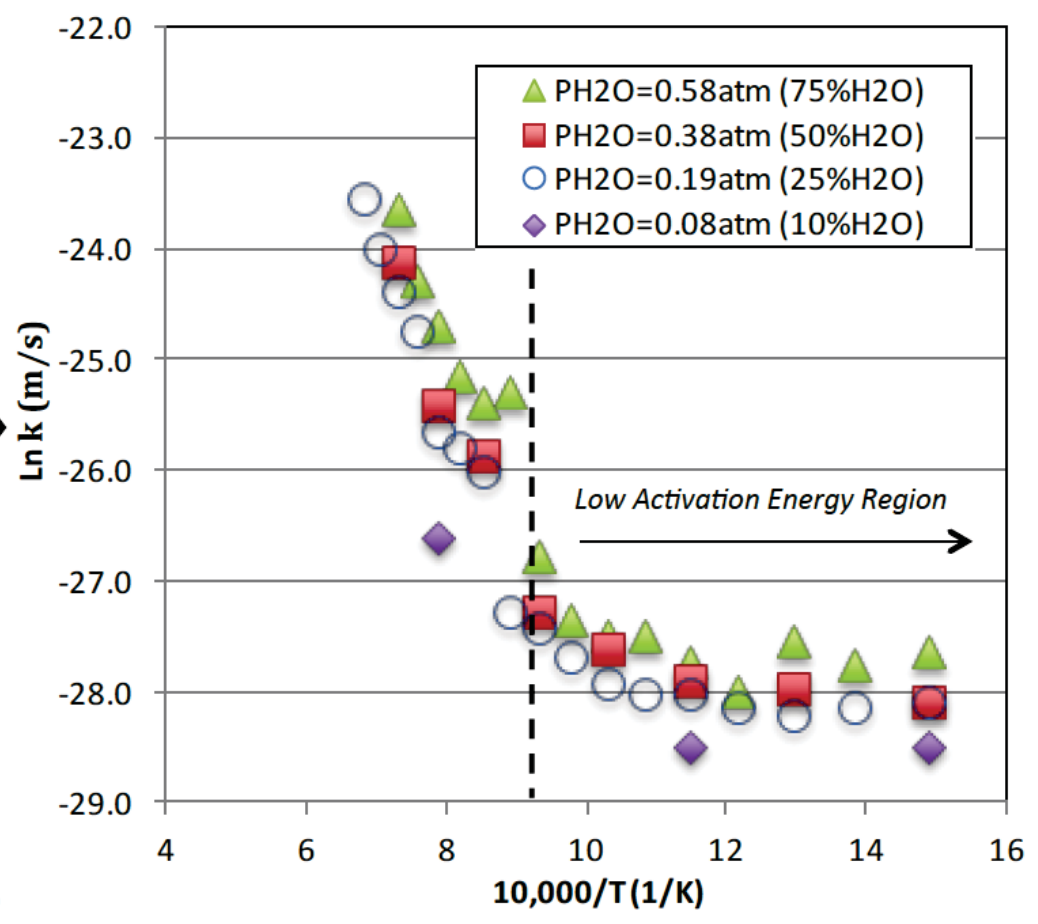

b)

Figure 5. Oxidation rate constants developed for UO2 exposed to various partial pressures of water vapor as required for kinetic rate studies illustrating the impact of temperature on oxidation and degradation of $\mathrm{UO}_{2}$ at elevated temperatures. Sample families of oxidation curves are shown at left.

A drastic change in the calculated activation energies is observed at roughly $700^{\circ} \mathrm{C}$. Below this temperature, activation energies limit the potential for rapid oxidation of LWR fuels in water vaporcontaining environments such as those provided by LWR coolant. However, exposure to water vapor above this temperature will result in rapid loss of mechanical integrity and pulverization of the fuel pellet in a matter of hours due to the oxygen potential not present if oxidation of traditional zirconium cladding is acting as a source of hydrogen. An accurate understanding of the kinetics that dictate the evolution of $\mathrm{UO}_{2}$ fuel as provided by this study will not only assist in analyses of fuel's response to off-normal conditions, but also will provide critical understanding necessary to the development of new accident tolerant fuel forms.

\subsection{Severe Accident Test Facility}

L. Snead (ORNL)

A high-temperature furnace, capable of temperatures up to $1700^{\circ} \mathrm{C}$, has been developed and installed in a hot-cell to do Beyond Design Basis Accident (BDBA) testing of advanced fuel forms. This furnace is part of the Severe Accident Test Station (SATS) available to AFC and the community for testing of advanced concepts. The facility is capable of exposing materials of interest to pure steam or steam-hydrogen mixtures over a large range of temperatures, pressures, and flow velocities (Figure 6). 


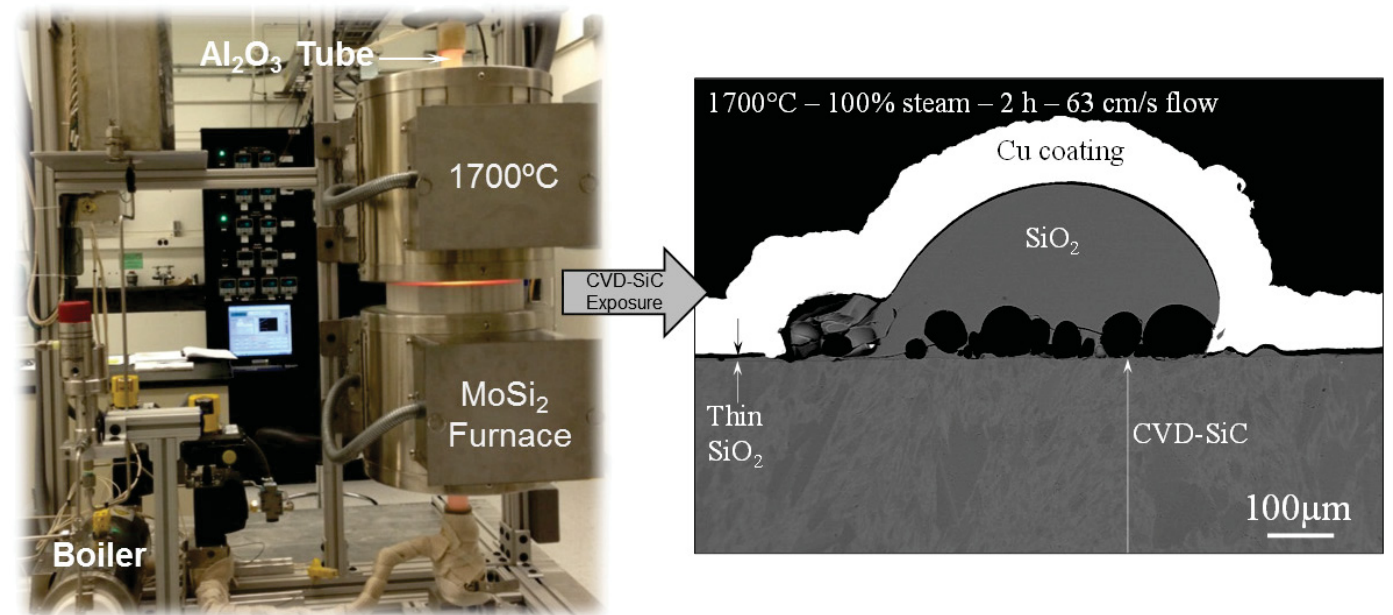

Figure 6. Severe Accident Test Station and Associated CVD-SiC Exposure Test Results

\section{LOCA Testing of Advanced LWR Cladding Alloys}

High temperature steam exposure has been carried out on a suite of advanced fuel forms to determine kinetics of attack. Results have been analyzed and provided to reactor core accident modelers to determine whether improvement in performance or coping time of the reactor is achieved. For the case of advanced steel clad this unique facility has provided insight into the protection allowed in the ATF FeCrAl nearly to the base metal melting point (Figure 7.)
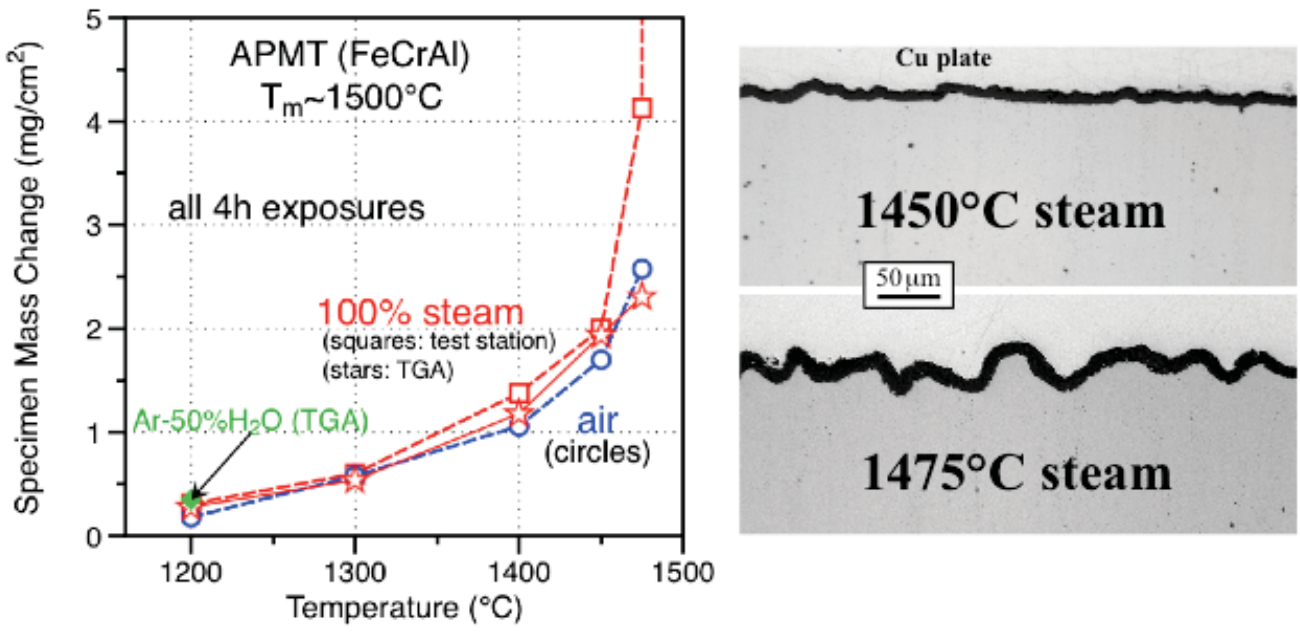

Figure 7. ATF FeCrAl LOCA Test

\subsection{Thermochemical Experiment and Modeling of U-RE-0 Systems \\ S. Voit, T. Besmann, J. McMurray, B. Slone, D. Shin (ORNL); S.M. Lee, T. Knight (USC)}

Accurate thermodynamic representations of urania-rare earth (RE) systems are needed for the development of predictive fuel performance models of solid fission product behavior in $\mathrm{UO}_{2}$ and advanced oxide nuclear fuels. During irradiation, temperature and oxygen chemical potential gradients are quickly established in the fuel (Figure 8) and have a profound effect on the fission product-fuel chemistry and changing physical properties with burnup. Lanthanoids and actinoids with specific valence states, such as $\mathrm{Ce}^{3+, 4+}, \mathrm{Nd}^{3+}$, and $\mathrm{Th}^{4+}$, represent metals that readily dissolve in 
the $\mathrm{UO}_{2}$ fluorite structure, depending on temperature, oxygen potential, and composition; thus are ideal for use in understanding thermochemistries of irradiated oxide fuel.
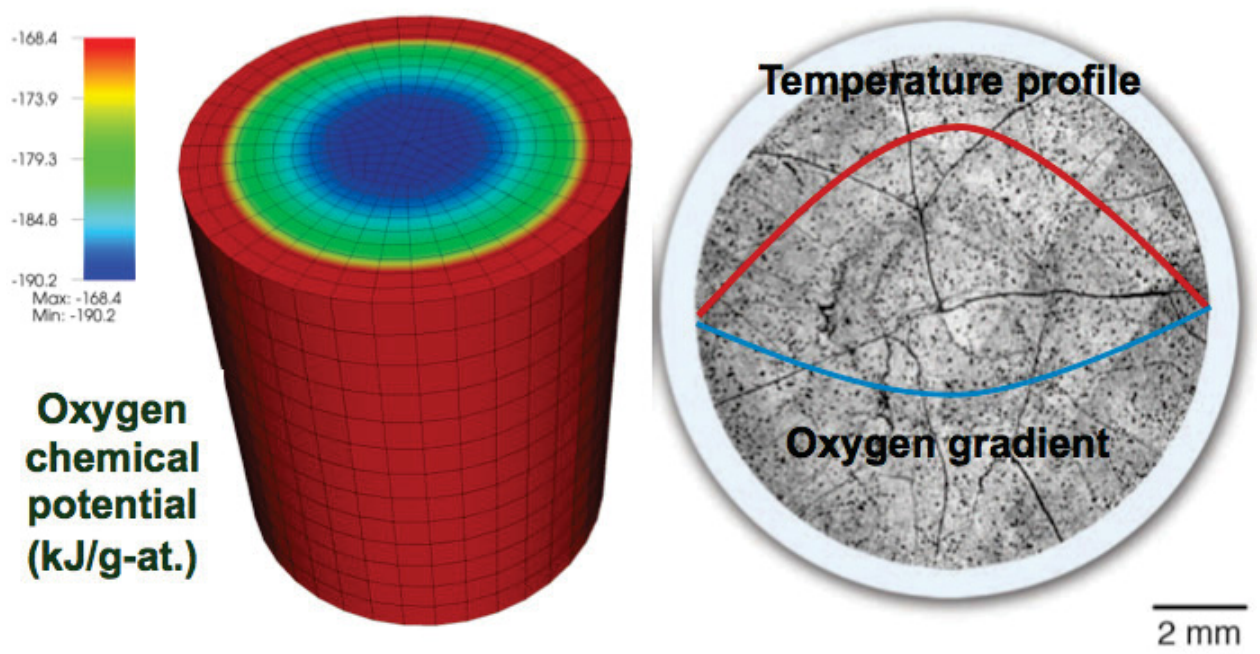

Figure 8. Oxygen Distribution in Irradiated Fuel Pellet

In FY 2013, the oxide thermodynamics and phase equilibria of the U-Ce-O, U-Gd-O, and U-Nd-O systems were studied. The foundation for modeling of these systems is the Compound Energy Formalism, which allows optimization of thermodynamic parameters of solution phases in a sublattice configuration. Model optimization is performed using experimental data and with the U-Ce0 system, data measurements at ORNL supplementing literature data. For the U-Gd-O system, lattice stabilities for non-fluorite structure end members were calculated using Density Functional Theory and added to literature data. For example, results from the optimized U-Gd-O model in Figure 9 display a good fit between calculation and experimental data. Papers on the U-Ce-O and UGd-O systems were submitted to the Journal of Nuclear Materials satisfying FCRD Level 2 and Level 3 milestones, respectively. In addition, a paper on the U-La-O system was published in the journal in FY 2013. Work on the U-Nd-O system at the University of South Carolina (USC) is expected to be completed in FY 2014.
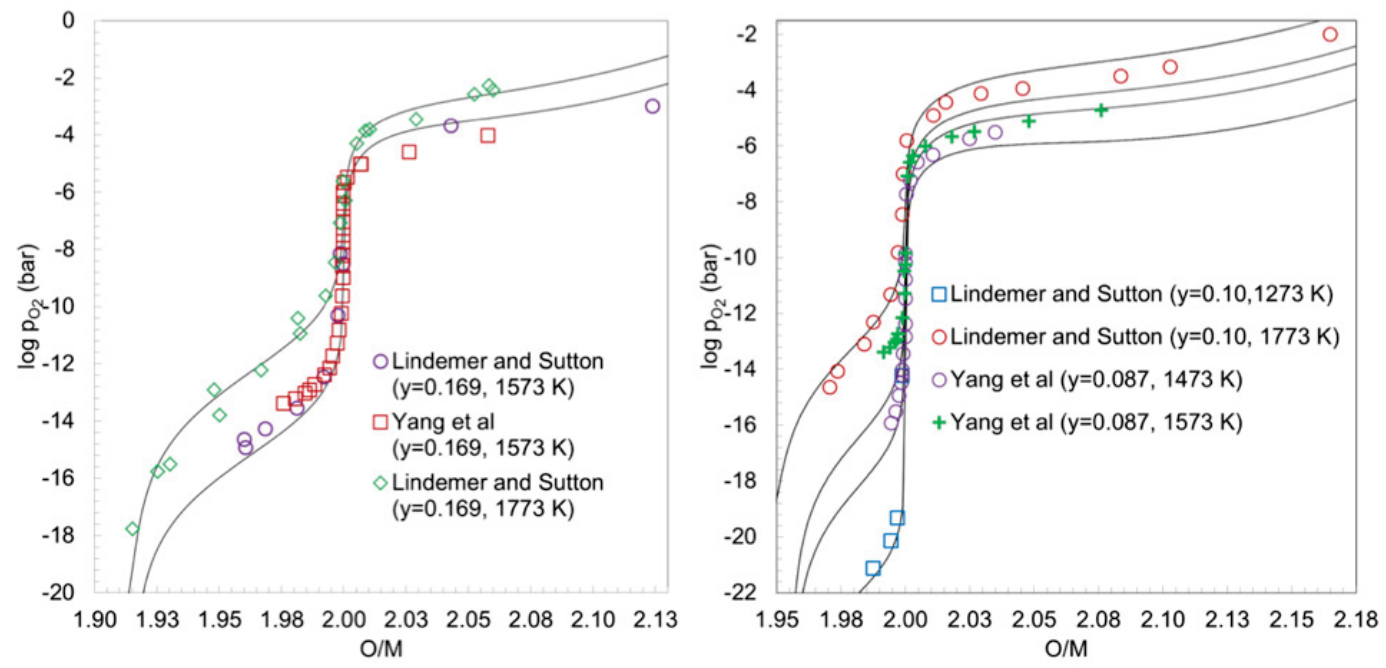

Figure 9. Calculated versus experimental oxygen pressures in $U_{1-y} G d_{y} O_{2 \pm x}$ 


\subsection{Advanced LWR Fuels Development}

Advanced technologies for LWR reactors include development of technologies improving the base fuel form and development of improvements to the cladding system. Combination of these two technologies provides potential improvement to the fuel system performance in both normal and accident conditions.

\subsubsection{Ceramic Fuel Technologies \\ K. McClellan (LANL)}

Ceramic fuel development for FY 2013 focused on oxide fuel, seeking transformational R\&D while also incrementally advancing fuel technology. Ceramic fuel development activities included: 1) National and International Technical Integration, 2) Advanced Accident Tolerant Ceramic Fuel Development, 3) Advanced Techniques and Reference Materials Development, and 4) Preparation for Fabrication of Enriched Ceramic Fuels.

Accomplishments for FY 2013 focused on ceramic fuels for LWRs with enhanced accident tolerance while also maintaining or improving normal operation performance. In addition, advanced PIE was explored to support more efficient testing and qualification of new fuel systems. Significant accomplishments include:

- A collaboration between LANL and JAEA researchers resulted in new detail on the oxidation behavior of oxide $\mathrm{UO}_{2}$ fuels under breach-of-cladding conditions. This data will help improve understanding of fuel degradation under severe accident conditions and the associated ability to predict and assess fuel dispersal. These experiments also provide insight and guidance for development of advanced fuel systems with improved performance under accident conditions.

- In collaboration between LANL and BNL, initial screening and assessment of new, advanced ceramic fuels was performed with a specific goal of achieving enhanced accident tolerance while maintaining economic and performance characteristics necessary for near-term deployment in existing LWR reactors. By coupling material compatibility screening experiments with assembly level neutronic analysis, several candidate systems were rapidly discarded allowing a more detailed assessment of remaining candidates. Thermo-physical properties of the pure high fissile density silicide phases were determined for the first time on unirradiated materials. It should be noted that this activity compliments the FOA projects on ATF development.

- Capabilities have been established at LANL for fabrication of ceramic fuels with tailored enrichment for testing of ATF concepts in ATR at INL. Enriched feedstock synthesis was demonstrated on a $10 \mathrm{~g}$ scale starting from $\mathrm{UF}_{6}$ precursor, which is essential for industrial process compatibility. The feedstock and fuel pellet fabrication glovebox capabilities are specifically targeted at ceramic fuel fabrication and can be available for fuel pellet fabrication to support ATF system irradiations for the FOA and IRP projects or the national lab-designed concepts.

- Accurate thermodynamic representations of urania-rare earth systems are important for the development of predictive fuel performance models of solid fission product behavior in $\mathrm{UO}_{2}$ and advanced oxide nuclear fuels. In FY 2013, the oxide thermodynamics, and phase equilibria of the U-Ce-O, U-Gd-O, and U-Nd-O systems was studied by researchers at ORNL and papers on the U-Ce-O and U-Gd-O systems were submitted to the Journal of Nuclear Materials. In addition, a paper on the U-La-O system was published in the journal in FY 2013. 
- $\quad$ Rapid, low temperature field assisted sintering has been demonstrated for $\mathrm{UO}_{2}$-based fuels. The techniques compliment work done under a University of Florida NEUP on spark plasma sintering and provide potential for commercially viable pellet fabrication of composite fuels that cannot be made by conventional routes. This work, along with contributions from the UF NEUP, is proposed as the basis for an INERI with EURATOM which would begin in FY 2014.

- Collaboration between INL and LANL researchers demonstrated neutron beam and proton beam-based advanced, non-destructive PIE of fuel rods. Initial experiments show that these capabilities can allow more rapid development and qualification of new fuel systems by providing 3-D imaging of the fuel microstructure, defects and chemistry. A second generation of $\mathrm{UO}_{2}$ fuel rodlet mockups was fabricated for non-destructive examination at the LANSCE facilities at LANL and at the NRAD facility at INL. The mockups are needed to further define the spatial resolutions of the various techniques and to establish experience in sample transfer and handling, which will be necessary as this new paradigm of PIE is implemented.

\subsubsection{High Density Fuels Glovebox C Knight, R. Damiana (INL)}

Installation of the High Density Fuels Glovebox in the Experimental Fuels Facility (EFF) at INL was completed (Figure 10). The new glovebox provides new capability to fabricate ceramic fuel, including uranium-based oxide fuel and new accident tolerant fuel types. Programs that will benefit from this new capability include FCRD, industry, Electric Power Research Institute (EPRI), Nuclear Energy University Program (NEUP), and Light Water Reactor Sustainability (LWRS). It is anticipated that the facility will also be used to support international collaborations.

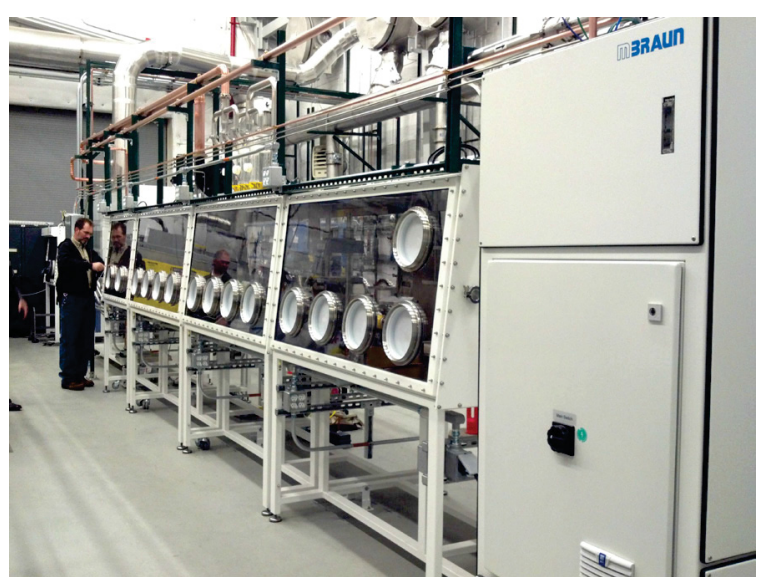

Figure 10. High Density Fuels Glovebox in EFF.

\subsubsection{Composite Fuel Development A. Nelson, K. McClellan (LANL); M. Todosow, N. Brown (BNL)}

Exploration of new reactor fuels with enhanced accident tolerance remains a primary mission within the ceramic fuels area with emphasis placed on three key areas: thermal conductivity, oxidation resistance, and high temperature mechanical properties. One approach that can provide key advantages in each of these three areas is design of a composite nuclear fuel.

A wide range of uranium compounds can provide fissile densities near or even higher than that of reference $\mathrm{UO}_{2}$. Initial screening of a matrix of candidate composites was initiated in FY 2013 to evaluate the potential of these compounds to assess their attractiveness from both an accident tolerance and reactor performance standpoint. Assessment is being performed by neutronic analysis at Brookhaven National Laboratory (BNL) in parallel with experimental property determination and compatibility testing. Initial performance includes analysis of fuel burn-up, cycle length, and assembly and core reactivity coefficients (see Table 1). 
Table 1. Calculated cycle length for various fuel options at $5 \%{ }^{235} \mathrm{U}$ enrichment with a soluble boron concentration of $500 \mathrm{ppm}$.

\begin{tabular}{|c|c|c|c|c|c|c|c|}
\hline Fuel & $\begin{array}{c}\mathrm{UO}_{2} \\
(0.95)\end{array}$ & $\begin{array}{l}\text { UN } \\
(0.95)\end{array}$ & $\begin{array}{l}\text { UN } \\
(0.8)\end{array}$ & $\mathrm{UN}_{-3} \mathrm{Si}_{5}$ & $\mathrm{UN}-\mathrm{U}_{3} \mathrm{Si}_{2}$ & $\mathrm{UN}-\mathrm{ZrO}_{2}$ & UN-UB 4 \\
\hline $\begin{array}{l}\text { Batch Burn-up } \\
(\mathrm{GWd} / \mathrm{t})\end{array}$ & 17.6 & 17.7 & 18.0 & 17.9 & 17.9 & 17.7 & 17.8 \\
\hline $\begin{array}{l}\text { Discharge Burn-up } \\
\text { (GWd/t) }\end{array}$ & 52.7 & 53.1 & 54.1 & 53.8 & 53.7 & 53.2 & 53.5 \\
\hline $\begin{array}{l}\text { Cycle Length } \\
\text { (EFPD) }\end{array}$ & 456 & 647 & 552 & 579 & 601 & 543 & 584 \\
\hline
\end{tabular}

The family of compounds investigated so far has been the uranium silicides $\mathrm{U}_{3} \mathrm{Si}_{1} \mathrm{U}_{3} \mathrm{Si}_{2}$, and $\mathrm{U}_{3} \mathrm{Si}_{5}$. Both $\mathrm{U}_{3} \mathrm{Si}$ and $\mathrm{U}_{3} \mathrm{Si}_{2}$ have seen limited historic use as fissile phase in aluminum plate fuel for research reactors, but very little is known regarding their thermophysical properties or oxidation resistance at the temperatures of LWR operation. They are hypothesized to offer substantial enhancements in thermal conductivity over $\mathrm{UO}_{2}$, and may be capable of enhanced accident tolerance if found to form a $\mathrm{SiO}_{2}$ layer when exposed to the atmospheres encountered during a LOCA.

Initial work focused on synthesis of the three phases and exploration of the thermophysical properties, oxidation resistance, and compatibility with probable high-density components such as $\mathrm{UN}$ and $\mathrm{UO}_{2}$. The three phases were produced using arc melting and verified to be phase pure using X-Ray Diffraction (XRD) and Scanning Electron Microscope (SEM) analysis. Measurement of the thermal conductivity, heat capacity, and thermal expansion of the three phases was performed from room temperature to near the melt point. A plot is provided in Figure 11a, of the thermal conductivity determined for $\mathrm{U}_{3} \mathrm{Si}$ and $\mathrm{U}_{3} \mathrm{Si}_{2}$, illustrating the significant gains available in comparison to the reference $\mathrm{UO}_{2}$. Improved thermal conductivity afforded by the inclusion of a silicide phase would provide benefits to reactor startup, steady state operation, and possible transients.
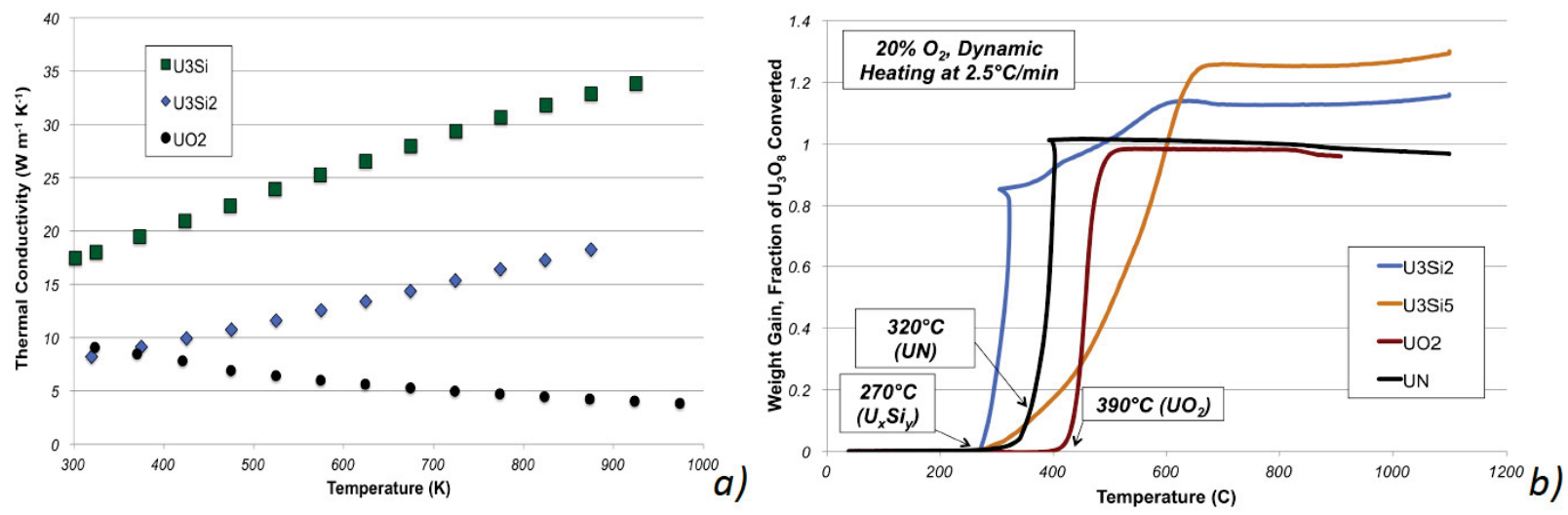

Figure 11. (a) Thermal conductivity of $U_{3} S i$ and $U_{3} S_{2}$ as a function of temperature compared to that of $\cup_{2^{*}}$ (b) Oxidation of $\mathrm{U}_{3} \mathrm{Si}_{2}$ and $\mathrm{U}_{3} \mathrm{Si}_{5}$ in synthetic air compared to $\mathrm{UN}$ and $\mathrm{UO}_{2}$.

Oxidation testing of the silicide phases in oxygen and steam-containing environments is also being executed in parallel with ongoing neutronics studies at BNL to evaluate the potential of uranium silicides and other uranium-bearing compositions to improve LWR performance. Figure 11b highlights the oxidation of $\mathrm{U}_{3} \mathrm{Si}_{2}$ and $\mathrm{U}_{3} \mathrm{Si}_{5}$ compared to $\mathrm{UN}$ and $\mathrm{UO}_{2}$. While $\mathrm{U}_{3} \mathrm{Si}_{2}$ degrades at a rate similar to UN under this condition, $\mathrm{U}_{3} \mathrm{Si}_{5}$ appears to possess enhanced oxidation resistance in comparison to the reference $\mathrm{UO}_{2}$. The mechanisms responsible for this behavior are currently being 
explored in order to determine if fuels containing $\mathrm{U}_{3} \mathrm{Si}_{5}$ could offer improved resistance to degradation under LOCA conditions.

\subsubsection{Fabrication of Enriched Ceramic Fuels E. Luther and B. Nolen (LANL)}

Capabilities have been established to fabricate ceramic fuels with tailored enrichment for testing of Accident Tolerant Fuel concepts in the ATR at INL. The fabrication processing line includes synthesis of enriched powder feedstock, batching, milling, sieving, pressing, and sintering operations. All processes can be performed in a glovebox under inert atmosphere. Sintering can be performed under vacuum, inert and reducing environments to temperatures of up to $2400^{\circ} \mathrm{C}$. A high precision, continuous process centerless grinder has been set up to grind pellets to final dimensions as seen in Figure 12.

Enriched $\mathrm{UO}_{2}$ feedstock synthesis was demonstrated on a $10 \mathrm{~g}$ scale (Figure 13) starting from $\mathrm{UF}_{6}$ precursor using a "dry" route approach that is essential for industrial process compatibility. A new reactor vessel is being designed and fabricated to allow $100 \mathrm{~g}$ synthesis capacity. Carbothermal reduction conversion of oxide to non-oxides (carbides and nitrides) has been demonstrated.

The feedstock and fuel pellet fabrication capabilities are specifically targeted at ceramic fuel fabrication. Enrichment levels of up to $19.9 \%$ are supported and pellets with non-conventional geometries can be produced; (e.g. annular pellets). This capability can be available for fuel pellet fabrication to support ATF system irradiations for the FOA and IRP projects or the national labdesigned concepts.

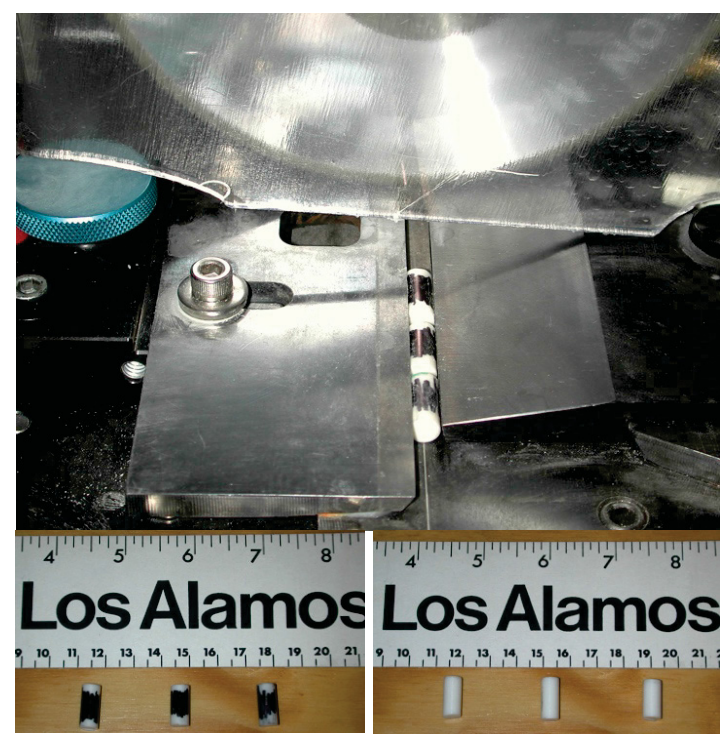

Figure 12. Centerless grinder preparing to grind three alumina surrogate pellets. Pellets before and after grinding.

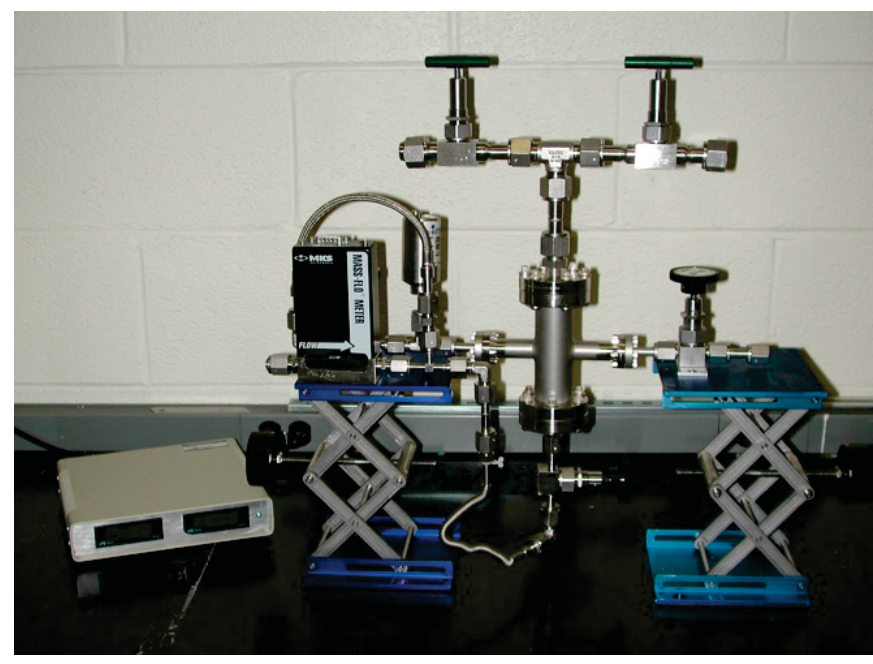

Figure 13. UF $F_{6}$ Deconversion Lab-scale Reactor Vessel 


\subsubsection{Field Assisted Sintering Technique (FAST)}

J. Valdez, D. Byler, K. McClellan (LANL)

The field assisted sintering technique (FAST) is a method of sintering materials using an applied field. FAST covers sintering methods such as flash sintering (FS), as well as microwave and spark plasma sintering (SPS). These techniques, when compared with conventional sintering, offer the capability to reduce the sintering temperature and time for a given fuel material and also allows sintering of novel fuel materials that cannot be fabricated by conventional routes due to the nominal sintering temperature necessary for densification. These techniques have been applied to numerous technical ceramic systems including in recent work to $\mathrm{UO}_{2}$ and have

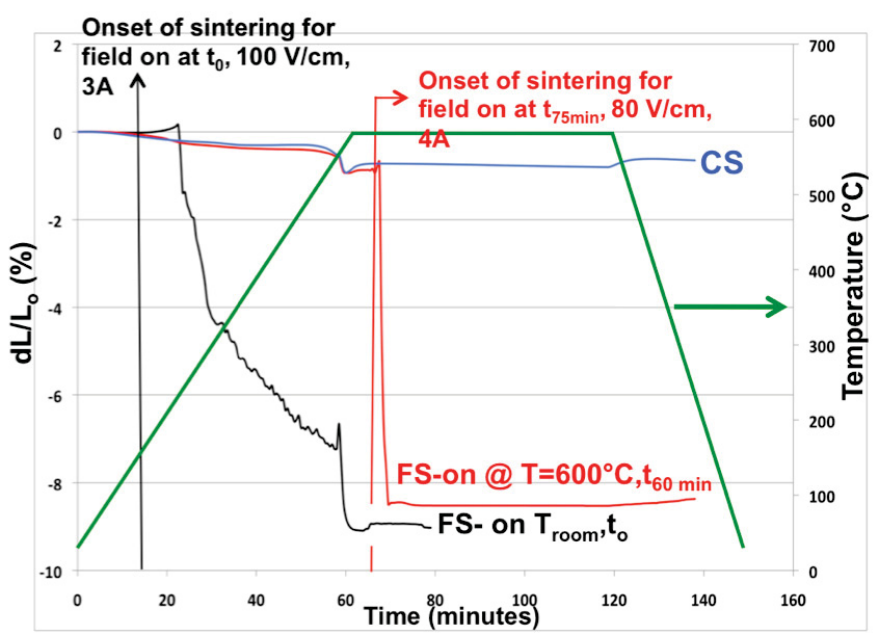

Figure 14. Comparison of the sintering rates of conventional versus field assisted sintering for $\mathrm{UO}_{2}$ pellets. shown significant decreases in the sintering temperature and time necessary to attain the same level of pellet densification.

Initial tests with $\mathrm{UO}_{2}$ using $\mathrm{FAST}$ have shown rapid densification of pellets with substantial densification being measured so far to temperatures as low as $125^{\circ} \mathrm{C}$. An interesting illustration of the field effect is observed at $600^{\circ} \mathrm{C}$ where effectively no sintering occurs for a conventional process but sintering does occur with a power density of $320 \mathrm{~W} / \mathrm{cm}$ under an applied field of $80 \mathrm{~V} / \mathrm{cm}$. This is shown in Figure 14 with the typical densification curve of a conventionally sintered pellet at $600^{\circ} \mathrm{C}$ compared to a pellet under the same atmosphere and conditions with the applied field. The as-pressed density of the $\mathrm{UO}_{2}$ pellets is approximately $53 \%$ of the theoretical density (TD) of $\mathrm{UO}_{2}$ and ends at approximately 68\% TD for the FAST pellet, while the non-field assisted pellet remains at only $\sim 54.5 \%$ TD. This is an extremely rapid net increase in density of $14 \%$ using FAST. Note also that field assisted densification is illustrated in another sample at $\sim 200^{\circ} \mathrm{C}$ for a power density of $300 \mathrm{~W} / \mathrm{cm}$.

Based on these and other results not covered in this report, it is clear that the field assisted sintering technique can result in:

- Faster sintering times

- Lower sintering temperatures than with conventional sintering

- Ability to sinter materials that are difficult or impossible using conventional methods

- Potential capability to control materials properties such as porosity, grain size, and defect density during rapid sintering.

Other work with FAST has been performed under a University of Florida NEUP on spark plasma sintering (SPS) and has shown significant advances in the development and understanding of the SPS process for composite material systems. Additionally, an INERI with the Institute for Transuranium Elements (ITU) was proposed to further explore the field assisted sintering techniques. 


\section{Advanced Fuels Campaign \\ FY 2013 Accomplishments Report}

\subsubsection{Particulate Based Fuels \\ L. Snead, K. Terrani, J. Hunn (ORNL)}

The development of advanced microencapsulated fuels relies on the knowledge bases developed on coated particle fuel technology for advanced reactor platforms. The potential fission product retention and high temperature operation capabilities make this fuel form a candidate for the basis of an enhanced ATF system. The development activities are highly integrated with direct modeling, fuel fabrication, irradiation testing, and post-irradiation performance evaluation. FY 2013 focus areas included modeling, transuranic TRISO fuel, LWR microencapsulated fuel, and testing advanced clad and fuel materials for enhanced safety. Of significant note was the successful fabrication of high density uranium carbo-nitride fuel kernels required to achieve high fuel density.

Uranium carbo-nitride $[\mathrm{U}(\mathrm{C}, \mathrm{N})]$ kernel production technology, assumed critical to achieve normal cycle length in the application of fully ceramic microencapsulated fuels, has been demonstrated to > 92\% theoretical density. The dense kernels are produced in batch quantities without cracking and are now available for coating development. Early sets of analyses (Figure 15) predict superior inpile performance for $\mathrm{U}(\mathrm{C}, \mathrm{N})$ kernels when compared to $\mathrm{UO}_{2}$ and $\mathrm{UO}_{2}-\mathrm{UC}_{\mathrm{x}}$ kernels since absence of oxygen in the system reduces internal pressurization of the particles and eliminate kernel migration. Therefore, this is deemed as a potential enabling technology for next generation gasreactor fuels as well.
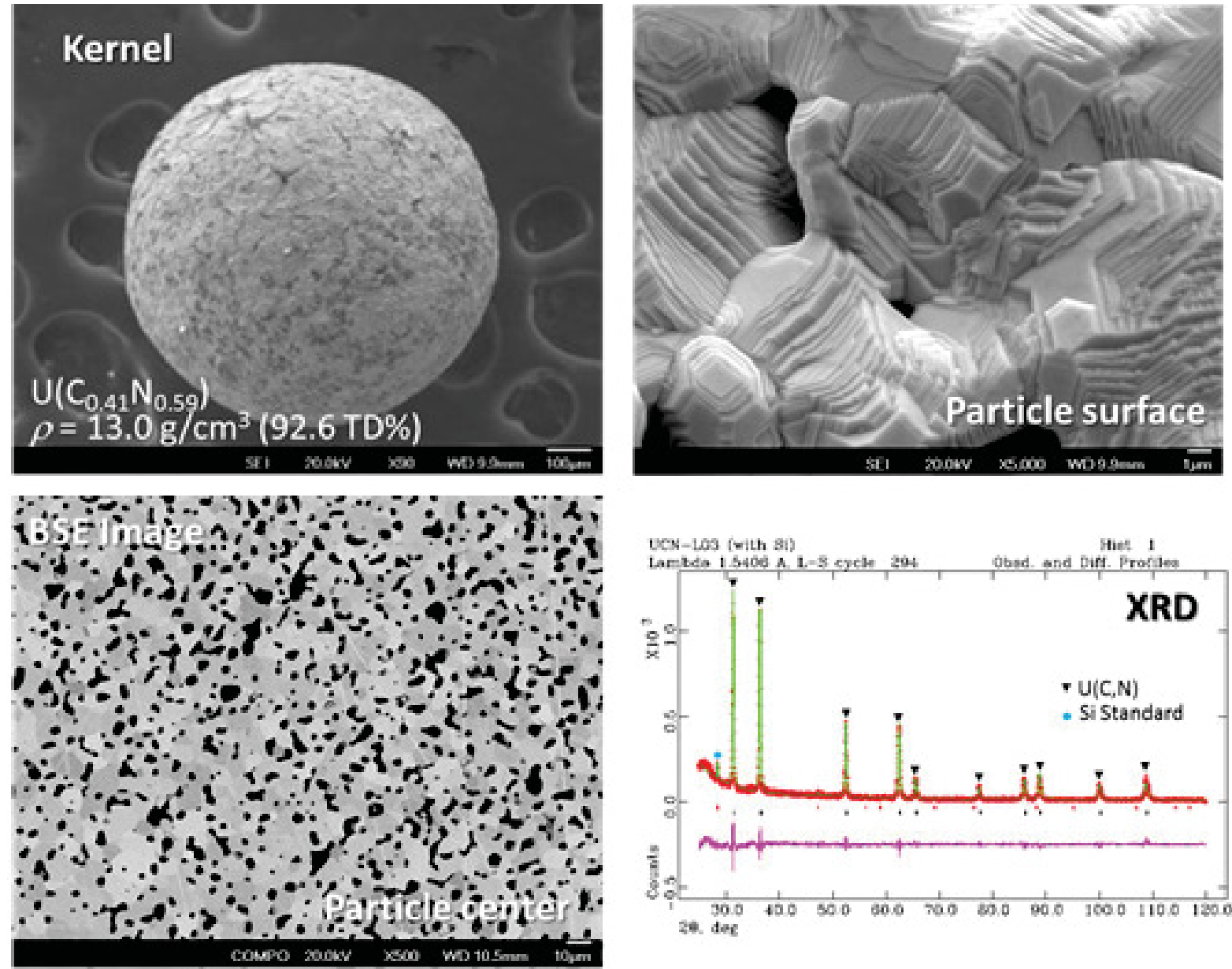

Figure 15. High density $U(C, N)$ kernels have been fabricated and characterized via electron microscopy and X-ray diffractometry. 


\section{Advanced Fuels Campaign FY 2013 Accomplishments Report}

Examination of surrogate fully ceramic micro encapsulated fuel irradiated to LWR-lifetime conditions $\left[320-360^{\circ} \mathrm{C}\right.$ range to a maximum dose of $7.7 \times 1025 \mathrm{n} / \mathrm{m} 2(\mathrm{E}>0.1 \mathrm{MeV})]$ has revealed excellent performance of both fuel matrix and constituent layers of the TRISO fuel. Figure 16 also shows the results of micro-tomography as well as transmission electron microscopy on irradiated pellets. Essentially, the various coating layers in the particle and the matrix show excellent stability while the bonding in all the essential interfaces is maintained. This is important to enable efficient heat transport away from the fuel kernel and to avoid local temperature excursions. As expected buffer-layer shrinkage was observed resulting in deboning of that layer from surrogate $\mathrm{ZrO} 2$ kernel. In case of UO2-UCx kernels in gas reactor fuel, high binding strength of the kernel-buffer interface results in buffer debonding from the inner pyrocarbon (IPyC).
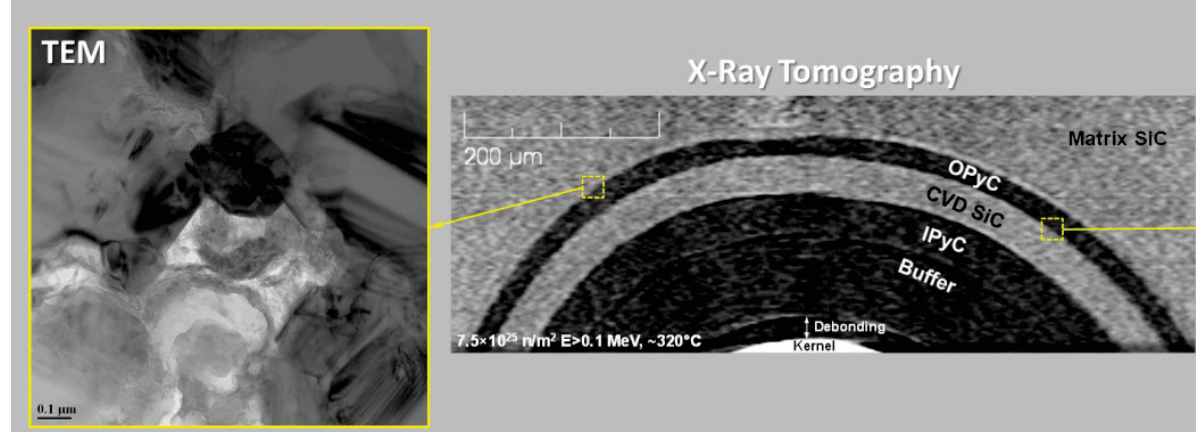

Figure 16. Examination of surrogate fully ceramic micro encapsulated fuel irradiated to LWR-lifetime conditions has revealed excellent performance of both fuel matrix and constituent layers of the TRISO fuel.

\subsubsection{U-Mo Advanced LWR Fuel R. Omberg, D. Love (PNNL)}

The development and demonstration of co-extrusion on coated depleted U-Mo for corrosion testing was completed. The complete extrusion process was demonstrated with simulated components. These components have been fabricated and a rodlet with the dimensions of an ATF-1 test rodlet will be co-extruded early in FY 2014. The development of the U-Mo extrusion process required a set of calibration runs to determine the proper set of temperatures, pressures, rates, and forces to produce acceptable depleted U-Mo billets. The extrusion press is shown in Figure 17 and extruded billets are shown in Figure 18.

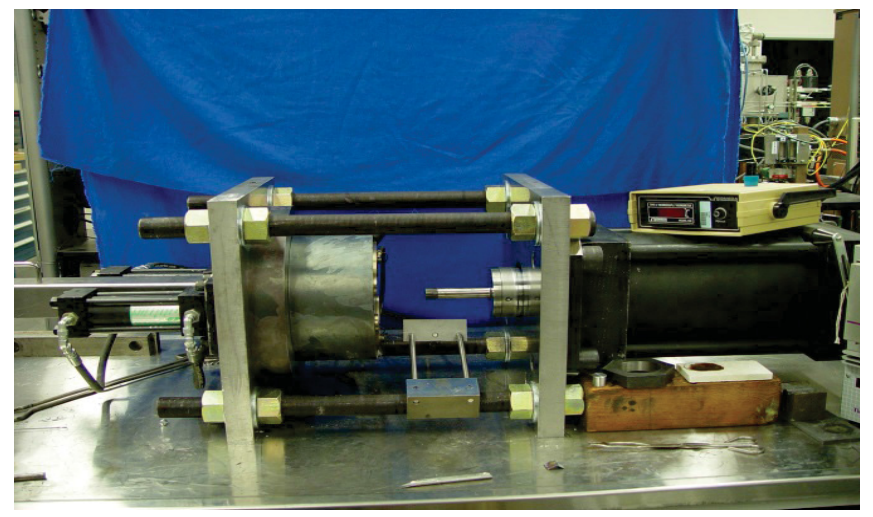

Figure 17. U-Mo Extrusion Press

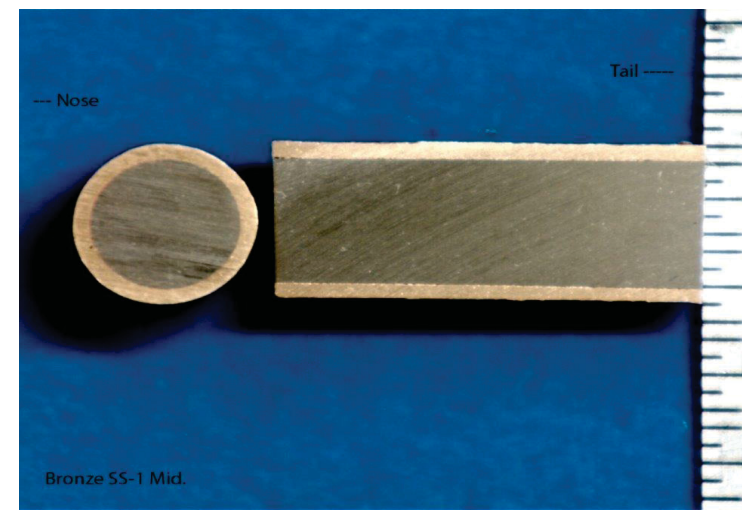

Figure 18. Coextruded Samples 
Depleted U-Mo disks have been coated with pure aluminum and with aluminum and niobium in several ratios, i.e. $1 / 1,3 / 1$ and $1 / 3$ aluminum to niobium using the Physical Vapor Deposition (PVD) process. These samples are being tested to determine the metal-water reaction rate and to ultimately determine the most favorable level of trace elements in U-Mo for minimizing the reaction rate. One such sample is shown in Figure 19. Continuing of this testing will allow the program to take a position on the most favorable U-Mo composition for in-reactor testing for un-encapsulated tests.

\subsection{Advanced LWR Cladding Development}

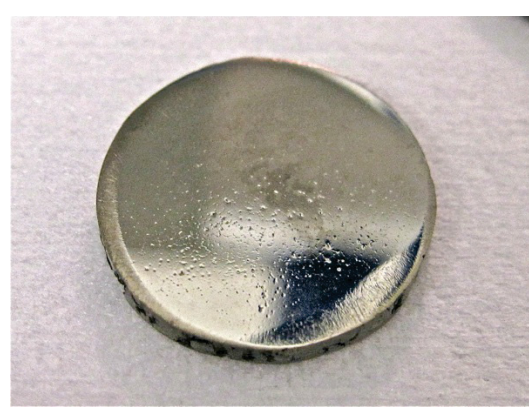

Figure 19. PVD Coated U-Mo Disk Ready for Corrosion Testing

One of the main focus areas for the nuclear energy industry, spurred by the Fukushima disaster, is development of improved accident tolerant structural materials. Nuclear fuel cladding is regarded to be the most important component for both safety and energy production efficiency. The AFC is currently investigating the possible use of a variety of advanced steel, ceramic, and refractory metal alloys as possible cladding materials. Efforts in FY 2013 have focused on the fabricability, weldability, material property measurements, and oxidation and steam reaction behavior of these materials. Key highlights from these activities are provided.

\subsubsection{Advanced FeCrAl Alloy Development} L. Snead (ORNL)

A new enhanced accident tolerant steel alloy has been developed in the FeCrAl composition with exceptional resistance to steam attack at conditions that would consume Zircaloy alloys. Within the defined nuclear compositional range, alloys exhibit good mechanical properties, ease of welding, and are formable into thin walled tubes. The $\mathrm{Cr}$-Al composition figure below gives an indication of the number of alloys that have been fabricated and whether those alloys, depending on their $\mathrm{Al}$ and Cr composition, are able to resist $1200^{\circ} \mathrm{C}$ steam accident attack. Given this data a number of alloys have been chosen for further study including welding, thin-walled tube drawing and eventual irradiation. Figure 20 provides radiography and metallographic images of a prototype irradiation capsule constructed to demonstrate concept viability for the ATF-1 irradiation vehicle.
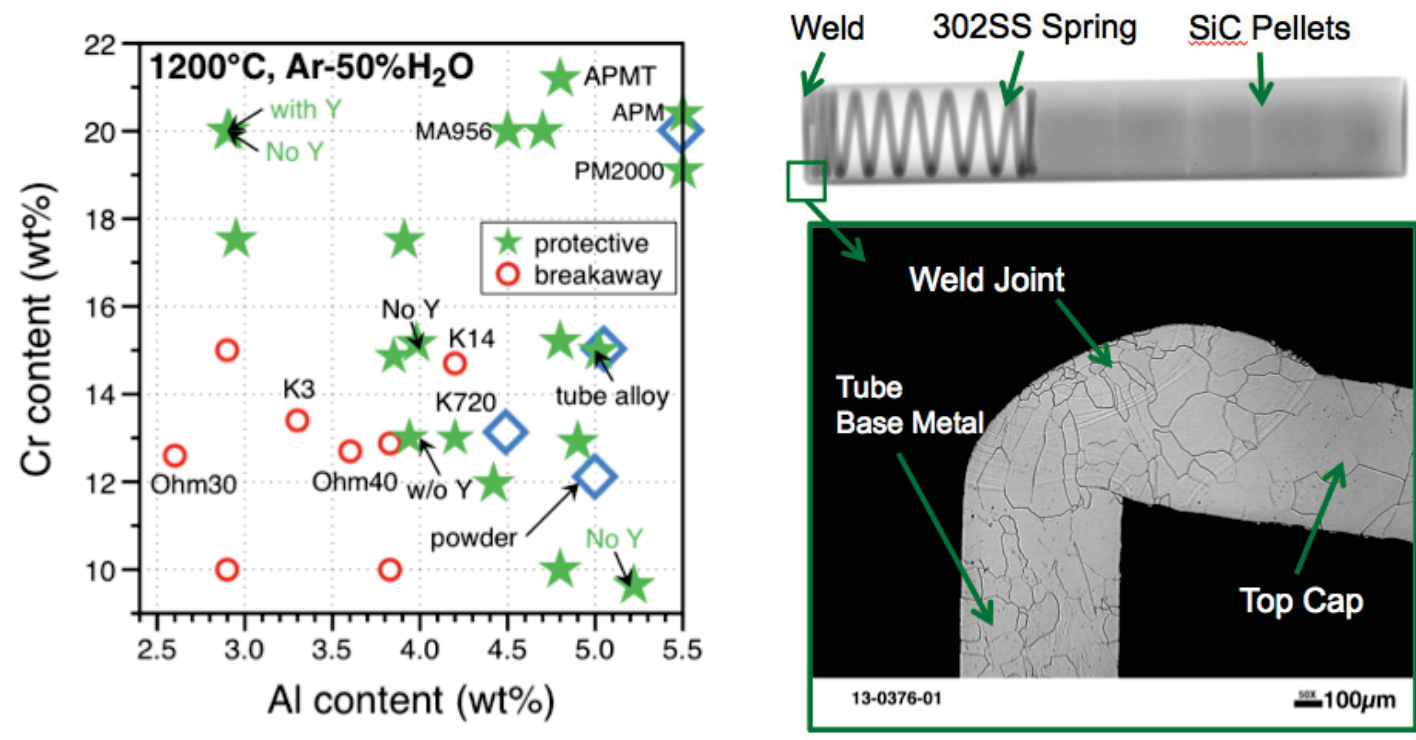

Figure 20. Radiography and metallographic images of a prototype irradiation capsule 


\section{Advanced Fuels Campaign FY 2013 Accomplishments Report}

\subsubsection{Molybdenum LWR Clad Development through CVD Processing I. Usov, D. Devlin (LANL)}

Molybdenum (Mo) and its alloys are considered to be promising candidates for nuclear fuel cladding applications. The most attractive property of Mo is its high strength, high creep resistance and remarkable stability in water vapors at elevated temperatures. It is believed that mechanical and radiation tolerance properties can be improved even further for high purity and grain refined Mo. Currently, one major hurdle in industrial applications of Mo is a lack of a fabrication method for thin wall $(\sim 0.25 \mathrm{~mm})$ and fine grain (submicron grain size) tubing. Therefore, the production of Mo tubing using fluidized bed chemical vapor deposition (FBCVD) processing will be investigated.

CVD is a well-established and scalable industrial process employed at LANL since 1950's to solve difficult materials problems posed by nuclear energy applications. Project Rover developed FBCVD coatings to protect carbon tubing from hightemperature hydrogen. CVD tungsten fuel cladding was produced in the 1990's for the SP-100 space nuclear power reactor. Parts fabricated by the conventional CVD process are typically composed of large columnar type grains, which are detrimental to mechanical properties. To disrupt columnar structure evolution, the FBCVD method was developed at LANL in the 1970's. The goal of our work was to expand previous LANL FBCVD work to produce testable Mo specimens in size and geometry applicable as fuel cladding, as well as evaluate specifics of Mo synthesis by FBCVD. Three synthesis routes were tested based on $\mathrm{Mo}(\mathrm{CO})_{6}, \mathrm{MoCl}_{5}$, and $\mathrm{MoF}_{6}$ precursors. From our evaluations, we selected $\mathrm{MoCl}_{5}$ as the primary synthesis route based on cost

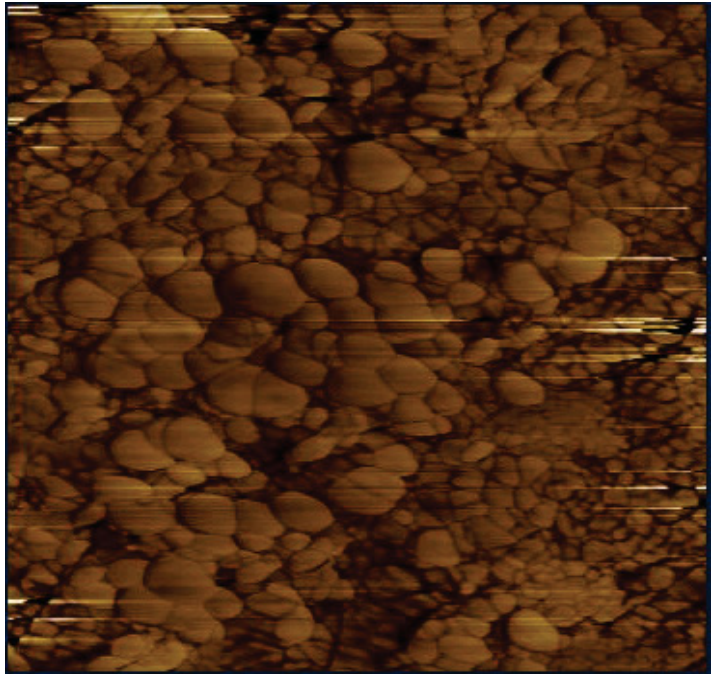

Figure 21. 1x1 $\mu \mathrm{m}$ atomic force microscopy (AFM) image from FBCVD Mo film, showing grain size ranging from 10 to $130 \mathrm{~nm}$. and quality of product. An initial set of Mo samples was produced and characterized to analyze the microstructure, chemical composition and mechanical properties. Preliminary results indicated that fine grain (10's to 100's nm, see Figure 21) and high purity Mo (with the highest impurity being oxygen) tube samples can be fabricated by FBCVD. It was determined that FBCVD Mo possessed high hardness values of $9.95 \pm 0.7 \mathrm{GPa}$ and modulus typical to Mo tabulated values of $255 \pm 13 \mathrm{GPa}$. Our current set up enables fabrication of tubing with a diameter up to $3 \mathrm{~cm}$ and lengths up to $10 \mathrm{~cm}$. A tube with a diameter of 1-1.5 cm and length 3-4 m represents typical cladding dimensions. The FBCVD process can be readily scaled up to produce required lengths.

\subsubsection{SiC Gap Analysis and Feasibility Study for LWR Application S. Bragg-Sitton (INL)}

Recent investigations aimed at determining the feasibility of using Silicon Carbide (SiC) in LWR applications, such as for nuclear fuel cladding or other structural components, continue to demonstrate the benefits of $\mathrm{SiC}$ materials relative to $\mathrm{Zr}$-based alloys via both experimental demonstration and computational analyses. However, many data and technology gaps remain, particularly for $\mathrm{SiC}$ composite materials.

Preliminary analysis using a modified version of the MELCOR severe accident code considered complete replacement of all Zr-alloy components with SiC (material properties for Zircaloy were redefined to be those of monolithic $\mathrm{SiC}$ for the initial evaluation). 
Applying the existing data on $\mathrm{SiC}$ properties, the analysis results suggest significant improvement in the reactor coping time with $\mathrm{SiC}$ materials versus $\mathrm{Zr}$-alloys under a selected loss of coolant accident (LOCA) scenario (i.e., the Three Mile Island [TMI-2] plant accident; see Figure 22). This work was conducted in coordination with DOE's Light Water Reactor Sustainability Program (LWRS).

Insufficient data is currently available to draw a clear conclusion regarding the potential licensing and adoption of $\mathrm{SiC}$ components in LWR applications. Perhaps the most limiting factor in the adoption of $\mathrm{SiC}$ composite materials in LWR components is the current cost of the base materials and fabricated components. Although these costs could be reduced if production of nuclear grade $\mathrm{SiC}$ fiber increases in response to increased demand or if fabrication processes are refined. The estimated cost for $\mathrm{SiC}$ cladding is still expected to be significantly greater than that for zirconium alloys. Additional testing is also recommended to further characterize $\mathrm{SiC}$ composites for potential nuclear service.

\subsubsection{Neutron Irradiation Testing of ATF Cladding Materials S. Maloy (LANL)}

To understand the effects of irradiation on candidate cladding materials for improved accident tolerant LWR fuels, tensile and fracture toughness specimens are being tested after irradiation in the ATR. Specimens of candidate ATF engineering alloys (ferritic steels and ferritic oxide dispersion strengthened steels) that were irradiated in ATR to doses up to $6 \mathrm{dpa}$ at $290^{\circ} \mathrm{C}$ were shipped from INL to LANL hot cells. Tensile and compact tension specimens were unloaded at the LANL hot cells and ultrasonically cleaned to remove alpha contamination. Compact tension specimens were shipped to ORNL for fracture toughness testing. Tensile specimens are being tested at LANL. A photo of a tensile specimen in the LANL hot cells is shown in Figure 23.

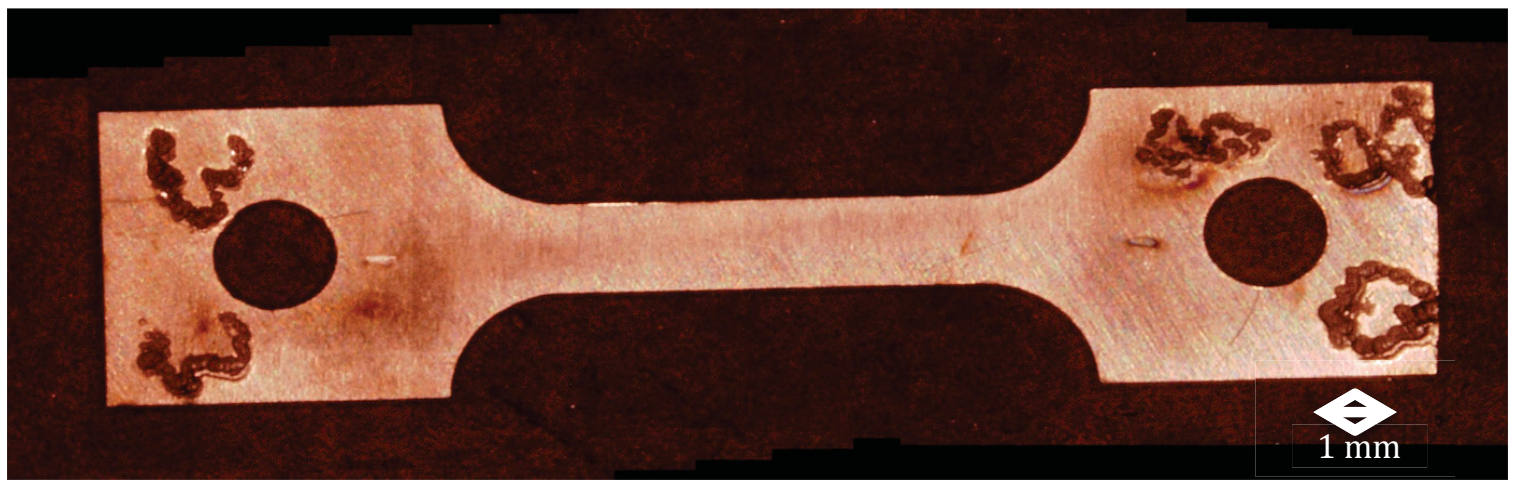

Figure 23. Optical image showing tensile specimen of 14YWT (ferritic oxide dispersion strengthened steel) after irradiation in ATR to 6 dpa at a temperature of $290^{\circ} \mathrm{C}$. 


\subsection{LWR ATF Irradiation Testing \\ K. Barrett, S. Hayes, S. Bragg-Sitton (INL)}

Per congressional direction, AFC's goal is to support the insertion of lead test rods (LTRs) or lead test assemblies (LTAs) of an ATF into a commercial Light Water Reactor (LWR) by the end of FY 2022. To support this goal, an irradiation testing program has been established that includes progress from feasibility experiments under normal operating conditions to integral demonstrations under accident conditions. Table 2 shows the long-term irradiation testing program for ATF. The first phase of this plan (ATF-1) is scheduled for initial testing in the INL ATR as a drop-in capsule experiment.

Table 2. ATF Irradiation Testing and Qualification Test Series (Planning)

\begin{tabular}{|c|c|c|c|c|}
\hline Test Series & ATF-1 & ATF-2 & ATF-3 & ATF-4 \\
\hline Test Reactor & ATR & ATR & TREAT & TREAT \\
\hline Test Type & Drop-in & Loop & Loop & Loop \\
\hline Test Strategy & $\begin{array}{l}\text { Scoping - } \\
\text { Many Composition } \\
\text { Nominal conditions }\end{array}$ & $\begin{array}{c}\text { Scoping - } \\
\text { Focused } \\
\text { Composition } \\
\text { Nominal conditions }\end{array}$ & $\begin{array}{c}\text { Focused } \\
\text { Composition } \\
\text { Accident conditions }\end{array}$ & $\begin{array}{c}\text { Focused } \\
\text { Composition } \\
\text { Accident conditions }\end{array}$ \\
\hline Fuel & $\mathrm{UO}_{2}, \mathrm{U}_{3} \mathrm{Si}_{2}, \mathrm{UN}$ & & Fuel rodlets from & \\
\hline Cladding & $\begin{array}{c}\text { Zr w/ coatings, } \\
\text { stainless steels, } \\
\text { advanced alloys, SiC }\end{array}$ & $\begin{array}{l}\text { Down-selected } \\
\text { concepts }\end{array}$ & $\begin{array}{l}\text { ATF-1 and test rods } \\
\text { from ATF-2 } \\
\text { irradiations }\end{array}$ & $\begin{array}{l}\text { Test Rods from } \\
\text { LTR/LTA irradiations }\end{array}$ \\
\hline Key Features & $\begin{array}{c}\text { Fuel-cladding } \\
\text { interactions }\end{array}$ & $\begin{array}{c}\text { Fuel-cladding- } \\
\text { coolant interactions }\end{array}$ & Integral testing & Integral testing \\
\hline Timeframe & FY14 - FY18+ & FY16 - FY22 & FY18 - FY25 & FY26 - ?? \\
\hline
\end{tabular}

During FY 2013, the AFC program has focused on design, safety analyses, and ATR acceptance of the ATF-1 drop-in capsule tests planned for initial reactor insertion in mid-FY 2014. ATF-1 design and testing is a collaborative effort with experiment team participants from multiple national laboratories (INL, PNNL, LANL, and ORNL), private industry (Westinghouse, General Electric, AREVA, and Ceramic Tubular Products) and universities (University of TN, University of IL, and Georgia Tech).

FY 2013 accomplishments provide a basis for ATR irradiation testing readiness:

- Development of the ATF-1 Test Plan to identify the experiment objectives, test matrix (Table 3).

- Proposed ATR positions, and test conditions, and the experiment hardware design (Figure 25,25 , and 26).

- Completion of the ATR bounding safety analysis of the test hardware (neutronics, thermal hydraulics, and structural).

- Design review and ATR design acceptance.

- Development of an ATF Program Quality Implementation Plan. 
Table 3. Proposed ATF-1 Test Matrix

\begin{tabular}{|c|c|c|c|c|c|c|c|}
\hline \multirow{3}{*}{ ATF Development Lead } & \multirow[b]{3}{*}{ Fuel } & \multirow[b]{3}{*}{ Anticipated Fuel Enrichment } & \multirow[b]{3}{*}{ Cladding } & \multirow[b]{3}{*}{ Coating } & \multicolumn{3}{|c|}{ Desired Irradiation Conditions: } \\
\hline & & & & & PICT & LHGR & Burnup \\
\hline & & & & & $\left({ }^{\circ} \mathrm{C}\right)$ & $(\mathrm{W} / \mathrm{cm})$ & $(\mathrm{GWd} / \mathrm{MT})$ \\
\hline & FCM-UO2, UN & $19.70 \%$ & Zircaloy & \multirow{3}{*}{$\mathrm{n} / \mathrm{a}$} & \multirow{3}{*}{$350-450$} & \multirow{3}{*}{$180-280$} & \multirow{3}{*}{$10,30,50$} \\
\hline \multirow[t]{2}{*}{ ORNL } & $\mathrm{UO}_{2}$ & $4.96 \%$ & FeCrAl & & & & \\
\hline & $\mathrm{UO}_{2}$ & $4.96 \%$ & $\mathrm{SiC}$ & & & & \\
\hline \multirow[t]{2}{*}{ PNNL } & U-10Mo & $3-6 \%$ & MA-956 & $\mathrm{n} / \mathrm{a}$ & $300-400$ & $200-350$ & 15,30 \\
\hline & U-7Mo & & & & & & \\
\hline LANL & $\mathrm{UO}_{2}$ & $5-6 \%$ & Mo & $\mathrm{n} / \mathrm{a}$ & $300-360$ & $350-500$ & 25,50 \\
\hline \multirow{2}{*}{ Westinghouse } & $\mathrm{UN}+\mathrm{U}_{3} \mathrm{Si}_{2}$ & $\begin{array}{l}\sim 5 \% \text { for } 5 \text { to } 10 \mathrm{kw} / \mathrm{ft} \\
\sim 19 \% \text { for } 20 \text { to } 30 \mathrm{kw} / \mathrm{ft}\end{array}$ & $\begin{array}{l}\text { Zircaloy } \\
\text { SiC }\end{array}$ & $\begin{array}{c}\mathrm{Ti}_{2} \mathrm{AlC} \\
\text { and/or } \\
\text { Nanosteel }\end{array}$ & \begin{tabular}{|c|}
$300-$ \\
$400^{\circ} \mathrm{C}$ \\
\\
(not \\
critical - \\
see note)
\end{tabular} & $\begin{array}{c}195-1050 \\
\text { (not critical } \\
\text { see note) }\end{array}$ & $20,40,70$ \\
\hline & $\mathrm{U}_{3} \mathrm{Si}_{2}$ & $\begin{array}{l}\sim 5 \% \text { for } 5 \text { to } 10 \mathrm{kw} / \mathrm{ft} \\
\sim 19 \% \text { for } 20 \text { to } 30 \mathrm{kw} / \mathrm{ft}\end{array}$ & $\mathrm{Zr}$ & $\begin{array}{c}\mathrm{Ti}_{2} \mathrm{AlC} \\
\text { and/or } \\
\text { Nanosteel }\end{array}$ & \begin{tabular}{|c|}
$300-$ \\
$400^{\circ} \mathrm{C}$ \\
\\
(not \\
critical - \\
see note)
\end{tabular} & $\begin{array}{c}195-1050 \\
\text { (not critical } \\
\text { see note) }\end{array}$ & $20,40,70$ \\
\hline \multirow{3}{*}{ AREVA } & $\mathrm{UO}_{2}$ & $<5 \%$ & Zircaloy & none & $300-420$ & $180-350$ & 25,50 \\
\hline & $\mathrm{UO}_{2}+\mathrm{Cr}_{2} \mathrm{O}_{3}$ & TBD by & & & & & \\
\hline & $\mathrm{UO}_{2}+\mathrm{Cr}_{2} \mathrm{O}_{3}+\mathrm{SiC}$ & INL analysts & & & & & \\
\hline \multirow[b]{2}{*}{ General Electric } & $\mathrm{UO}_{2}$ & $\begin{array}{c}4.9 \% \\
\text { (from } \mathrm{GNF} \text { ) }\end{array}$ & $\begin{array}{l}3 \text { Different } \\
\text { Advanced } \\
\text { Steels }\end{array}$ & None & $300-400$ & $500 \mathrm{~W} / \mathrm{cm}$ & 20,80 \\
\hline & No Fuel & No Fuel & $\begin{array}{c}3 \text { empty } \\
\text { rodlets (Nano } \\
\text { Featured, } \\
\text { APMT, Alloy } \\
33 \text { ) } \\
\end{array}$ & None & $300-400$ & $500 \mathrm{~W} / \mathrm{cm}$ & 20,80 \\
\hline U. Illinois & $\mathrm{UO}_{2}$ & $<5 \%$ & Mod. $\mathrm{Zr}$ & $\mathrm{n} / \mathrm{a}$ & & & \\
\hline U. Tennessee & $\mathrm{UO}_{2}$ & $<5 \%$ & Zircaloy & Ceramics & $\mathrm{n} / \mathrm{a}$ & $\mathrm{n} / \mathrm{a}$ & $\mathrm{n} / \mathrm{a}$ \\
\hline \multirow[t]{2}{*}{ Georgia Tech } & $\mathrm{U}_{3} \mathrm{Si}_{2}$ & $5-10 \%$ & $\mathrm{FeCrAl}$ & $\mathrm{n} / \mathrm{a}$ & & & \\
\hline & & Test Nat-U, $5 \%, 8 \%$ enriched & & & & & \\
\hline Ceramic Tubular Products & $\mathrm{UO}_{2}$ & not specified; assume $<5 \%$ & SiC TRIPLEX & none & $300-400$ & $500-600$ & $20,50,100$ \\
\hline
\end{tabular}

ATF Test Capsule

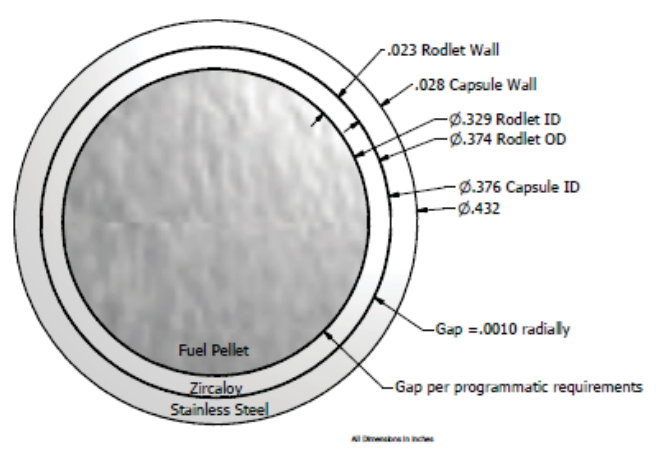

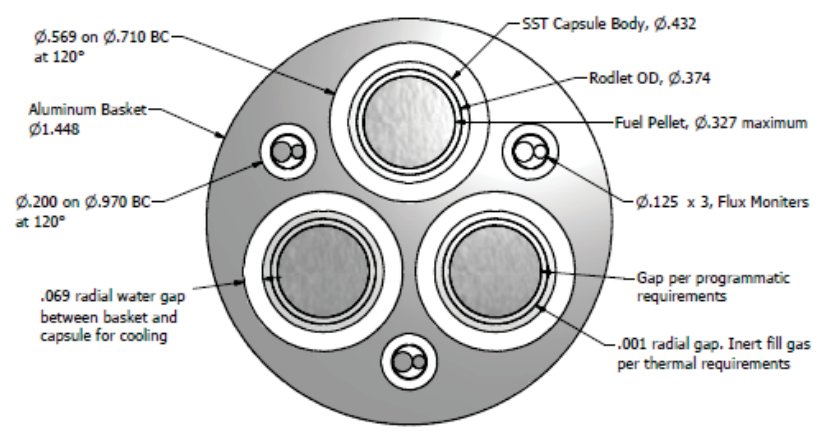

Figure 24. ATF-1 Experiment Component Cross Sections. 


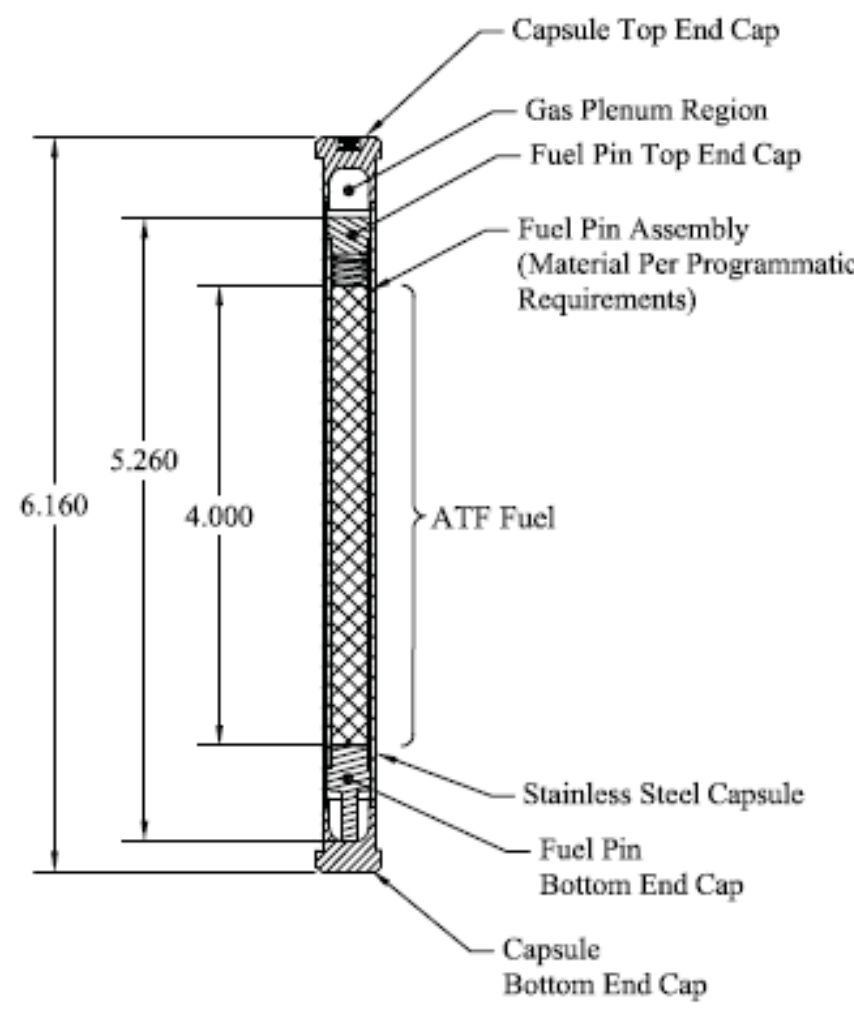

Medium Capsule Assembly

Figure 25. ATF-1 Capsule and Rodlet Design

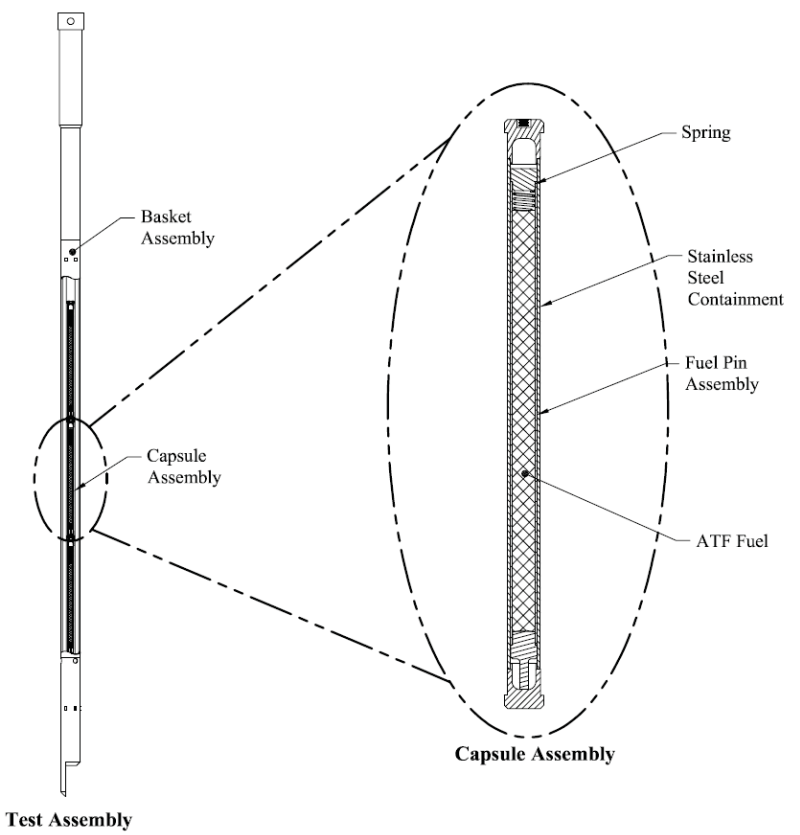

Figure 26. LWR Basket Design. 


\subsection{Advanced LWR Fuel Systems - Key Publications}

A.T. Nelson, M.M. Giachino, J.C. Nino, K.J. McClellan, "Effect of Composition on Thermal Conductivity of MgO-Nd2Zr207 Composites for Inert Matrix Materials," J. Nuc. Mater., Accepted 15-July, 2013.

D. Shin, T.M. Besmann, "Thermodynamic modeling of the (U,La) $\mathrm{O}_{2 \pm x}$ solid solution phase," J. Nuc. Mater., 433, pp.227-232 (2013).

G.W. Egeland, J.A. Valdez, S.A. Maloy, K.J. McClellan, K.E. Sickafus, G. M. Bond, "Heavy-ion irradiation defect accumulation in ZrN characterized by TEM, GIXRD, nanoindentation, and helium desorption," J. Nuc. Mater., 435[1-3], pp. 77-87 (2013).

H.C. Lim , K. Rudman, K. Krishnan, R. McDonald, P. Dickerson, D. Byler, P. Peralta, C. Stanek, K. McClellan, "Microstructurally Explicit Simulation Of Intergranular Mass Transport In Oxide Nuclear Fuels," Nuc. Tech., 182[2], pp. 155-163 (2013).

J.T. White, A.T. Nelson, "Thermal Conductivity of $\mathrm{UO}_{2}+\mathrm{X}$ and U409-Y," J. Nuc. Mater., 443, pp. 342350 (2013).

J.W. McMurray, D. Shin, B.W. Slone, T.M. Besmann, "Thermochemical modeling of the $\mathrm{U}_{1-\mathrm{y}} \mathrm{Gd}_{\mathrm{y}} \mathrm{O}_{2 \pm x}$ phase," J. Nuc. Mater., 443, pp.588-595 (2013).

K. Rudman, P. Dickerson, D. Byler, R. McDonald, H. Lim, P. Peralta, C. Stanek, K. McClellan, “ThreeDimensional Characterization Of Sintered U02+X: Effects Of Oxygen Content On Microstructure And Its Evolution," Nuc. Tech., 182[2], pp. 145-154 (2013).

N.R. Brown, Ludewig, H., Aronson, A., Raitses, G., Todosow, M., 2013. "Neutronic Evaluation of a PWR With Fully-Ceramic Micro-Encapsulated Fuel, Part I: Lattice benchmarking, cycle length, and reactivity coefficients," Annals of Nuclear Energy, doi:10.1016/j.anucene.2013.05.025.

N.R. Brown, Ludewig, H., Aronson, A., Raitses, G., Todosow, M., 2013. "Neutronic Evaluation of a PWR With Fully-Ceramic Micro-Encapsulated Fuel, Part II: Nodal core calculations and preliminary study of thermal hydraulic feedback," Annals of Nuclear Energy, doi:10.1016/j.anucene.2013.05.027.

\section{CONFERENCE PROCEEDINGS/WORKSHOP SUMMARIES}

L. Braase, S.M. Bragg-Sitton, "Advanced Fuels Campaign Cladding \& Coatings Meeting Summary," INL/EXT-13-28628 (2013).

L. Braase, "Enhanced Accident Tolerant LWR Fuels, National Metrics Workshop Report," INL/EXT13-28090 (2013).

J. Carmack, F. Goldner, S.M. Bragg-Sitton, L.L. Snead, "Overview of U.S. DOE Accident Tolerant Fuel Development Program,” Top Fuel 2013, Charlotte, NC, Sept. 16-20, 2013, (2013).

OECD/NEA, "Increased Accident Tolerance of Fuels for Light Water Reactors," Nuclear Science and Nuclear Safety, Workshop Proceedings, NEA/NSC/DOC (2013)9, June 2013.

S.M. Bragg-Sitton, L. Braase, R. Montgomery, C. Stanek, R.H. Montgomery, L.J. Ott, L.L. Snead, M.C. Billone, "Enhanced Accident Tolerant LWR Fuels: Metrics Development," American Nuclear Society TopFuel 2013, Charlotte, NC, September 2013. 
This page intentionally left blank. 


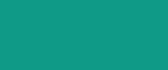

(1)

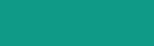

(a) 


\section{METALLIC TRANSMUTATION FUELS TECHNOLOGIES}

Metallic-based Fuels Technologies focused on research and development to gain a fundamental understanding of metallic fuels. Priority was on low-loss fabrication methods and capability and on developing a fundamental understanding of the phase, microstructure, and chemical migration behavior of metallic fuel constituents. The desired outcome is to develop an understanding of the key phenomena affecting metallic fuel performance and behavior under irradiation.

\subsection{Pure Feedstock (Np + Am) \\ P. Lessing (INL)}

A critical need of the Advanced Fuels Campaign is a source of purified feedstocks of the actinides in order to produce higher quality fuels with lower impurity levels for irradiation testing and to obtain high fidelity data on the fundamental properties and behavior of actinide bearing nuclear fuel type materials. Neptunium (Np) metal feedstocks are in short supply and there are no americium (Am) metal feedstocks available for study. To alleviate this shortcoming, techniques are being developed to produce high purity metallic (i.e. elemental) feedstocks of $\mathrm{Np}$ and Am from available feedstocks of their oxides (typically containing a variety of impurities). As part of this program, an apparatus has been developed and tested to distill metallic Am from a material mass bearing other elements and to concurrently monitor the accumulation of the desired product. The demonstration represents the final step in the purification process.

A previously designed, small high temperature distillation/condensation apparatus (Figure 27, right) was installed and tested in an inert atmosphere (Ar gas) glovebox at the INL (Figure 27, left). Elemental americium metal was distilled away from an americium feedstock material containing approximately $5 \mathrm{wt} \%$ neptunium at temperatures up to $1300^{\circ} \mathrm{C}$ under vacuum. The purified americium metal was condensed in the cold zone of the apparatus and 4.1 grams of material recovered (Figure 28). Although some modifications to the apparatus are needed to optimize performance, the demonstration represents an important step to providing high quality materials for experimentation in support of the science-based approach to understanding the behavior and performance of nuclear fuels.

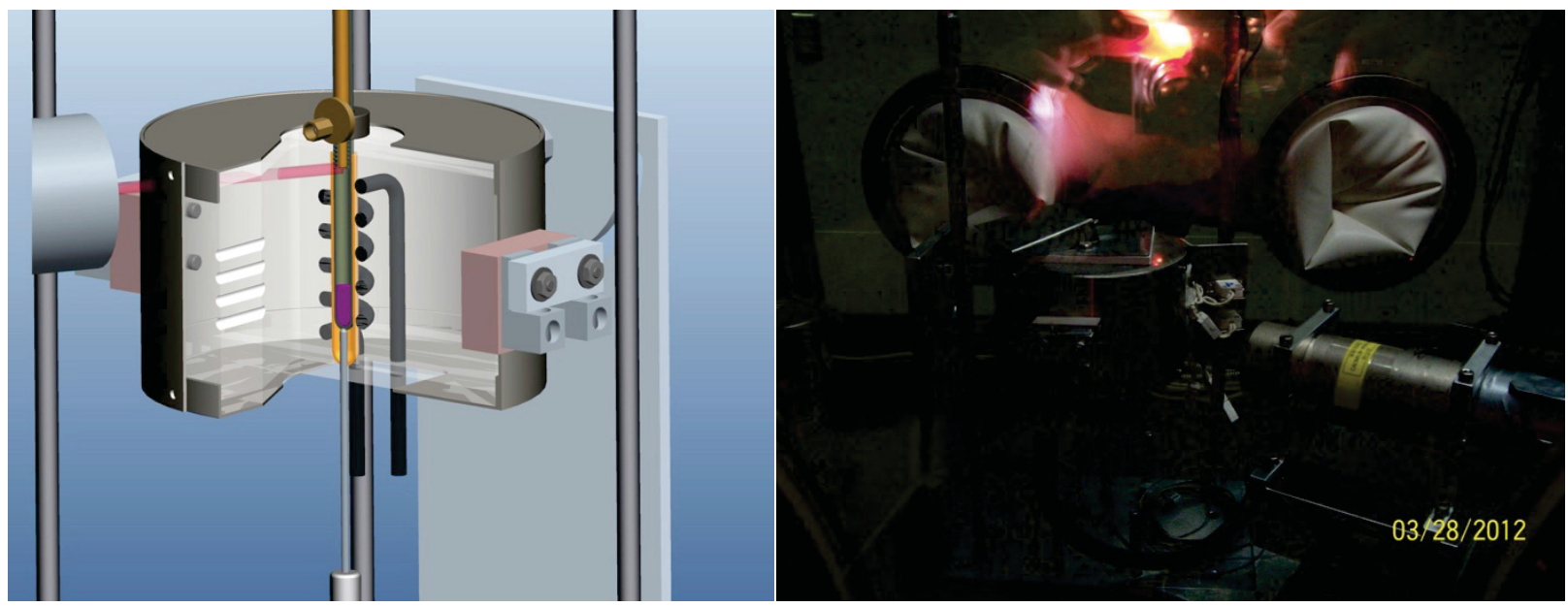

Figure 27. Left: design drawing of the Americium Distillation Furnace including tantalum tube (olive color) containing molten Americium (plum color) and special gamma detector (upper left of picture). Right: actual Americium Distillation Furnace assembled in glovebox showing the special gamma detector (tube with yellow tape at right) that accurately measures movement of radioactive metal from hot distillation zone to cold condensation zone. 


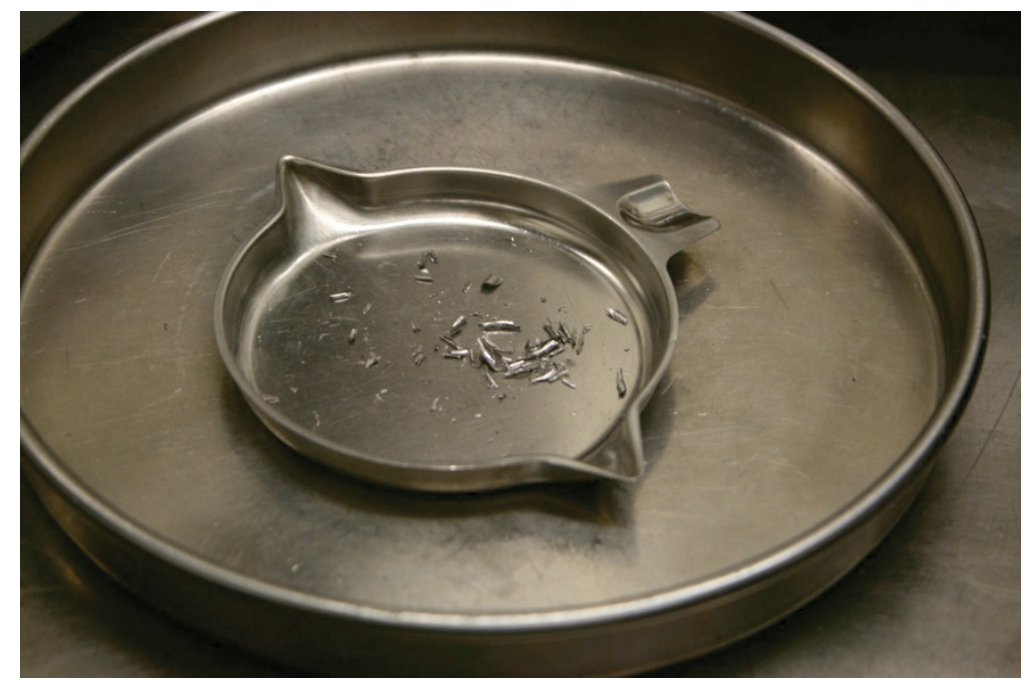

Figure 28. Photo of purified Am chips obtained using Americium Distillation/Condensation apparatus at INL. A total of 4.1 grams were recovered.

\subsection{Advanced Transmutation Fuel Fabrication Technique Development R. Fielding (INL)}

All metallic irradiation test fuel samples produced to date in the FCRD program (and its forerunner programs) have been via an arc-melting/casting process. Although effective for the limited material quantities required for these tests, the technique is not and never has been considered for ultimate application to a full in-cell fuel fabrication recycle process. The technique is not easily scalable to larger (i.e. full length) fuel pin fabrication, remote operation engineering would be difficult at best, and it is not parametrically controllable in order to optimize the process and obtain quantifiable data on the various solid, liquid, and gas states of matter produced during operation. A furnace based casting system is being developed that will allow longer fuel pins to be fabricated, is scalable to higher production levels, can be adapted to remote operation, and is versatile in its design. This will allow testing and quantification of many of the critical properties associated with the casting process including retention of volatile casting materials, fluid/liquid properties, and materials interactions. This experimental work is being performed in conjunction with casting modeling efforts at LANL.

Crucial to these studies is to perform experiments (and fuel fabrication) on true actinide materials, including plutonium and americium, instead of surrogate type materials. These activities require the casting furnace apparatus to be installed and operated in an inert atmosphere plutonium qualified glovebox. The designed, built, and tested (preliminary surrogate materials) casting furnace apparatus was named the Glovebox Advanced Casting System (GACS). It was successfully installed and tested following extensive modifications and upgrades to the aged workhorse Casting Laboratory glovebox at INL (Figure 29).

The installation of the GACS furnace into this

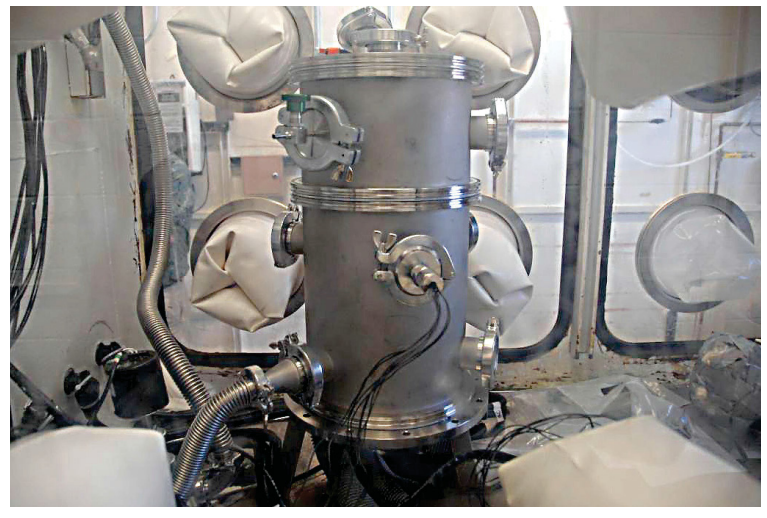

Figure 29. Glovebox Advanced Casting System installed and assembled in the Casting Laboratory glovebox. 
glovebox in a very important accomplishment that will enable the casting of plutonium and minor actinide bearing fuels at either near atmospheric or increased pressure using gravity casting into a re-usable mold on the 100-300 gram scale. The current design allows 3 pins of approximately 4.3 $\mathrm{mm}$ diameter and $250 \mathrm{~mm}$ long to be cast. A log showing the heating profile of a test run of the furnace in which copper was heated and cast is shown in Figure 30 (testing with plutonium and minor actinides is awaiting final authorization). Through this casting work, americium retention during prototypic casting runs will be verified (a computational model of the atmospheric pressure required to mitigate gas phase diffusion and loss of americium already established).

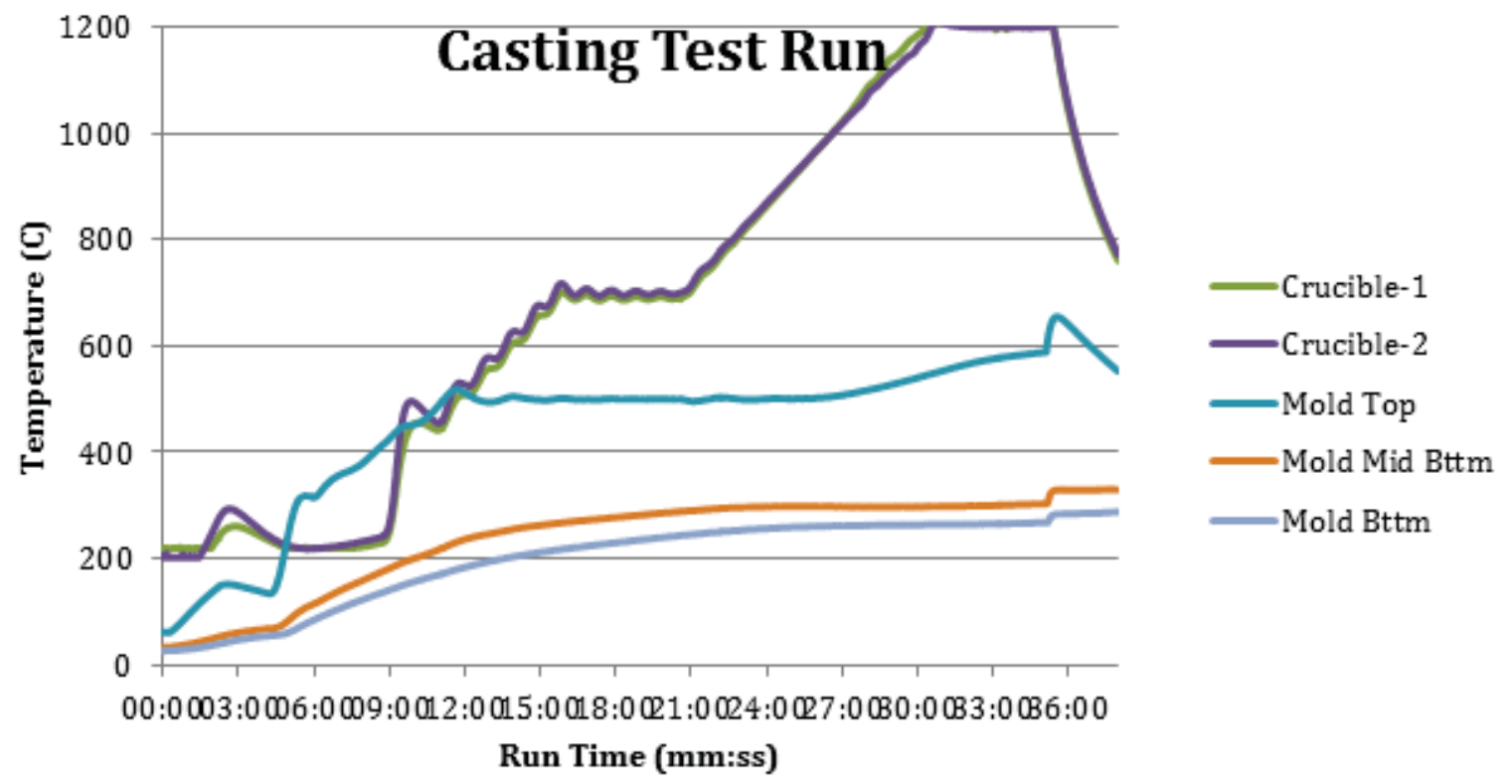

Figure 30. Temperature log of typical test casting run of the GACS performed as validation test in the CL glovebox.

An important feature of GACS is its scalability and adaptability for remote operation. AFC supports the Joint Fuel Cycles Studies (JFCS) CRADA with the Korean Atomic Energy Research Institute (KAERI) in their goal to demonstrate a closed fuel cycle employing molten salt electrochemical separations technology coupled to remote fuel fabrication in the Hot Fuel Examination facility (HFEF) at INL. Irradiation testing of that fuel will follow.

In addition to showing americium retention, the GACS furnace will be used to develop casting parameters and produce fuel samples of likely prototypic JFCS fuel compositions for further characterization. This effort is important to fully characterize the fuel compositions that are likely to be included in the fuels irradiation test that will be fabricated under the JFCS. These fuel compositions will include U-TRU-Zr-RE alloys, as it is likely some rare earth fission products will be carried over from the electrochemical recycling steps. The microstructure of this fuel may impact fuel behavior and may drive fuel design changes and therefore fully characterizing likely compositions as soon as possible is vitally important to the success of the JFCS agreement. Also as part of the JFCS, the GACS furnace will be used for studying and testing crucible coating material interactions. Coating materials will be tested against U-TRU-Zr alloys and U-TRU-Zr-RE alloys to identify barrier materials that can be used to reduce fuel losses and increase productivity in a closed fuel cycle.

The modeling performed at LANL has shown there is a need for actinide material melt (i.e. liquid) properties characterization. A common characteristic "property" used in the casting industry, although somewhat empirical, is the fluidity test on the molten alloys whereby the alloy is cast into 
a long cylindrical shape with a constant cross section. The length of flow is the empirical property called fluidity and essentially takes into account many of the melt properties needed for modeling, such as viscosity, surface tension, mold interaction, etc. A database will be developed on general flow characteristics of the pertinent alloys and will provide a means to perform well defined experiments in conjunction with the modeling effort.

\subsection{Fabrication of Metal Fuel Samples for Irradiation Testing R. Fielding (INL)}

A total of four drop in style irradiation tests were fabricated in FY 2013 including the AFC-3C, AFC3D, AFC-4A, and AFC-4B tests. These tests include both advanced composition as well as fuel structural design concepts. The fuel concepts that are part of the AFC-3C/D and AFC-4A tests include advanced fuel alloys that are both solid sodium bonded fuel and well as annular helium bonded fuels. AFC-4B is a cooperative test between AFC and TerraPower wherein fuel compositions relevant to TerraPower and cladding liners of interest to both programs are included. In order to establish exacting dimensional control, all the fuels were cast oversized and then machined down using a Computer Numerical Control (CNC) lathe to maintain tight tolerances as well as enabling center void concentricity in the annular fuels. Table 4 lists the nominal fuel compositions, dimensions, and bond materials for the tests. The left side picture in Figure 31 shows an example of the outside of a final machined product and the right side the center void of an annular fuel. Figure 32 shows the final encapsulated test pins for the AFC-3C irradiation.

Table 4. Fuel summary from FY 2013 fabricated irradiation tests

\begin{tabular}{|c|c|c|c|c|c|}
\hline Fuel ID & Composition & Fuel Type & Outside Diameter & Inside Diameter & Bond Type \\
\hline $3 C-1$ & U-10Mo & Solid & $0.168 "$ & NA & $\mathrm{Na}$ \\
\hline $3 C-2$ & U-10Mo & Annular & $0.193 "$ & $0.130 "$ & $\mathrm{He}$ \\
\hline $3 C-3$ & $\mathrm{U}-10 \mathrm{Zr}$ & Solid & $0.158^{\prime \prime}$ & NA & $\mathrm{Na}$ \\
\hline $3 C-4$ & $\mathrm{U}-10 \mathrm{Zr}$ & Annular & $0.193 "$ & $0.130 "$ & $\mathrm{He}$ \\
\hline $3 C-5 a$ & $\mathrm{U}-1 \mathrm{Pd}-13 \mathrm{Zr}$ & Solid & $0.168 "$ & NA & $\mathrm{Na}$ \\
\hline $3 C-5 b$ & $\mathrm{U}-2 \mathrm{Pd}-13 \mathrm{Zr}$ & Solid & $0.168 "$ & NA & $\mathrm{Na}$ \\
\hline $3 \mathrm{D}-1$ & $\mathrm{U}-10 \mathrm{Zr}$ & Annular & $0.193 "$ & $0.130 "$ & $\mathrm{He}$ \\
\hline $3 \mathrm{D}-2$ & U-4Pd-13Zr & Solid & $0.144 "$ & NA & $\mathrm{Na}$ \\
\hline $3 D-3$ & U-10Mo & Solid & $0.144 "$ & NA & $\mathrm{Na}$ \\
\hline $3 D-4$ & U-10Mo & Annular & $0.193 "$ & $0.130 "$ & $\mathrm{He}$ \\
\hline $3 D-5$ & U-4Pd-13Zr & Annular & $0.193 "$ & $0.130 "$ & $\mathrm{He}$ \\
\hline $4 \mathrm{~A}-1$ & U-10Mo & Annular & $0.193 "$ & $0.115^{\prime \prime}$ & $\mathrm{He}$ \\
\hline $4 \mathrm{~A}-2$ & U-10Mo-2.5W & Solid & $0.168 "$ & NA & $\mathrm{Na}$ \\
\hline $4 A-3$ & U-5Mo-4.3Ti-0.7Zr & Solid & $0.168 "$ & NA & $\mathrm{Na}$ \\
\hline $4 \mathrm{~A}-4$ & U-5Mo-4.3Ti-0.7Zr-2Pd & Solid & $0.168 "$ & NA & $\mathrm{Na}$ \\
\hline $4 A-5$ & $\mathrm{U}-10 \mathrm{Zr}$ & Solid & $0.168 "$ & NA & $\mathrm{Na}$ \\
\hline 4B-1 & U & Annular & $0.184 "$ & $0.114 "$ & $\mathrm{He}$ \\
\hline 4B-2 & U & Annular & $0.190 "$ & $0.133 "$ & $\mathrm{He}$ \\
\hline 4B-3 & U & Annular & $0.189 "$ & $0.117^{\prime \prime}$ & $\mathrm{He}$ \\
\hline 4B-4 & $U$ & Annular & $0.189 "$ & $0.117^{\prime \prime}$ & $\mathrm{He}$ \\
\hline 4B-5 & U & Annular & $0.185^{\prime \prime}$ & $0.128 "$ & $\mathrm{He}$ \\
\hline
\end{tabular}



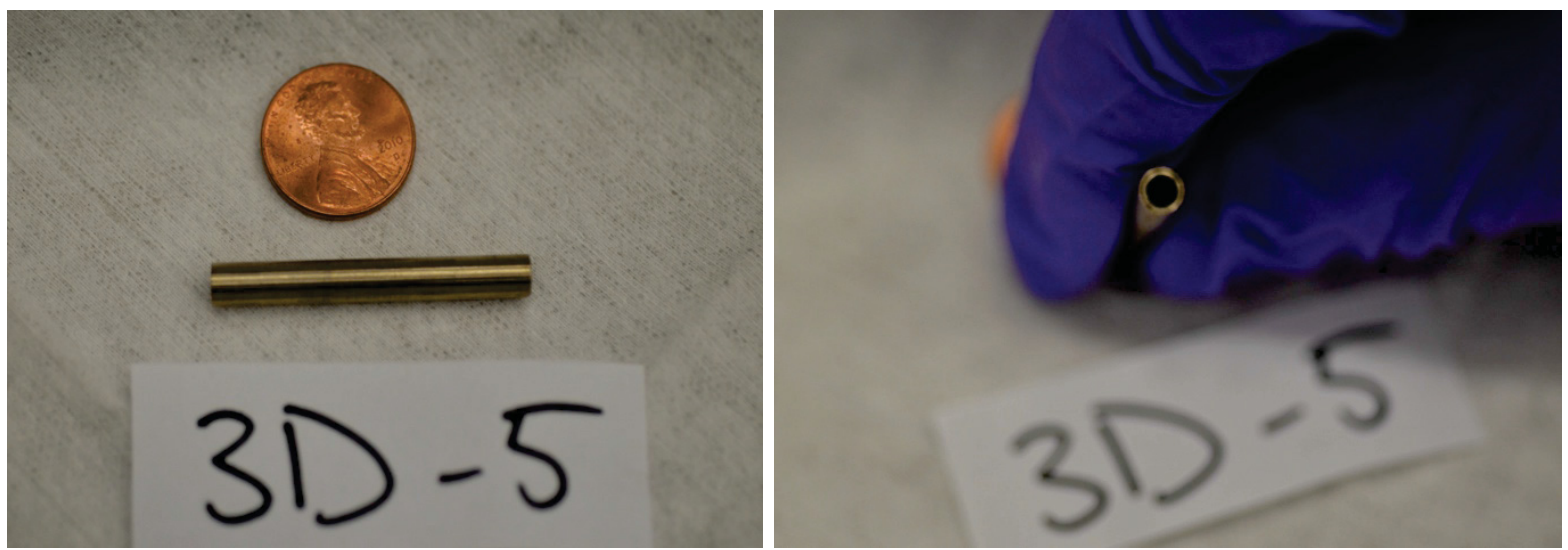

Figure 31. Right: example showing outside surface of as machined fuel slug product. Left: same as machined fuel slug showing annulus.

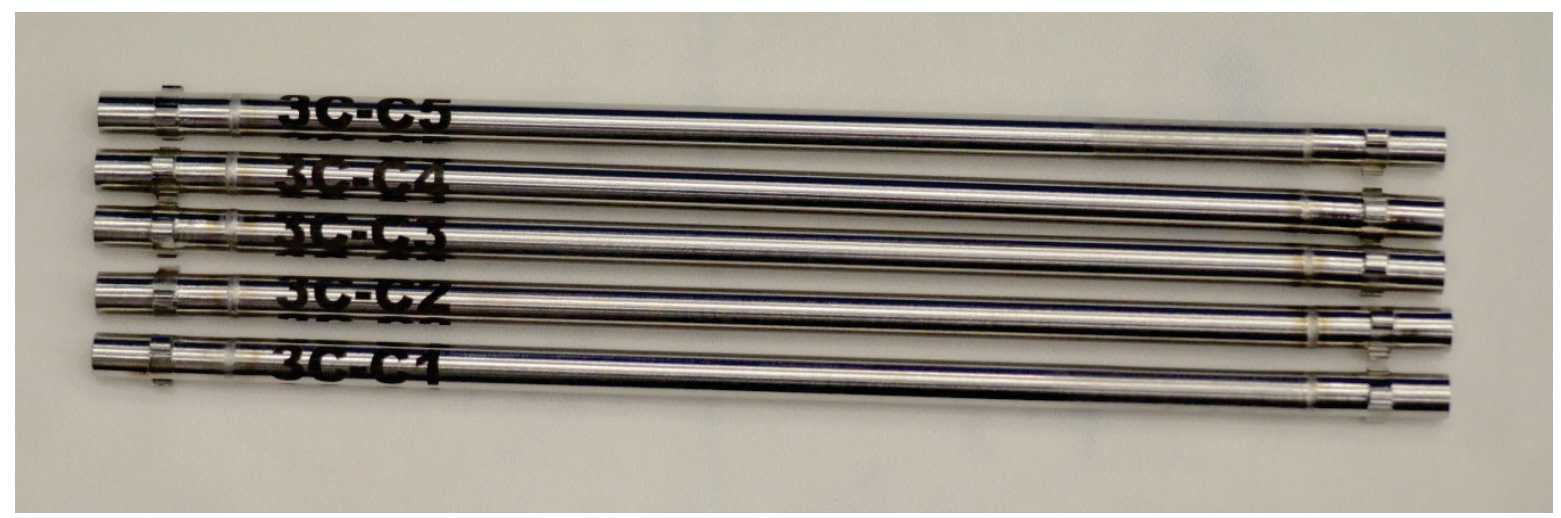

Figure 32. Finished AFC-3C irradiation test capsules.

\subsection{Transmission Electron Microscopy Analysis of U-Pu-Zr Alloys D. Janney (INL)}

In order to better understand the nature of metallic transmutation fuels and to better integrate experiment with computation and modeling with respect to the scientific approach directive, Transmission Electron Microscopy (TEM) studies were completed on various fuel types. These high spatial resolution microstructure studies are investigating a base U-Pu-Zr alloy in collaboration with Lawrence Livermore National Laboratory (LLNL) (INL sent FIB prepared samples to LLNL for study), a 52U-20Pu-3Am-2Np-8.0 Ln-15Zr fuel composition that includes both minor actinides (MA) and lanthanides ( $\mathrm{Ln}$ ), and diffusion couples between U-Pu-Zr alloys and iron (Fe, representing cladding). These studies are the first of their kind with regard to use of the focused ion beam (FIB) for sample preparation of metallic transmutation fuels (TRU bearing fuel type materials) and the use of the TEM and its associated techniques (electron diffraction for single phase crystallite structure determination, energy dispersive spectroscopy for microchemical analysis) to investigate specific microstructural features of the fuel materials. Data from the U-PuZr work and diffusion couple studies are still forthcoming but some very interesting and important preliminary results from the $52 \mathrm{U}-20 \mathrm{Pu}-3 \mathrm{Am}-2 \mathrm{~Np}-8.0 \mathrm{Ln}-15 \mathrm{Zr}$ study are given below.

Many Scanning Electron Microscopy (SEM) studies that do not allow the high spatial resolution possible with TEM have observed the as cast U-Pu-Zr fuels microstructure as an undefined mixture of light and dark contrast phases, including various shading of gray contrast material. It was speculated that this interesting feature could represent a nano-sized grain structure composed of $\zeta$ - 


\section{Advanced Fuels Campaign \\ FY 2013 Accomplishments Report}

$(\mathrm{U}, \mathrm{Pu}, \mathrm{Zr})$ and $\delta-(\mathrm{U}, \mathrm{Pu}) \mathrm{Zr}_{2}$ phases. Figure 33 shows a micrograph of a gray shaded area and reveals that indeed the as-cast microstructure is composed of nano-sized grains on the order of only a few tens of nanometers across. Electron diffraction analysis strongly suggests that one of the phases is in fact $\zeta-(\mathrm{U}, \mathrm{Pu}, \mathrm{Zr})$.

The ubiquitous Zr inclusions observed in virtually all U-TRU-Zr fuels have generally been interpreted to form due to impurities (oxygen, nitrogen, silicon, etc.) introduced as part of the feedstock material or from the casting process and should exist in the $\alpha$-Zr structure. Our singlecrystal electron diffraction analyses (Figure 34) on these inclusions show this isn't necessarily true and in fact the high-Zr inclusions have a face-centered cubic structure that haven't been reported previously in the literature.

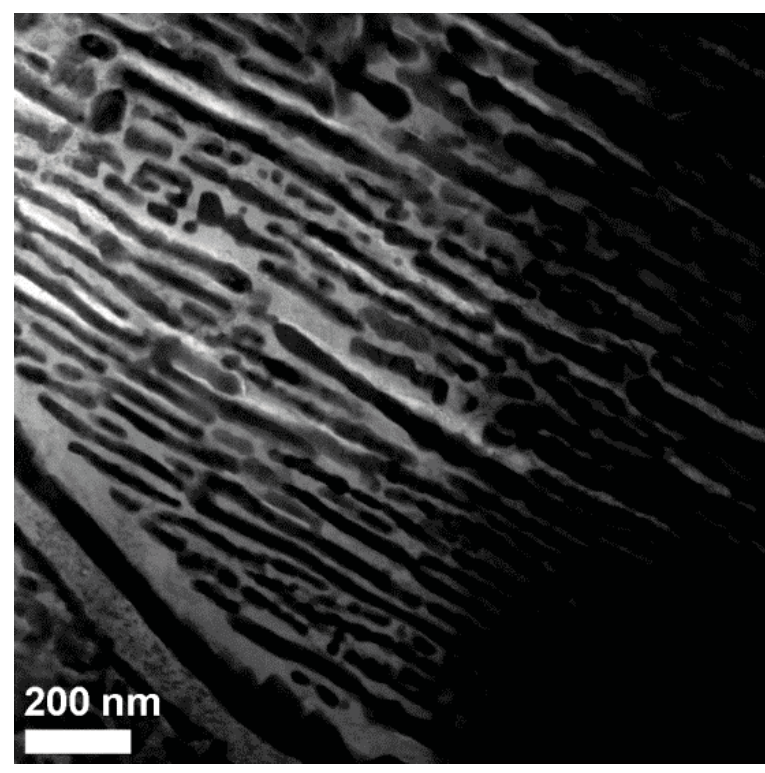

Figure 33. TEM micrograph obtained from an as-cast 52U-20Pu-3Am-2Np-8.0Ln-15Zr sample showing nanosized light and dark contrast grain structure.

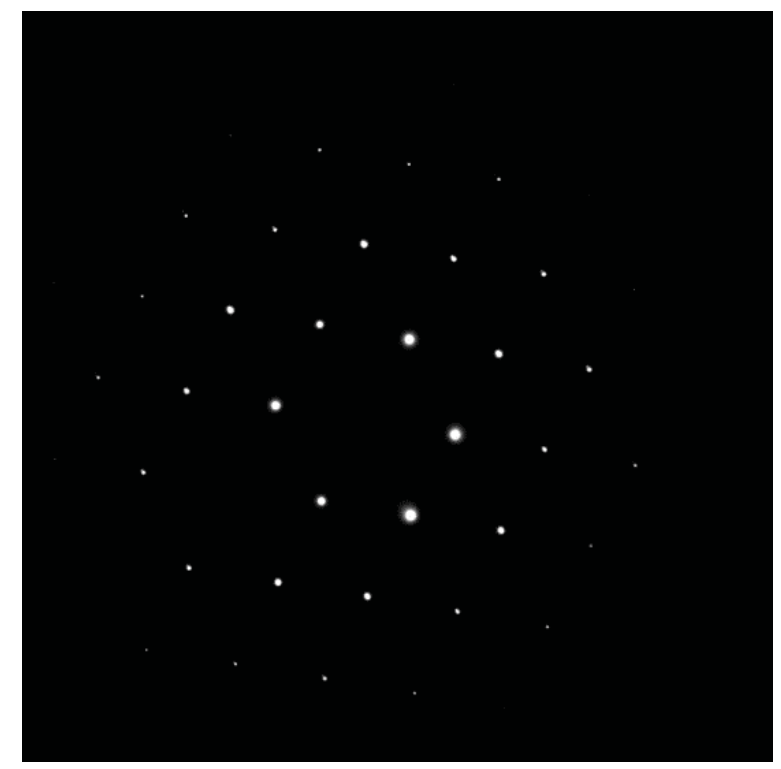

Figure 34. Electron diffraction pattern from a $\mathrm{Zr}$ rich inclusion along the [110] axis revealing it to be in the, to date, unreported face-centered-cubic structure.

Additional findings show, as previously reported in SEM data, there are two kinds of RE inclusions: high-Nd ("dark") and high-Am ("light"). Although all of the RE inclusions are high in Nd, proportions of other elements differ. High Nd content inclusions can have significant concentrations of oxygen and low concentrations of actinides. High Ce content inclusions are also high in Am and have significant concentrations of $\mathrm{Pu}$. Interestingly, all of the observed high $\mathrm{Zr}$ inclusions are adjacent to high Ce inclusions, but not all high Ce inclusions are adjacent to high-Zr inclusions (Figure 35). The implications of these observations are still under consideration. 


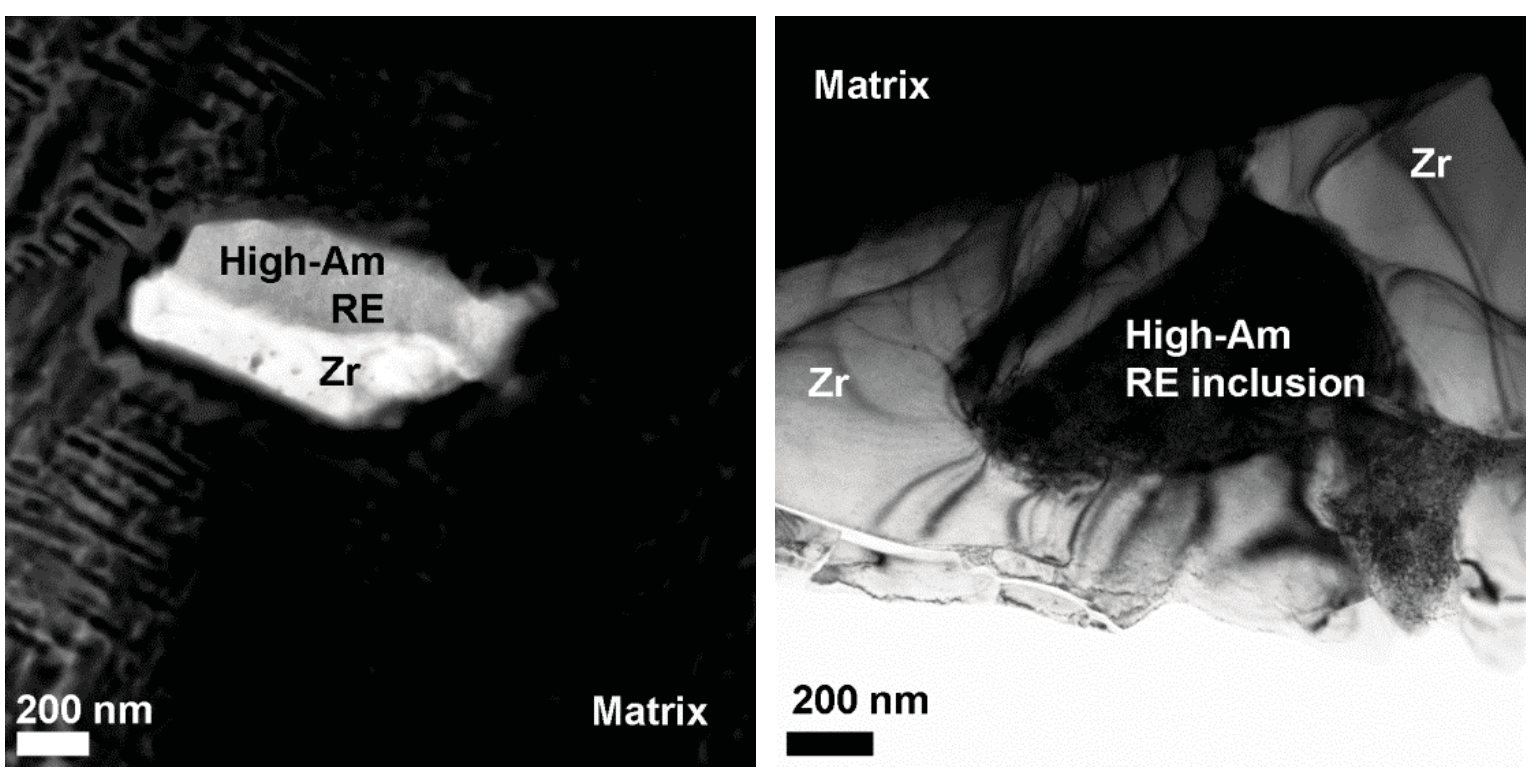

Figure 35. Left: high Am content RE inclusion surrounded by high Zr content inclusion. Right: combined high Zr content and high Am content inclusion.

\subsection{Performance modeling of the AFC-2A, 2B irradiation experiments P. Medvedev, INL}

The primary objective of this work is to determine the fuel and cladding temperature history during irradiation of the AFC-2A, 2B transmutation metallic fuel alloy irradiation experiments. As a result of this study, performance of six double-encapsulated AFC-2A and AFC-2B experiments during irradiation was investigated.

It was found that during nominal operation the fuel and cladding temperatures remained within the experiments design limits. Rodlet 4 was found to have operated at the greatest temperature; therefore, it was assumed that it was the first one to breach.

Irradiation simulation assuming single breached rodlet demonstrated that cladding temperature rise due to breach in a single rodlet is sufficient to cause breaches in remaining rodlets as shown in Figure 36.

Irradiation simulation assuming multiple breached rodlets provided an estimate of the actual fuel and cladding temperatures. It was determined that as a result of the temperature increase associated with the fission gas release from breached rodlets into the capsule the cladding temperatures ranged from $928^{\circ} \mathrm{C}$ to $983^{\circ} \mathrm{C}(\mathrm{AFC}-2 \mathrm{~A})$, and from $1000^{\circ} \mathrm{C}$ to $1040^{\circ} \mathrm{C}(\mathrm{AFC}-2 \mathrm{~B})$, and with peak fuel temperatures ranged from $1144^{\circ} \mathrm{C}$ to $1235^{\circ} \mathrm{C}(\mathrm{AFC}-2 \mathrm{~A})$, and from $1201^{\circ} \mathrm{C}$ to $1286^{\circ} \mathrm{C}$ (AFC-2B). 

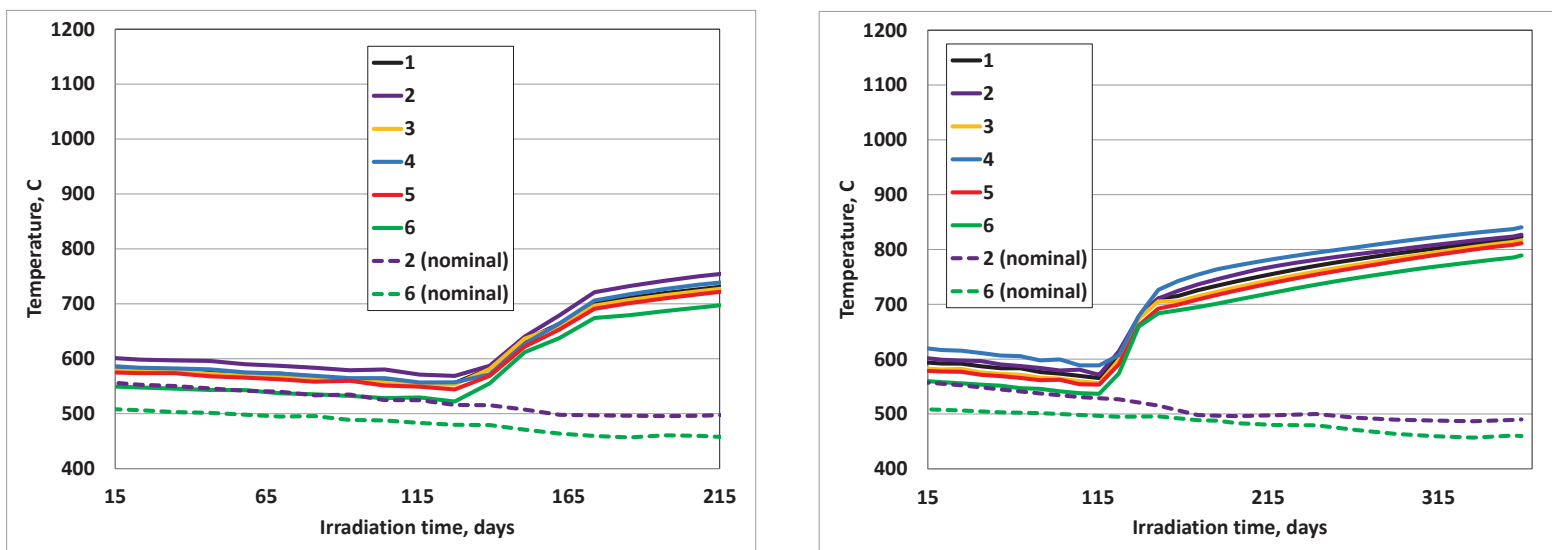

Figure 36. Effect of a breach in rodlet 4 on the cladding temperature during the AFC-2A (left) and AFC-2B (right) irradiation.

The objective of the next study was to determine the fuel temperature history and radial temperature profile during irradiation of the AFC-2C, 2D irradiation experiments. Specifically, it attempts to explain asymmetrical location of the central void and the restructured fuel zone observed during the PIE of the AFC-2C Rodlet 3.

The study determined the temperature history in AFC-2C, 2D rodlets operating at an average power of $321 \mathrm{~W} / \mathrm{cm}$ for 261.9 and 633.1 days respectively. It was found that the peak fuel temperature varies from $2300^{\circ} \mathrm{C}$ to $2675^{\circ} \mathrm{C}$ during irradiation. The key factors affecting the fuel temperature history are the dynamics of the fuel-cladding and cladding-capsule gaps, fission gas release, and fuel restructuring. The fuel performance modeling results suggest that the irradiation conditions during AFC-2C, 2D experiments are prototypic of a fast reactor.

In light of the PIE findings of the eccentric location of the central void and the restructured fuel zone, the possible effect of the fuel and cladding eccentricity on the location of the peak fuel temperature and the $1700^{\circ} \mathrm{C}$ isotherm was examined. It was found that fuel and cladding eccentricity could cause displacement of the central void and the restructured fuel zone. Calculated locations of the peak fuel temperature and the $1700^{\circ} \mathrm{C}$ isotherm were in a qualitative agreement with the PIE image as shown in Figure 37.

Investigation of the effect of power peaking at the edge of the fuel pellet on the fuel temperature revealed that power peaking results in a $47^{\circ} \mathrm{C}$ decrease of the fuel centerline temperature and $52^{\circ} \mathrm{C}$ increase of the fuel temperature at the location of 0.8 pellet radius. 

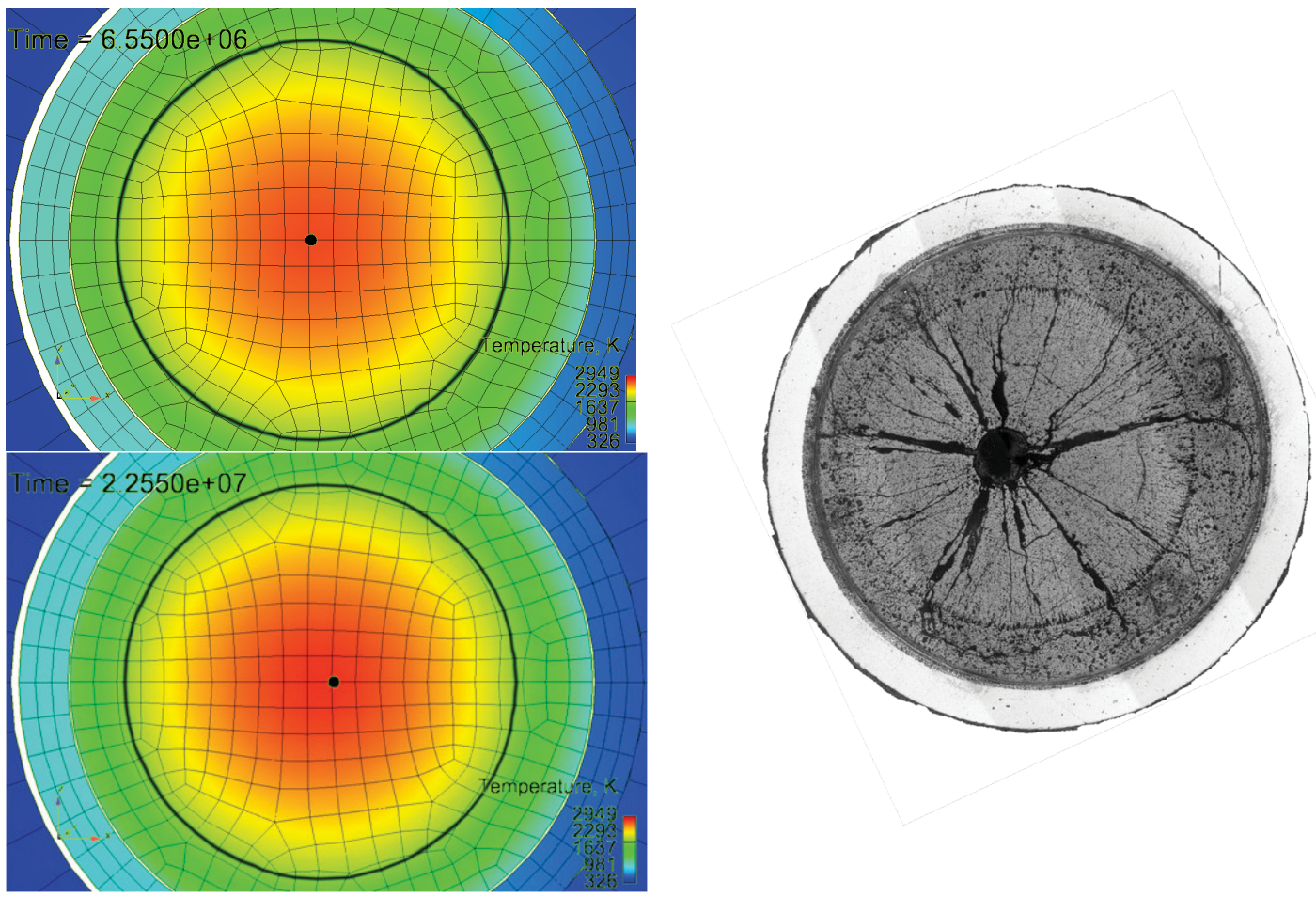

Figure 37. Comparison of the calculated location of the $1700 \mathrm{C}$ isotherm and peak temperature with the post irradiation examination image.

\subsection{Metal Fuel Performance Sensitivity Assessment \\ J. Galloway, N. Carlson, C. Unal, LANL}

AFC metallic fuels currently being tested have higher zirconium and plutonium concentrations than those tested in experimental breeder reactors in the past. Current metal fuel performance codes have limitations and deficiencies in predicting fuel performance. Our primary objective is to develop an initial analysis tool by incorporating state-of-the-art knowledge, constitutive models and properties of metal fuels into the MOOSE/BISON framework in order to analyze metallic fuel tests.

This year a robust species redistribution formulation for modeling metallic nuclear fuel, with a special focus on validation for U-Pu-Zr based fuels, has been successfully developed, tested and implemented in the BISON/MOOSE code framework. Ref. 1 discusses the derivation of diffusion equations and their implementation algorithm into BISON. Experimental data from EBR-II, fuel pin T179 (Ref. 2) was used as the validation case. Using the available phase diagram and diffusion coefficients (Ref. 2) and design values of this test, we solved a coupled thermal-diffusion problem with BISON. Results with no modification to initial modeling parameters did not agree with the experimental data. This indicated that solution given in Ref. 2 uses an unrealistic temperature profile.

Several improvements have been implemented. The first improvement considers modeling of rod power as a function of uranium distribution for fuel rod T179, calculated by MCNP (Ref. 3). A new fuel thermal conductivity model is developed to consider full zirconium spectrum from 0 to 100 percent. The diffusion equation is revised to force zirconium flux to go to zero when concentration approaches to zero and (1-Con $\mathrm{C}_{\mathrm{Pu}}$ ). Initial sensitivity studies were performed using operational data and educated guesses for phase-dependent material properties (since U-Pu-Zr fuel has multiple phases present) and many of these physical properties have not been experimentally 
derived. The resulting Zirconium distributions were compared against the experimentally measured distribution for fuel pin T179. In this sensitivity study, three cases were obtained that showed strong agreement with the experimental distribution. These cases required either perturbing the rod power, edge temperature boundary condition, or transition temperatures on the phase diagram. The two bounding cases are shown in Figure 38 and Figure 39, respectively.

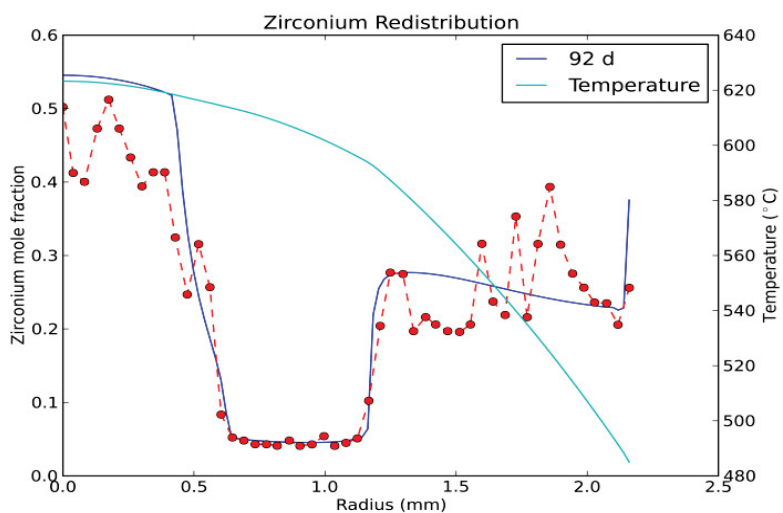

Figure 38. Case 1 - Literature values for phase diagram transition temperatures, adjust rod power and boundary condition

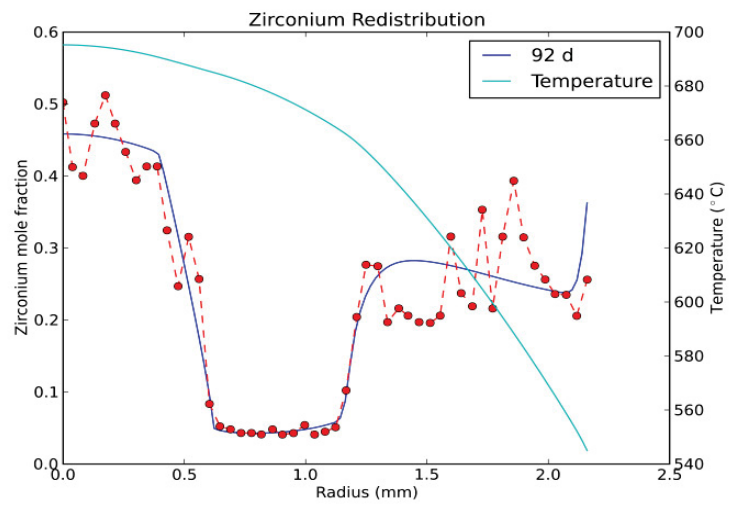

Figure 39. Case 2 -Operator data for power and temperature boundary condition, adjust the phase transition temperatures

Obtained from the sensitivity study were a series of material properties, such as phase diffusion coefficients, along with rod powers, temperatures, and phase diagram characteristics. Moving from a model of a single axial slice, a full rod model for fuel pin T179 was used, with a convective heat transfer boundary condition that allowed the heat to conduct across the rod, the sodium gap, and the D9 cladding. This model then gives insight into some of the bounding conditions, particularly for the fuel edge temperature boundary condition used. Figure 40 shows the end of cycle ( 92 days) zirconium distribution in both the axial and radial directions along with the power distribution in the same directions. While being in a fast reactor with an initially flat power distribution in the radial direction, as the Zirconium migrates in the radial direction, the Uranium moves in the opposite direction. Hence, where the Zirconium concentration goes low (the middle section of the rod), the power correspondingly increases. 


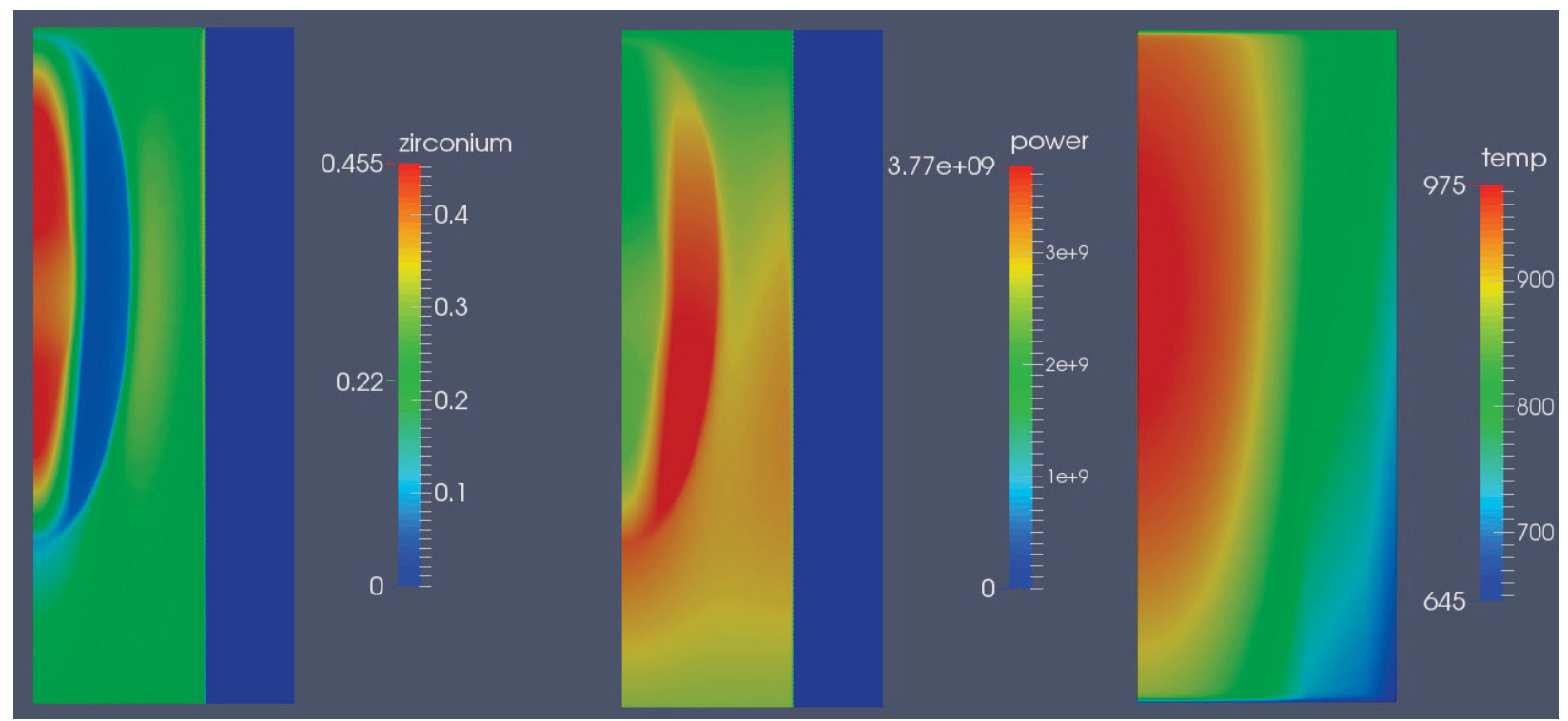

Figure 40. Full T179 Model

The third case, with results very similar to case 2 , was a hybrid between these two approaches which constituted an $8 \%$ reduction in the quoted power, $5 \%$ reduction in quoted temperature boundary condition and $\sim 10 \%$ increase in the phase diagram transition temperatures.

Over the course of this year, a robust formulation for species redistribution was completed. This included testing against experimental data from fuel pin T179 from EBR-II. A series of viable material properties for U-Pu-Zr based materials were determined through a sensitivity study on T179 which resulted in three cases with differing parameters that showed strong agreement with experimental data. Subsequently a full scale model of T179 was modeled to reduce uncertainties, particularly relating to the temperature boundary condition for the fuel.

\section{REFERENCES}

1. C. Unal, N. Carlson, J. Galloway, "Preliminary Simulation Results of the Constituent Distribution Model Implemented into the BISON Framework for the Analysis of Performance of Metallic Fuels," International Conference on Fast Reactors and Related Fuel Cycles: Safe Technologies and Sustainable Scenarios (FR13), March 4-7 2013, Paris France.

2. Y. S. Kim et al., "Modeling of Constituent Redistribution in U-Pu-Zr metallic Fuel," Journal of Nuclear Materials, Vol. 359, pp. 17-28, (2006).

3. Monte Carlo Team, MCNP - A General Monte Carlo N-Particle Transport Code, Version 5, Volume I: Overview and Theory, Los Alamos National Laboratory report LA-UR-03-1987, (2008).

\subsection{PIE Report on Legacy EBR-II Metallic Fuels}

$$
\text { D. Porter (INL) }
$$

X496 was an EBR-II experiment designed to demonstrate the operation of sodium-bonded metallic fuel in an once-through small modular reactor to very high burnup (BU). The fuel-pin design incorporated a low smeared density $(58.6 \%)$ and large gas plenum $(\mathrm{P} / \mathrm{F}=3)$. The fuel was enriched to $93 \%{ }^{235} \mathrm{U} / \mathrm{U}$ to accelerate the burnup of the fuel. The fuel achieved a maximum of 8.3 at. $\% \mathrm{BU}$ without fuel-pin breach. Recent efforts in design of advanced concept fuel for sodium-cooled fast reactors have incorporated some of the same design elements, and the X496 pins were examined to verify expected performance (swelling behavior, potential slumping at low burnup, etc.). 
Of special interest was fission-gas release. The gas plenums of two of the pins were punctured to measure gas pressure and plenum volume, and the two values were used to obtain the gas release percentage. The release was 84 and $85 \%$ for the two pins tested; previous testing of pins which used a 75\% smeared density measured about a 70\% gas release (Figure 41). Metallography proved that the fuel was very porous, facilitating a large fraction of gas released.

Axial fuel growth was expected to be greater than in fuels with higher smeared densities. More time/burnup is required to initiate fuel/cladding contact and so the fuel column has more time to expand freely in the axial direction. The results showed axial increase varying form 7-11\%, with an average of $8.8 \%$. The average growth in other EBR-II tests, with pins using 75\% smeared density, was similar.

Metallography of fuel pin cross-sections, especially at the ends of the fuel column, revealed a very porous structure, swollen to fill the cladding radial volume, despite the very low starting smeared density. Figure 42 shows the fuel radial center near the axial top of the fuel column. A radial zone structure, characterized by varying microstructural features and zirconium migration, was also observed. This and all other post-irradiation characteristics were very similar to those observed in other tests using conventional design features.

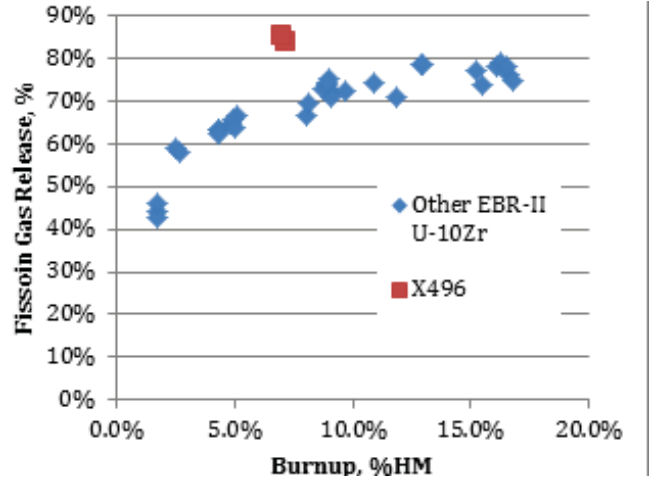

Figure 41. Fission gas release from $X 496$ pins compared to higher smeared density (75\%) U-10Zr irradiations in EBR-II.

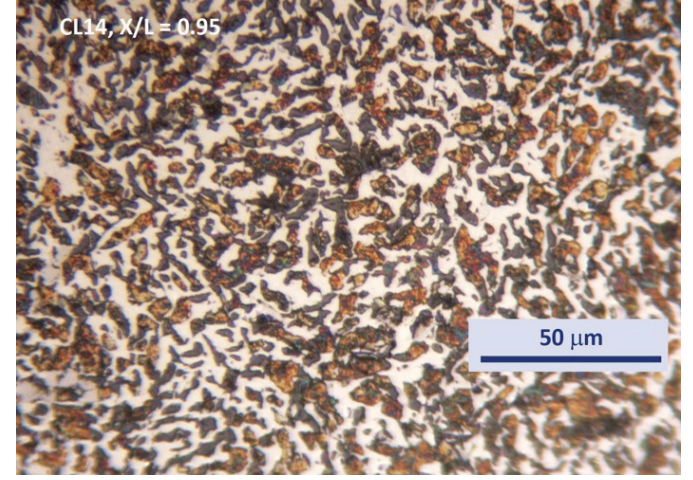

Figure 42. Optical micrograph of top axial section $(X / L$ $=0.95)$ of $X 496$ pin CL14. White colored areas are the fuel; dark is epoxy-impregnated porosity.

\subsection{Fast Reactor Cladding Development \\ S. Maloy, K. Clark (LANL); D. Hoelzer (ORNL); G. Odette (UCSB)}

High Dose irradiation data is needed on candidate cladding materials for fast reactors to doses up to 400 dpa. To obtain this data, specimens of HT-9 previously irradiated in the Fast Flux Test Facility (FFTF) to doses up to 155 dpa were packaged and shipped to Russia to be irradiated to higher doses at the same irradiation temperatures $\left(380-500^{\circ} \mathrm{C}\right)$ in the BOR-60 fast reactor. This activity is being funded through a CRADA with TerraPower as they have a mutual interest in obtaining similar high dose irradiation data. In addition, tubes fabricated from an advanced ODS alloy, 14YWT (FCRD-NFA1 heat), were laser marked and shipped to Russia to obtain new irradiation data on this promising radiation tolerant alloy. Images of these tubes before being sent to Russia are shown in Figure 43. 


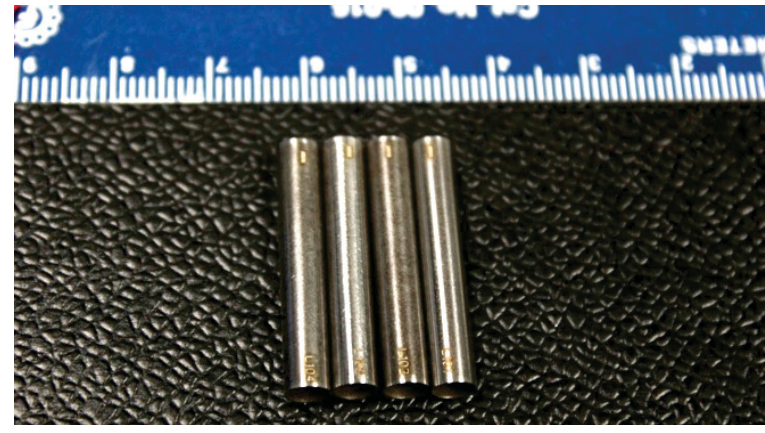

(a)

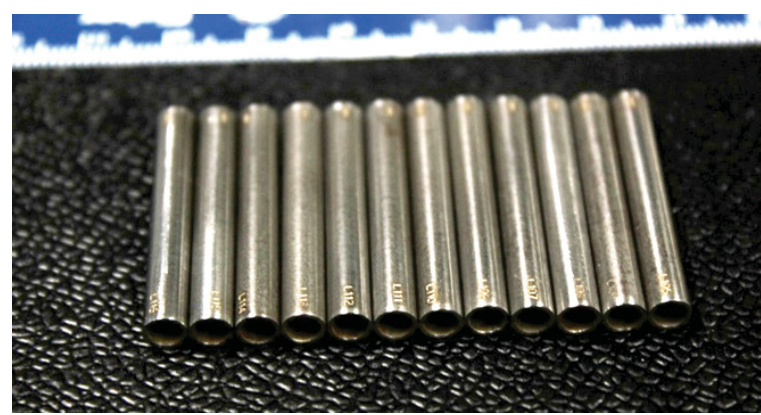

(c)

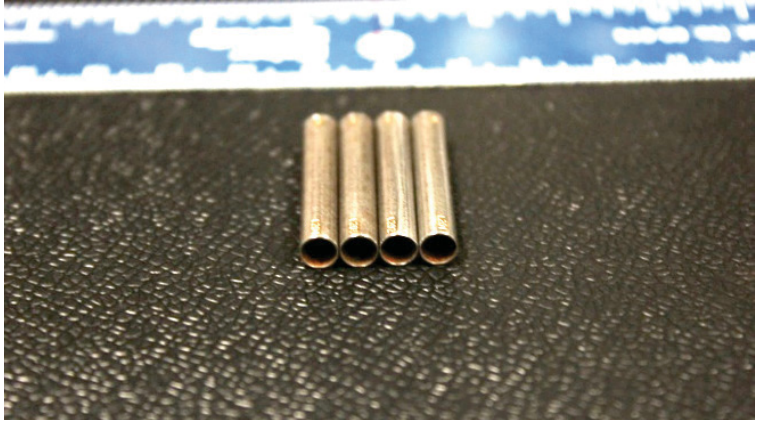

(b)

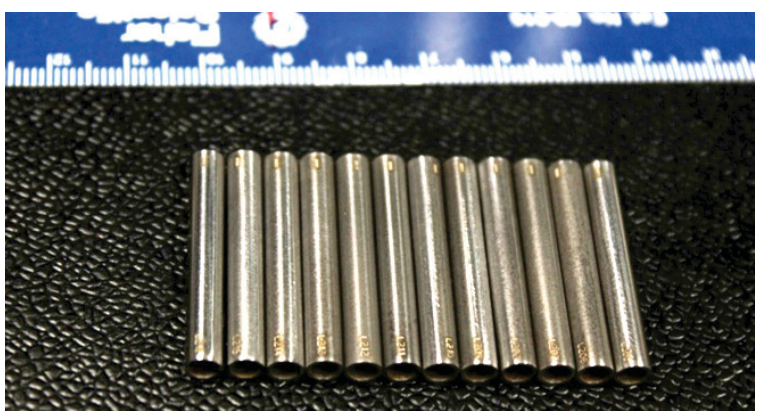

(d)

Figure 43. Tubes fabricated from 14YWT (FCRD-NFA1 heat) for irradiation in the BOR-60 reactor (a) Tubes L101L104 and (c) Tubes L105-L116 will be irradiated at 380C. Tubes (b) L201-L204 and (d) Tubes L205-L216 will be irradiated at $410 \mathrm{C}$.

\subsection{FFTF/MOTA Irradiation Results on Tempered Ferritic/Martensitic Steels \\ M. Toloczko, A. Certain (PNNL)}

The baseline clad and duct material, HT-9, is known to suffer from severe fracture toughness reduction when irradiated below $\sim 420^{\circ} \mathrm{C}$. With typical fast reactor sodium inlet temperatures of $\sim 370^{\circ} \mathrm{C}$, this embrittlement issue must be addressed. In an effort to fully understand the cause of the embrittlement, comparative fracture toughness testing and microscopy are underway between HT-9 and two newer alloys, GA3X and F82H that were all irradiated at $\sim 375^{\circ} \mathrm{C}$ to relevant dose of 5-7 dpa in FFTF. Room temperature fracture toughness testing revealed complete brittle response and very low toughness of the HT-9 while the two newer alloys exhibited fully ductile response with very high toughness. Recently completed atom probe tomography on the matrix microstructure of these materials revealed a high density of radiation induced second phase precipitates, G-phase and alpha-prime, in the HT-9 specimen. The 9Cr alloy, GA3X, had no G-phase but did have alpha-prime at about $10 \%$ of the density of the HT-9. The $8 \mathrm{Cr}$ alloy, F82H, had neither G-phase nor alpha-prime. Representative images are shown in Figure 44. The 10x higher density of radiation-induced precipitates in HT-9 contributes to its reduced toughness, but it is possible that grain boundary segregation may also be playing a role. For FY 2014, the effect of these precipitates on the hardening of the material will be assessed using barrier hardening calculations, and grain boundary segregation will be characterized by transmission electron microscopy and possibly by atom probe tomography. 

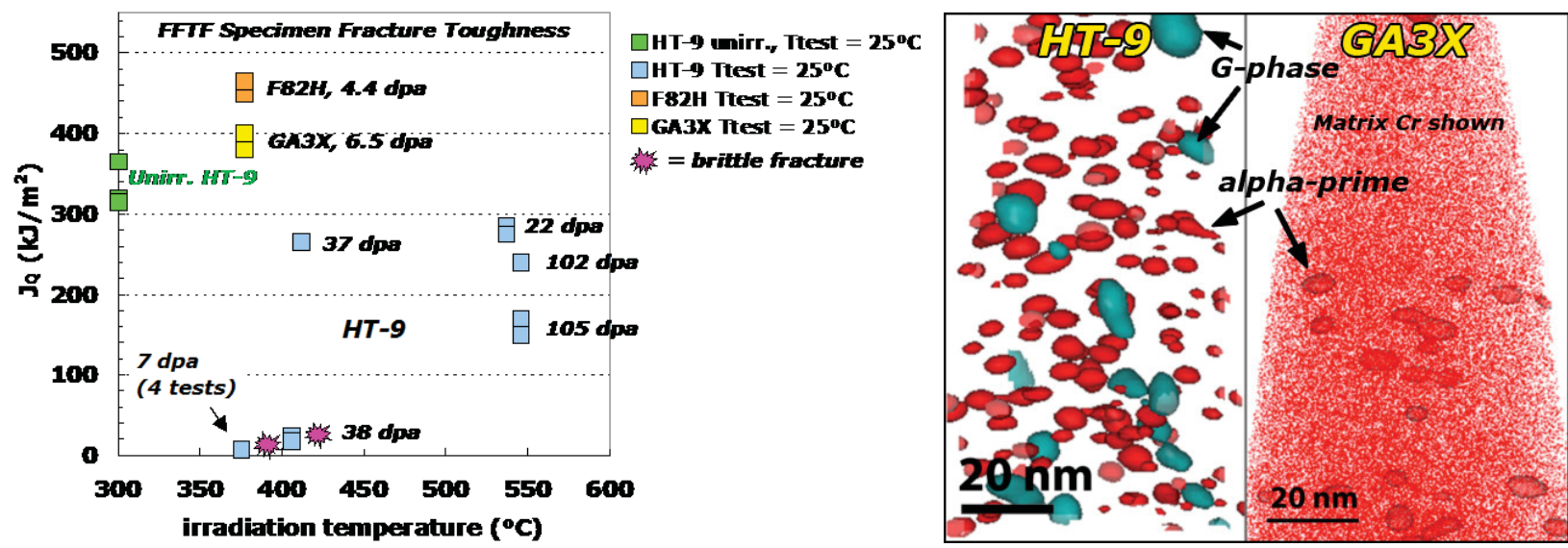

Figure 44. Fracture toughness of $H T-9, G A 3 X$ and $F 82 \mathrm{H}$ after $5-7$ dpa at $375^{\circ} \mathrm{C}$ and resulting matrix precipitates that form as viewed by atom probe tomography.

\subsection{High Dose Irradiation Results on MA957 Advanced ODS Ferritic Alloy M. Toloczko, A. Certain (PNNL)}

Ongoing tensile property studies of 100-120 dpa neutrons irradiated MA957 have revealed that this material exhibits excellent room temperature tensile properties when irradiated at $500^{\circ} \mathrm{C}$ or higher temperatures. However, the ductility falls drastically as the irradiation temperature falls below $\sim 420^{\circ} \mathrm{C}$. As shown in Figure 45, scanning electron microscopy of the fracture surface of tensile specimens irradiated at $412^{\circ} \mathrm{C}$ reveal a combination of classic ductile-dimple fractures and what appear to be intergranular fractures. Previously performed atom probe tomography on these materials suggests that as irradiation temperature decreases, the oxide particle population density may be increasing due to ballistic dissolution and reformation. In addition, a high density of alphaprime precipitates also forms. This increase in second phase population density will increase strength and potentially reduce ductility. More recently observed is that significant chromium depletion is occurring on the grain boundaries of MA957 as the irradiation temperature drops below $\sim 420^{\circ} \mathrm{C}$. It is thought that increase in precipitate density and the grain boundary compositional modifications together are playing a role in the embrittlement and intergranular fracture of this material. Research is continuing into understanding the causes of this embrittlement issue with this otherwise apparently excellent material.
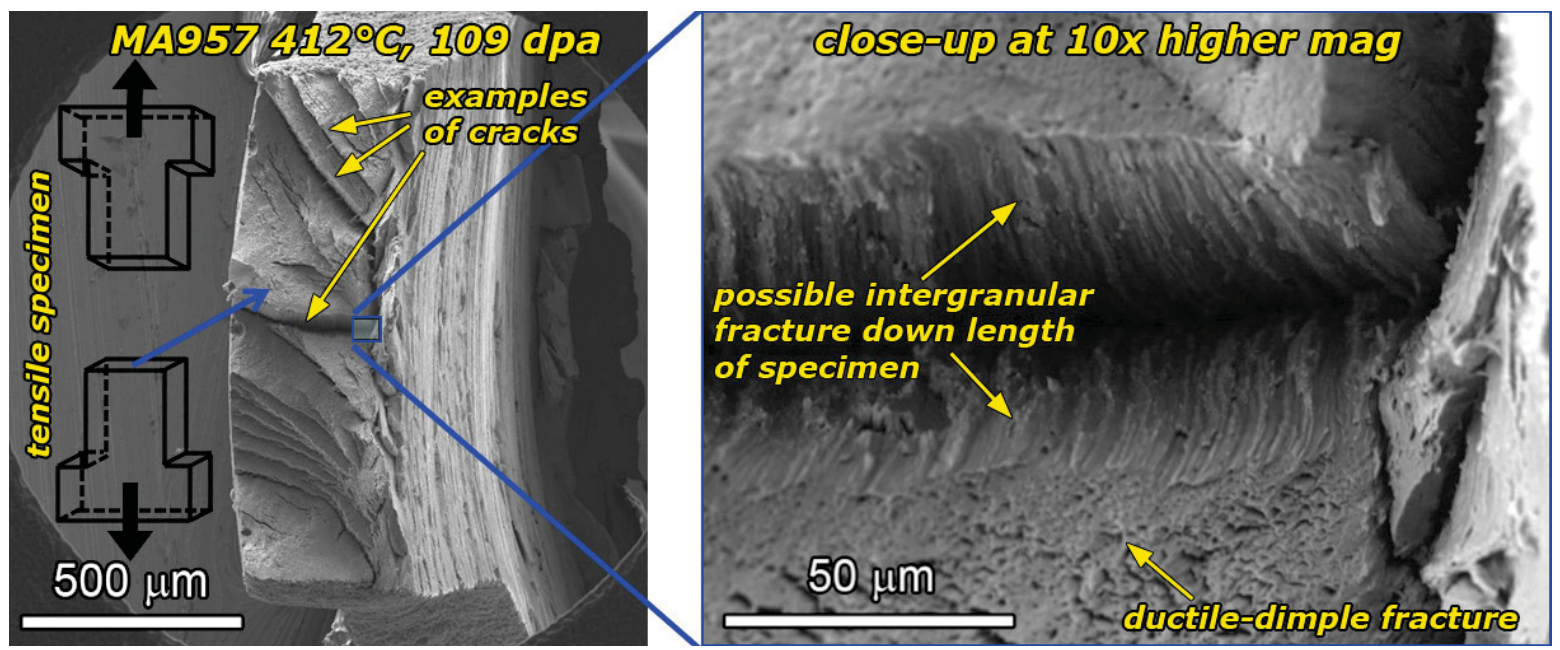

Figure 45. Fracture surface of an MA957 tensile specimen irradiated to $412^{\circ} \mathrm{C}$ at 109 dpa and tested at room temperature. 


\subsection{Radiation Resistance of a Large NQA-1 Heat of HT-9}

S. Maloy, T. Saleh, T. Romero (LANL); R. Fielding, J. Cole (INL); G. Odette (UCSB)

A new 300 pound heat of HT-9 (12Cr-1Mo) was procured following NQA-1 guidelines at INL with a small company called Metalwerks in 2008. Initial materials made were in the form of $1 / 2 \mathrm{in}$. thick sheet and 2 in. diameter bar. Tensile and fracture toughness specimens were included in an irradiation in the ATR reactor to $6 \mathrm{dpa}$ at $290^{\circ} \mathrm{C}$ along with numerous other ferritic/martensitic steels (e.g. T91, Eurofer). Initial tensile results measured at room temperature on this heat of HT-9 look very promising. As shown in Figure 46, uniform elongation measured after irradiation is over $5 \%$ and much better than all other ferritic/martensitic steels tested under identical conditions. One of the drawbacks with ferritic/martensitic steels is low temperature (under $400^{\circ} \mathrm{C}$ ) embrittlement after irradiation and this heat of HT-9 shows excellent resistance to it. Analysis is underway to investigate the significantly improved properties of this alloy.

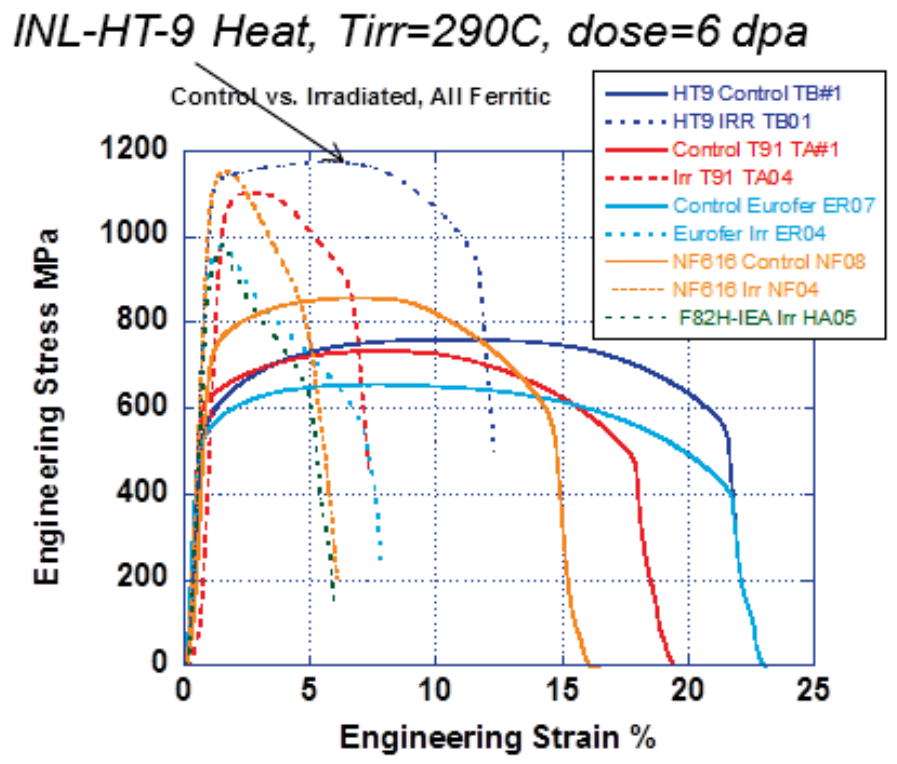

Figure 46. Stress/Strain curves plotted for ferritic/martensitic steels before and after irradiation in ATR to 6 dpa at 290C. Tests performed at room temperature.

\subsection{Metallic Transmutation Fuels Technologies - Key Publications}

D. Bhattacharyya, P. Dickerson, G.R. Odette, S.A. Maloy, A. Misra, M.A. Nastasi, "On the structure and chemistry of complex oxide nanofeatures in nanostructured ferritic alloy U14YWT," Philosophical Magazine, 92 (2012) 2089-2107.

C.-C. Wei, A. Aitkaliyeva, Z. Luo, A. Ewh, Y.H. Sohn, J.R. Kennedy, B.H. Sencer, M.T. Myers, M. Martin, J. Wallace, M.J. General, L. Shao, "Understanding the Phase Equilibrium and Irradiation Effects on the Fe-Zr System: New Insights from the Diffusion Couple", Journal of Nuclear Materials, 432 (2013) 205-211.

G.W. Egeland, R.D. Mariani, T. Hartmann, D.L. Porter, S.L. Hayes, and J.R. Kennedy, "Reducing Fuel Cladding Chemical Interaction: The Effect of Palladium on the Reactivity of Neodymium on Iron in Diffusion Couples." Journal of Nuclear Materials 432 (2013) 539-544.

K. Huang, Y. Park, A. Ewh, B.H. Sencer, J.R. Kennedy, K.R. Coffey, Y.H. Sohn, "Interdiffusion and Reaction Between Uranium and Iron”, Journal of Nuclear Materials424 (2012) 82-88. 
K. Jeoung Han, T.S. Byun, D.T. Hoelzer, K. Seong-Woong, L. Bong Ho, “Temperature dependence of strengthening mechanisms in the nanostructured ferritic alloy 14YWT: Part I - mechanical and microstructural observations," Materials Science and Engineering: A (Structural Materials: Properties, Microstructure and Processing), 559 (2013) 101-110

K. Jeoung Han, T.S. Byun, D.T. Hoelzer, P. Chan Hee, Y. Jong Taek, H. Jae Keun, “Temperature dependence of strengthening mechanisms in the nanostructured ferritic alloy 14YWT: Part IIMechanistic models and predictions," Materials Science and Engineering: A (Structural Materials: Properties, Microstructure and Processing), 559 (2013) 111-118.

M. B. Toloczko, F.A. Garner, and S.A. Maloy, Irradiation creep and density changes observed in MA957 pressurized tubes irradiated to doses of 40-110 dpa at 400-750 degrees C in FFTF. Journal of Nuclear Materials, 2012. 428(1-3): p. 170-175

O. Anderoglu, J. Van den Bosch, P. Hosemann, E. Stergar, B.H. Sencer, D. Bhattacharyya, R. Dickerson, P. Dickerson, M. Hartl, S.A. Maloy, 'Phase stability of an HT-9 duct irradiated in FFTF ." Journal of Nuclear Materials, 430 (2012) 194-204.

O. Anderoglu, T.S. Byun, M. Toloczko, S.A. Maloy, "Mechanical Performance of Ferritic Martensitic Steels for High Dose Applications in Advanced Nuclear Reactors," Metallurgical and Materials Transactions a-Physical Metallurgy and Materials Science, 44A (2013) 70-83.

R.D. Mariani, D.L. Porter, S.L. Hayes, and J.R. Kennedy, "Metallic Fuels: The EBR II Legacy and Recent Advances”, Procedia Chemistry 7 (2012) 513-520.

T.S. Byun, M.B. Toloczko, T.A. Saleh, S.A. Maloy, "Irradiation dose and temperature dependence of fracture toughness in high dose HT9 steel from the fuel duct of FFTF," Journal of Nuclear Materials, 432 (2013) 1-8.

T. W. Koenig, Olson, D. L., Mishra, B., King, J. C., Fletcher, J., Gerstenberger, L., Lawerence, S., Martin, A., Mejia, C., Meyere, M. K., Kennedy, R., Hu, L. Kohse, G., and Terry, J., “Advanced NonDestructive Assessment Technology to Determine the Aging of Silicon Containing Materials for Generation IV Nuclear Reactors", in Review of Progress in QNDE, edited by D. O. Thompson and D. E. Chimenti, American Institute of Physics, Melville, NY, 2012.

Y. Park, K. Huang, A. Ewh, H. Sencer, J.R. Kennedy, and Y. Sohn, "Diffusional Interaction between U 10wt.\% Zr and Fe at 903K, 923K and 953K" Metallurgical and Materials Transactions A, July, 2013.

\section{CONFERENCE PROCEEDINGS}

C. Unal, N. Carlson, J. Galloway, "Preliminary Simulation Results of the Constituent Distribution Model Implemented into the BISON Framework for the Analysis of Performance of Metallic Fuels," International Conference on Fast Reactors and Related Fuel Cycles: Safe Technologies and Sustainable Scenarios (FR13), March 4-7 2013, Paris France.

K.J. McClellan, H.J.M. Chichester, S.L. Hayes, and S.L. Voit, "Summary of the Minor Actinide-bearing MOX AFC-2C and -2D Irradiations," Proceedings of the IAEA International Conference on Fast Reactors and Related Fuel Cycles: FR13. Paris, France; 4-7 March 2013.

S. Hirooka, Kato, M., Tamura, T., Nelson, A.T., McClellan, K.J., and Suzuki, K., "Oxidation and Reduction Behavior of Plutonium and Uranium Mixed Oxide Powders," Proceedings of the IAEA International Conference on Fast Reactors and Related Fuel Cycles: FR13. Paris, France; 4-7 March 2013. 
This page intentionally left blank. 
CROSSCUTTING
TECHNOLOGIES

CROSSCUTING
TECHNOLOGIES 


\section{CROSSCUTTING TECHNOLOGIES}

A basic philosophy of AFC is the development and utilization of advanced scientific methods for the research and development of advanced, novel, high performance nuclear fuel systems. The Crosscutting Technologies area is focused on this guiding principal. Performing research on irradiated and highly radioactive fuel materials is difficult, time intensive, and technically challenging. Couple this with the desire to study the microstructural evolution of fuels and materials under irradiation provides the opportunity for the development of advances in nuclear fuels and materials R\&D science. The activities in this technical area are examples of the innovative and creative science and engineering accomplished by the technical scientific and engineering staff. In FY 2013, the activities in the Crosscutting Technologies area range from the development of advanced PIE and characterization methods, and development of experiments supporting the understanding of microstructure evolution in fuels and materials coupled with supporting development of advanced modeling and simulation capabilities.

\subsection{Advanced Non-Destructive Post Irradiation Examination D. Byler, M. Bourke, K. McClellan (LANL); M. Okuniewski (INL)}

Collaboration between INL and LANL demonstrates the capability for neutron beam and proton beam-based advanced non-destructive PIE of fuel rods, with the goal of evaluating irradiated fuel rods from the AFC-2C irradiations at ATR at INL. Initial experiments have shown that these capabilities can allow more rapid development and qualification of new fuel systems by providing 3-D imaging of the fuel microstructure, defects, and chemistry. These data sets can then be used to inform and validate modeling and simulation codes as well as improve understanding of the fundamental mechanisms active during irradiation.

A preliminary assessment of several advanced nondestructive evaluation (NDE) techniques was conducted at LANL in FY 2009-FY 2010 timeframe as a proof of concept. This assessment used a set of three mockup rodlets filled with $\mathrm{UO}_{2}$ pellets with various defects and densities to ascertain whether the neutron and proton radiography techniques could be effectively applied to nuclear fuel materials. The results were impressive and provided an indication of the strengths and weaknesses of the different techniques. This also showed where improvements could be made to generate higher quality data. Figure 47 shows a series of radiographs of $\mathrm{UO}_{2}$ clad in stainless steel. The radiographs show the location of intentionally introduced impurities in the form of tungsten and the associated neutron resonance spectra.

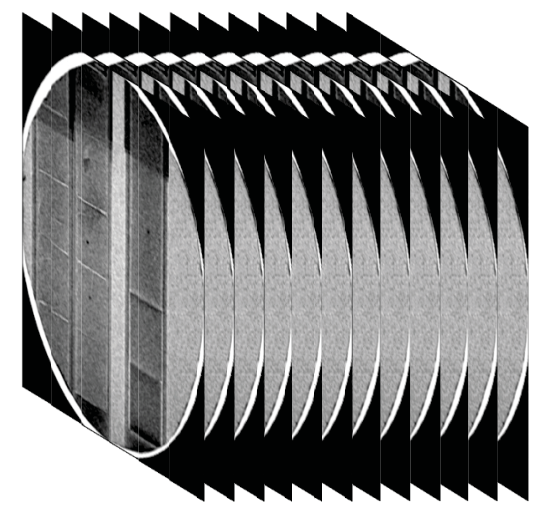

a)

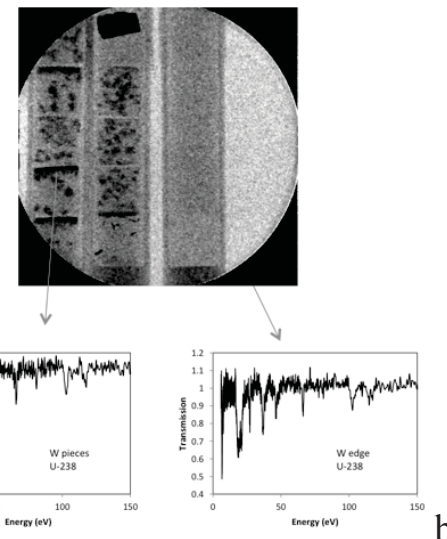

Figure 47. Illustration of a) the series of energy-specific radiographic images acquired for a single LANSCE neutron pulse for the first generation of $\mathrm{UO}_{2}$ mockup assemblies, and b) a single radiographic image at a specific energy with the associated n-resonance patterns. 
Based on this initial assessment and the need for improved PIE capabilities to provide better data sets to modeling and simulation and to provide an avenue to shortening the timeline required for development of new fuel forms, a detailed assessment of neutron and proton based NDE capabilities was started in FY 2013. This assessment is designed to evaluate the current and potential spatial resolutions available to non-destructively resolve defects and chemistry within the fuel rodlet. In December of 2012, a technical exchange was conducted at LANL with technical experts providing insight on the NDE options and determining a path forward to evaluate the techniques. As part of this path forward a second set of $\mathrm{UO}_{2}$ mockup rodlets was fabricated with more tightly constrained features and additional controls to determine spatial resolutions, defects and related chemistry. These mockup assemblies were transferred to LANSCE and are waiting for beam time to be evaluated during the 2013 run cycle. Table 5 provides a list of rodlet types fabricated for these tests.

Table 5. UO $\mathrm{O}_{2}$ mockup assemblies for advanced NDE assessments at LANSCE

\begin{tabular}{|c|c|c|}
\hline Pin Type & $5 \mathrm{~mm}$ (Fast) & $8.3 \mathrm{~mm}$ (LWR) \\
\hline Calibration & $\begin{array}{l}\text { Calibration pin (W-wire } \\
200,100,75,50,25 \text { microns dia.) }\end{array}$ & $\begin{array}{l}\text { Calibration pin (W-wire } \\
200,100,75,50,25 \text { microns dia.) }\end{array}$ \\
\hline Neutron resonance - redistribution & $\begin{array}{l}\text { Dispersions for } \mathrm{n} \text {-Res (mixtures of } \\
\mathrm{Nd}_{2} \mathrm{O}_{3} \text { and } \mathrm{Gd}_{2} \mathrm{O}_{3} \text { with } \mathrm{UO}_{2} \text { ) }\end{array}$ & $\begin{array}{l}\text { Dispersions for } \mathrm{n} \text {-Res (mixtures of } \\
\mathrm{Nd}_{2} \mathrm{O}_{3} \text { and } \mathrm{Gd}_{2} \mathrm{O}_{3} \text { with } \mathrm{UO}_{2} \text { ) }\end{array}$ \\
\hline $\begin{array}{l}\text { Missing surface/cracks and } \\
\text { cladding interactions }\end{array}$ & $\begin{array}{l}\text { Missing surfaces (corner, full edge, } \\
\text { slots, central void/cracks) }\end{array}$ & $\begin{array}{l}\text { Missing surfaces (corner, full edge, } \\
\text { slots, cracks) Hot loaded pellet }\end{array}$ \\
\hline Microstructural & Grain size variations and cracks & \\
\hline Density & $\begin{array}{l}\text { Pellets with density variations from } \\
90-98 \% \text { TD }\end{array}$ & \\
\hline
\end{tabular}

A second technical exchange was held at INL in August of 2013 in order to further define overall, integrated process and capabilities for PIE of irradiated fuels. Discussions were held to determine the next steps after testing of the mockups to moving forward on transporting and testing rodlets from the AFC-2C irradiations.

\subsection{Laser-based Characterization/PIE Technique Development D. Hurley (INL)}

The Mechanical Properties Microscope (MPM), shown in the left pane of Figure 48, is being designed to operate in a radiation hot cell environment via remote control manipulation. The MPM provides micron-level mechanical property information that is commensurate with microstructure heterogeneity. The development of the MPM connects closely with INL's larger PIE effort to provide new validation metrics for fundamental computational material science models. Currently in stage I mockup, the MPM is being used to provide important data on surrogate fuel samples. One example includes measuring the elastic anisotropy resulting from deformation texture in UMo fuel surrogates. Another example involves measuring the elastic constants of the UZr system as a function of composition (data presented in units of GPa in the left-middle pane of Figure 48). 


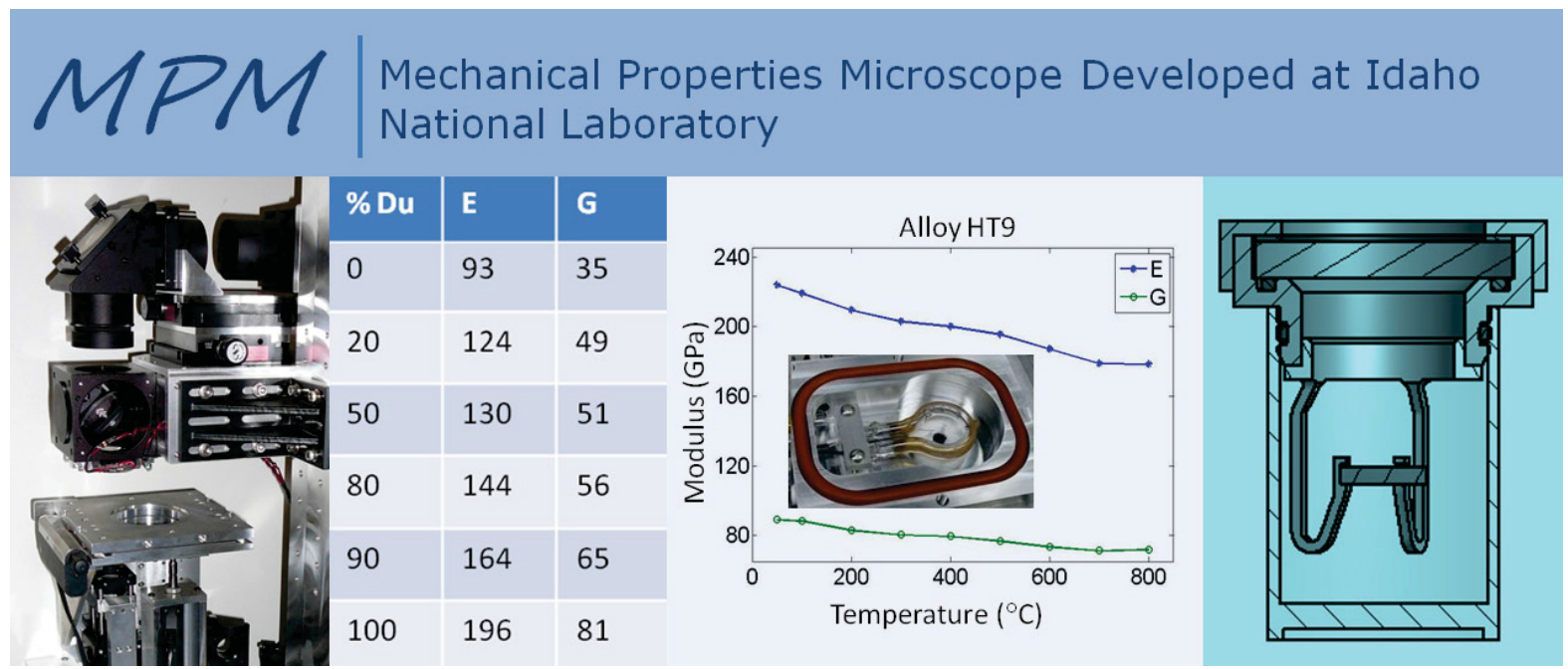

Figure 48. Left: Photograph of MPM, Left-middle: Elastic constants of UZr system vs. composition (values reported in GPa), Right-middle: Elastic constants of HT9 vs. temperature (inset: heating furnace), Right: Sample loading capsule.

A high temperature furnace was designed and constructed that can heat samples to $1000^{\circ} \mathrm{C}$, utilizing radiative heating (middle-right pane of Figure 48). To minimize heat transfer to the environment, the sample chamber is evacuated, which increases the maximum sample temperature and reduces optical lensing issues. As shown in right-middle pane of Figure 48, the functionality of the furnace has been demonstrated by measuring the elastic constants of a Ferritic-Martensitic alloy (HT-9) up to $800^{\circ} \mathrm{C}$.

The MPM requires optical access to both the top and bottom surfaces of the sample. Irradiated samples also require preparation and loading in a remote environment. To meet these requirements, a sample capsule along with a sample loading technique has been developed (right pane of Figure 48). The sample is held in place by four thin "J" shaped legs. A notch on the short side of each leg supports the sample. The legs deflect to allow the sample to be loaded into position. With the sample held captive in the sample holder, the holder is sealed under vacuum to a quartz tube with a quartz window in the bottom. This sealed capsule containing the sample can then be transported to the MPM for high temperature measurements. The long thin legs minimize thermal conduction away from the sample and allow maximum exposure of the sample to the IR radiation from the heating element.

A similar laser-based instrument, used to measure thermal conductivity, is also being developed. The optical access requirements for the Thermal Conductivity Microscope are similar to the MPM. As a consequence, some system components have dual-platform utility. For instance, a similar heating furnace as described above is being developed for the Thermal Conductivity Microscope (TCM). Minor changes to the existing furnace will include moving the sample closer to the front window to enable strong focusing with a microscope objective and removal of the backside window. Moving the sample closer to the front window will raise issues concerning uniform heating and uniform sample temperature. These issues are currently being addressed. 


\subsection{Atom Probe Tomography on U-Pu-Zr fuel \\ M. Teague (INL)}

The first ever atom probe tomography (APT) studies of AFC transmutation fuel were recently performed at the Center for Advanced Energy Studies (CAES) facility at INL. Samples for APT were prepared using the hot FIB at the Materials and Fuels Complex (MFC) and then transferred to CAES for analysis using the cutting edge LEAP 4000x HR atom probe. The first alloy studied was $\mathrm{U}-55 \mathrm{Pu}-20 \mathrm{Zr}$ in the annealed state. Due to instrumentation issues, an oxide layer formed on the outside of the samples. Figure 49 shows a reconstruction of an oxidized U-55Pu-20Zr sample. An interesting feature is the different oxidation behavior of the elemental components. The extent and depth of oxidation were element dependent with $\mathrm{Zr}$ having the thickest oxidation layer followed by $\mathrm{U}$ and then $\mathrm{Pu}$. The presence of oxidized zirconium within metallic $\mathrm{U} / \mathrm{Pu}$ is an interesting observation and further analysis is planned. $\mathrm{A} \mathrm{Pu} / \mathrm{U}$ rich and $\mathrm{Zr}$ depleted region was seen at the edge of the tip, which is hypothesized to be along a former grain boundary (Figure 50).

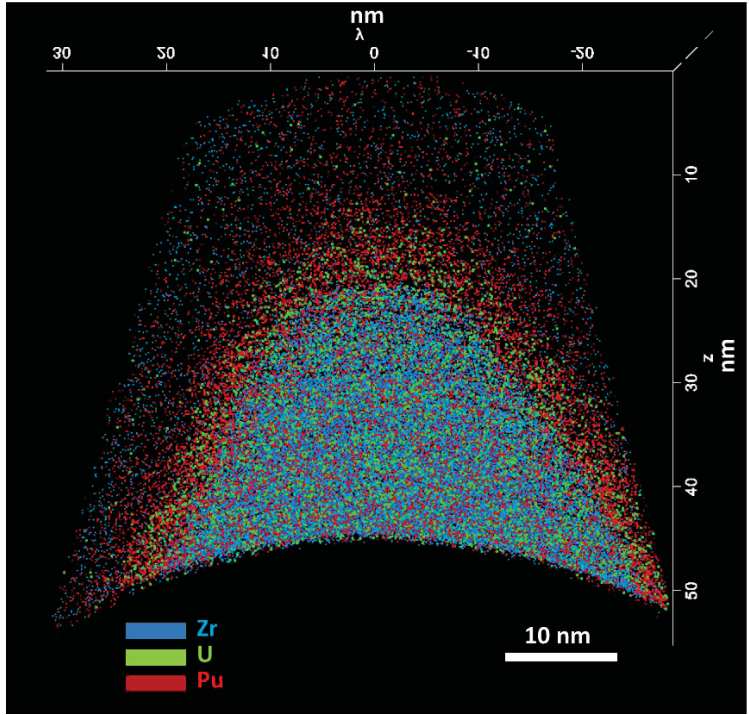

Figure 49. APT reconstruction of oxidized U-55Pu$20 Z$ r sample showing the different oxidation depths of the components. Only the metallic ions of $\mathrm{Zr}, \mathrm{U}$, and $\mathrm{Pu}$ are displayed to highlight different oxidation behavior. Though preliminary in scope, the application of APT to transmutation fuels is an exciting advance and has great potential for helping to understand the complex behavior observed in both irradiated and unirradiated fuels.

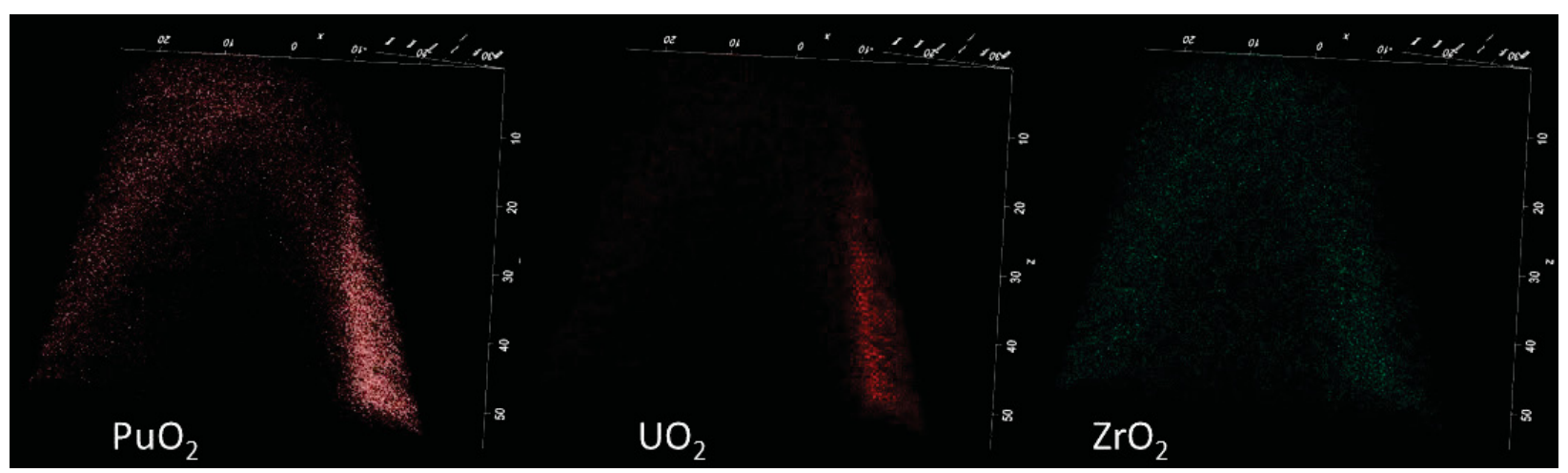

Figure 50. Reconstruction of U-55Pu-20Zr samples showing the Pu/U rich and $\mathrm{Zr}$ depleted region at the edge of the samples that is hypothesized to be a former grain boundary region.

\subsection{Metal Fuel Casting Modeling}

D. DeCroix, C. Unal (LANL)

Actinide burning fuels in fast reactor applications have been a traditional research approach. Recently, the use of metallic fuels in light-water reactors (LWR) applications has been suggested. Although there has been some experience with casting cylindrical metallic binary or ternary fuels in the past, renewed attention to the casting of metallic fuels arises due to the fact that not only do we 
need to cast traditional constituents such as $\mathrm{Pu}, \mathrm{Zr}$, and $\mathrm{U}$, but also add more difficult actinides such as Am and Np.

Casting metallic fuel rods shows great promise, but fuel and transuranic losses must be minimized. Issues critical to the manufacture of transuranic containing fuels include fuel holdup in crucibles and molds, fuel loss into dross from crucible and mold wash coatings, generation of contaminated wastes such as mold pieces, and loss of volatile constituents from the crucible during heating and casting. This final issue potentially constrains the caster to a positive pressure design because Am has a high partial pressure allowing it to volatize from the liquid metal under vacuum. There have been several primary studies investigating the actinide volatilization issue in order to improve the caster design. As part of these efforts, a bench scale casting apparatus has been designed. Fuel manufacturing process modeling and simulation is a cost effective way to explore some of the above-mentioned issues for the development of new manufacturing processes yielding minimum loss.

This year we investigated the feasibility of alternative fill geometries, to better understand the fuel rod breakage issue and to begin research in modeling binary alloy segregation, laying the groundwork for ternary alloy simulations. Previous experimental and computational work (Refs. 1 and 2) showed that casting breaks occurred due to the presence of the argon gas in the mold prior to fill and the geometric configuration of the bench scale caster. It was found that by decreasing the angle of the rods in the mold or adding a plenum for the argon to escape, break-free fuel rods could be cast. A number of alternative casting geometries using counter gravity injection and gravity casting were investigated via Flow3D simulations of the casting process.

Two caster geometries showed promise for casting a dense fuel rod. The major improvement to create both of these casting geometries is to place the crucible directly on the casting mold, removing some interaction between the melt and argon gas. As shown in Figure 51, the first geometry considers a single fuel rod gravity cast at an angle and the second cast is two fuel rods created by attaching an angled portion of the casting mold with a vertical portion. A volume of free space is used above the vertical section of the casting mold to aid in effective venting of the argon during filling. The simulation of the first geometry shows $84 \%$ of the melt to be solidified at 4 seconds of simulation time, and the second shows $100 \%$ of the melt to be solidified after 2 seconds of simulation time. Both of these casting approaches warrant further investigation experimentally, perhaps with a surrogate casting fluid. 


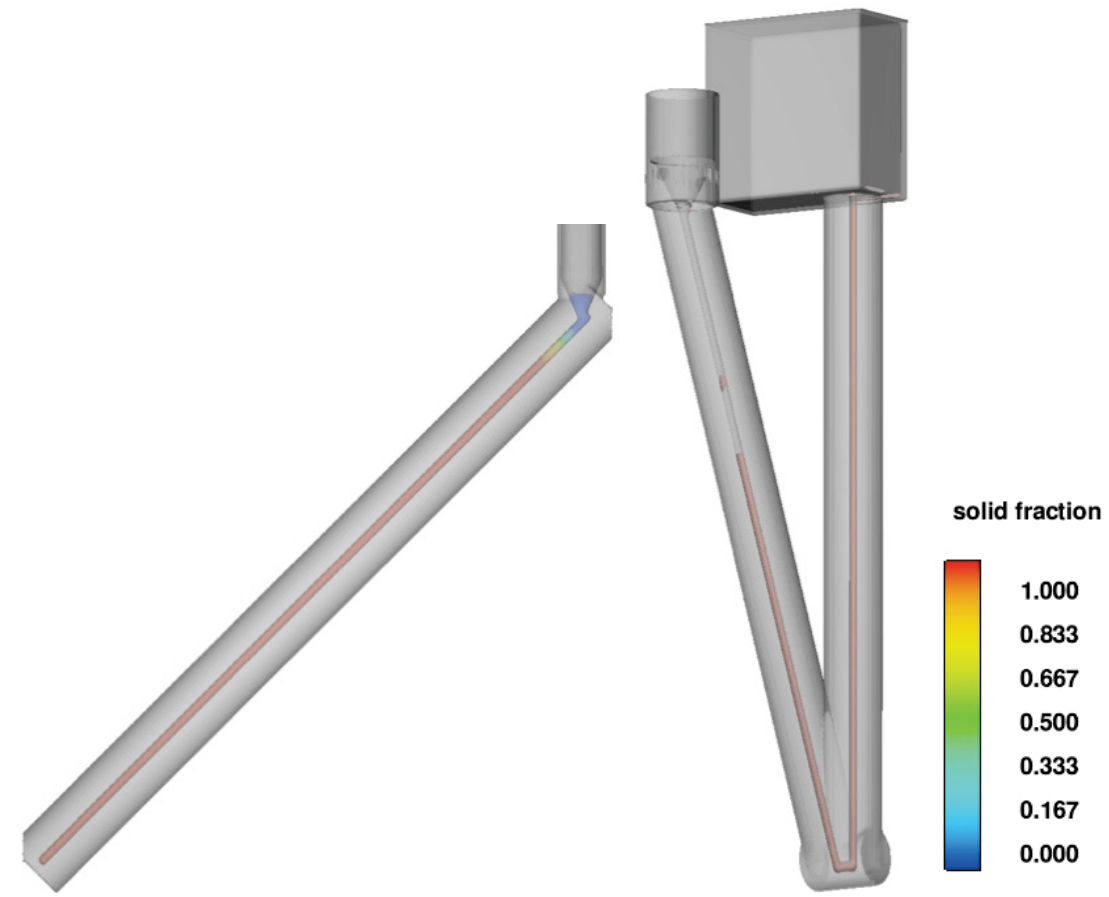

Figure 51. Two alternative mold geometries that show promise in reducing rod breakage.

Simulating binary alloy species segregation during solidification is physically very complex. Simulating the segregation for binary uranium-plutonium alloys is further complicated because of the U-Pu phase diagram. Examples of these phase diagrams, a simple linear and complex alloy, are shown in Figure 52. The basic problem is that most commercial CFD codes that can simulate alloy species segregation, assume a simple, linear phase diagram, shown on the left of Figure 52. However, the phase diagram for the alloys of interest in metallic fuels are far from simple, and in fact typically do not have a eutectic point. The phase diagram of uranium and plutonium alloys is shown in the left of Figure 52. Of primary interest are the top two lines, the liquidus and solidus lines; the area between these two lines is referred to as the mushy region. More complex phase diagrams, such as U-Pu and U-Zr, are not possible to implement directly in Flow3D. Simplifying assumptions, such as a eutectic point, constant solidus temperature, and a linear liquidus line, shown in Figure 52, must be made to simulate species segregation of complex alloys in Flow3D. Since Flow Sciences, developer of the Flow3D software, was not willing extending their phase diagram implementation to simulate more complex alloys, this general method was developed such that it could be implemented in the TRUCHAS code. This method was tested using another commercial CFD code, Ansys Fluent. It should be noted that modeling simple binary alloy segregation, that follow the linear phase diagram approximation, such as U-Mo, is possible using Flow3D.

A general method has been developed to allow for a general specification of the phase diagram in the modeling and simulation code, which also allows for the modeling of ternary alloys. This phase diagram representation is also used to model the species segregation. For binary alloys, one derives an analytical expression for the liquidus and solidus lines of the phase diagram as a function of solute concentration. For ternary alloys, one would derive a surface as a function of the alloy concentrations. With this numerical representation, or curve-fit, of the liquidus and solidus, in the CFD code for a given computational cell the species mass fractions are computed, and the corresponding liquidus and solidus temperatures are evaluated using the numerical representation. 

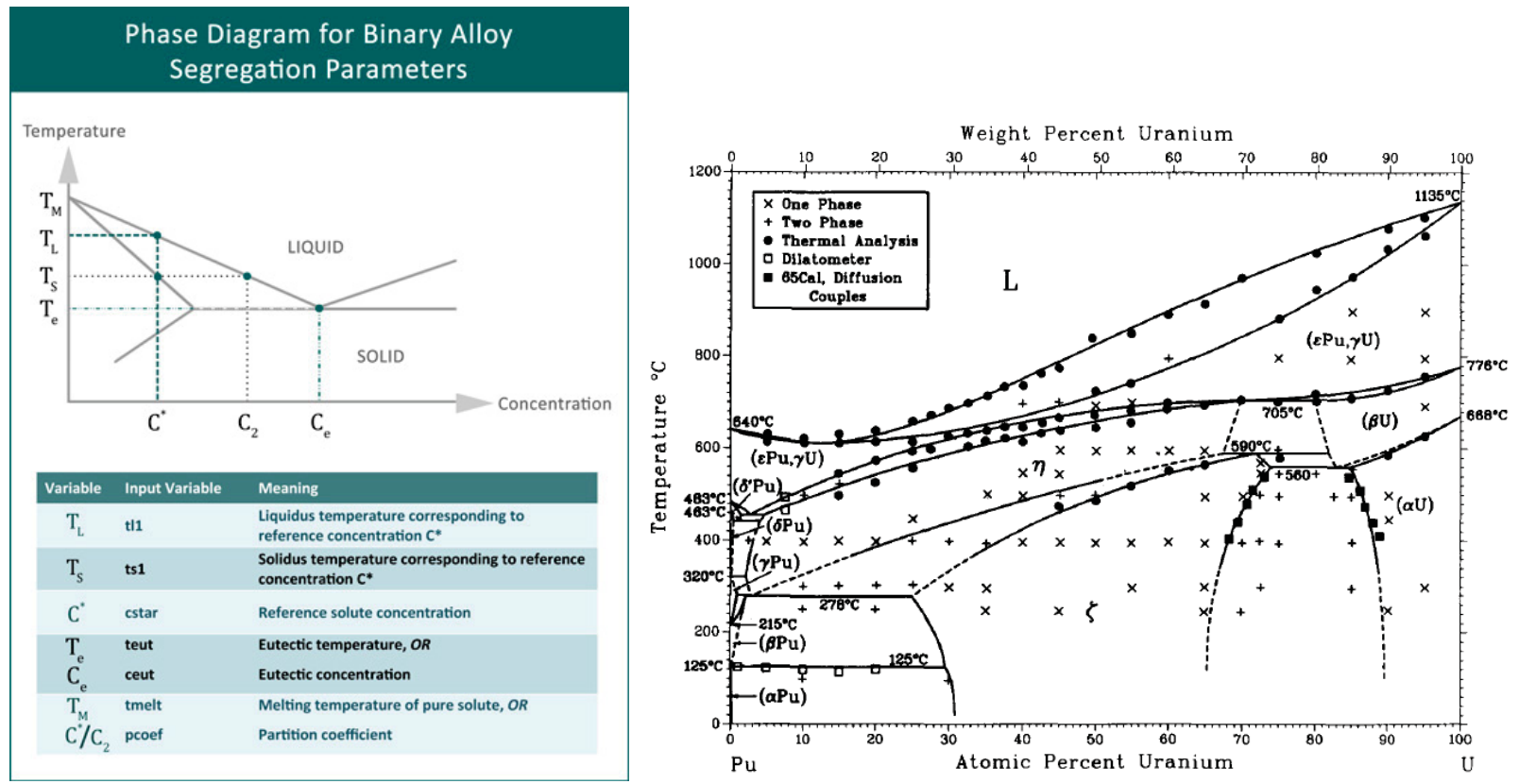

Figure 52. Phase diagram representations for simple, linear alloys, and complex uranium-plutonium alloys.

In addition to the phase diagram specification, the modeling of alloy species segregation typically use an enthalpy-porosity method. Essentially the thermodynamics of the solidification and segregation are modeled and as the melt solidifies, the porosity of the cell is reduced until the metal is completely solid, which corresponds to a porosity of zero. Two models for species segregation at the micro-scale are the Lever rule and the Scheil rule. The Lever rule assumes infinite diffusion of the solute species in the solid and the Scheil rule assumes zero diffusion. Both of these approximations have been tested, however "real" materials are expected to behave with a finite diffusion rate, thus is "in-between" these two approximations. Further research is required to develop a more realistic segregation diffusion model, however simulations using the Lever and Scheil methods could be used as bounding cases.

An example of uranium-plutonium species segregation is shown in Figure 53. For these simulations, the filling of the mold was not simulated so that only the solidification and species segregation could be investigated. The model consists of a cylindrical volume, initially filled with molten alloy, surrounded by a rectangular graphite block. The phase diagram of U-Pu shown in Figure 52, and the method outlined above were used in these simulations.

Also shown in Figure 53 are the mass fractions of plutonium after 1 second of simulation time. There is clearly a lateral variation of the species across the diameter of the fuel rod, and also (not shown here) as the simulation continues, the species vary along the length of the rod as well. These results are only preliminary and qualitative in nature; several alloy properties were estimated, which have a large effect on the quantitative effects of the species solidification and segregation. 

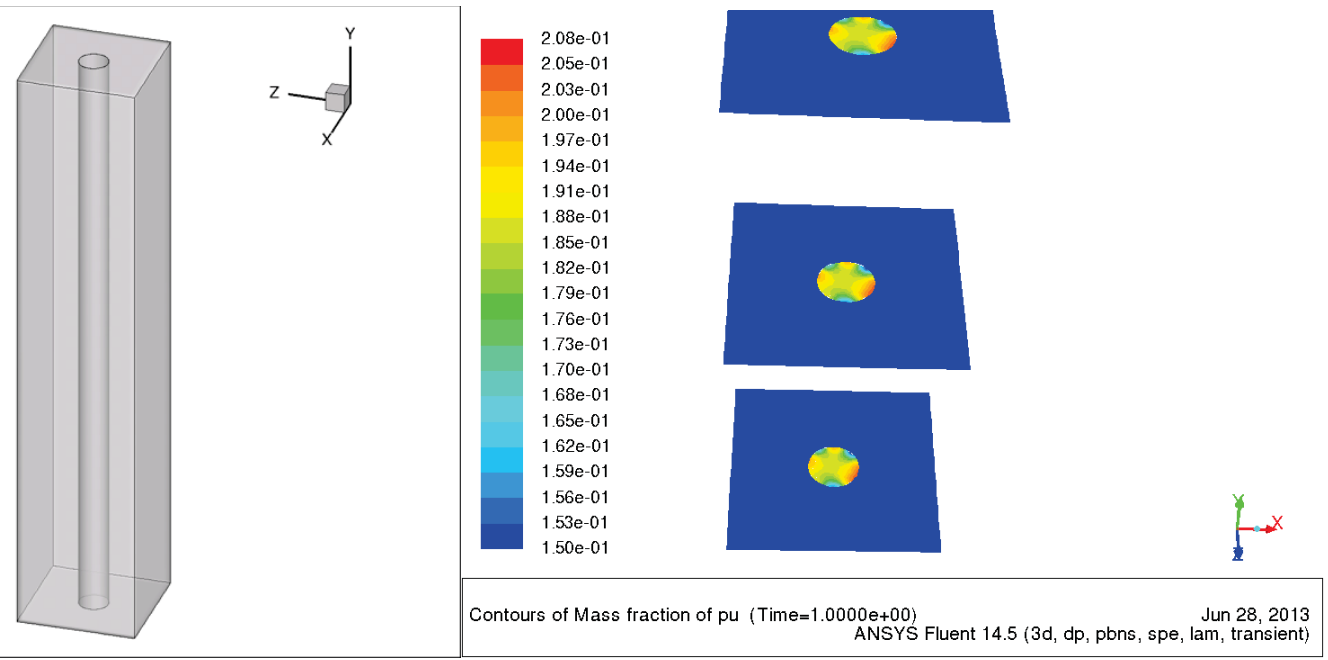

Figure 53. Simple fuel rod geometry and preliminary U-Pu segregation simulation results.

\section{REFERENCES}

1. J. Crapps, D. S. DeCroix' J. D. Galloway, D. A. Korzekwa, R. Aikin, R. Fielding, R. Kennedy, C. Unal, "Separate effects identification via casting process modeling for experimental measurement of U-Pu-Zr alloys, Journal of Nuclear Materials, in print, 2013

2. R. Fielding, J. Crapps, C. Unal, R. Kennedy, “Metal Fuel Casting Experiments and Simulations,” Submitted to International Conference on Fast Reactors and Related Fuel Cycles: Safe Technologies and Sustainable Scenarios (FR13), March 4-7 2013, Paris France

3. D.E. Peterson and E.M. Foltyn, "The Pu-U (Plutonium-Uranium) System," Bulletin of Alloy Phase Diagrams, Vol. 10, No. 2, pp. 160-164, 1987.

4. Flow3D User Manual, Release 10.1.0, Flow Science, Inc., November 2, 2012.

5. V.R. Voller and C. Prakash, "A Fixed-Grid Numerical Modeling Methodology for ConvectionDiffusion Mushy Region Phase-Change Problems," Int. J. Heat Mass Transfer, Vol. 30, pp. 17091720, 1987.

\subsection{In-Pile Instrumentation Development J. Rempe, J. Daw, R. Schley, K. Davis (INL)}

High fidelity, real-time data are essential for characterizing the performance of new fuels and materials during irradiation testing. Research efforts to develop the required sensors are focusing upon three technology areas: ultrasound-based sensors, fiber optics based sensors, and enhanced sensors for higher flux US materials testing reactors (MTRs). FY 2013 research accomplishments include:

- Completed laboratory evaluations to demonstrate that a new controlled load creep test rig (Figure 54) is ready for deployment in the recently reactivated ATR PWR loop, a capability only available at one other MTR.

- Completed laboratory evaluations of INL-developed magnetostrictive transducer design required for deployment of many ultrasonic sensors, including ultrasonic thermometers that allow an axial temperature profile to be measured from a single small diameter $(<1$ $\mathrm{mm}$ diameter) probe during high temperature (up to $2800^{\circ} \mathrm{C}$ ) fuel irradiations (Figure 55). INL-developed magnetostrictive transducers and candidate piezoelectric transducers will 
be included in an upcoming Massachusetts Institute of Technology Research Reactor irradiation.

- Initiated evaluations (Figure 56) to enhance INL-developed fiber optic elongation probe performance.

- Identified candidate sensors for deployment in the first Separate Effects Test (SET-1) capsule that could provide needed fuel performance code model development and validation data.

Additional details related to these accomplishments are provided in the reference below and associated publications.
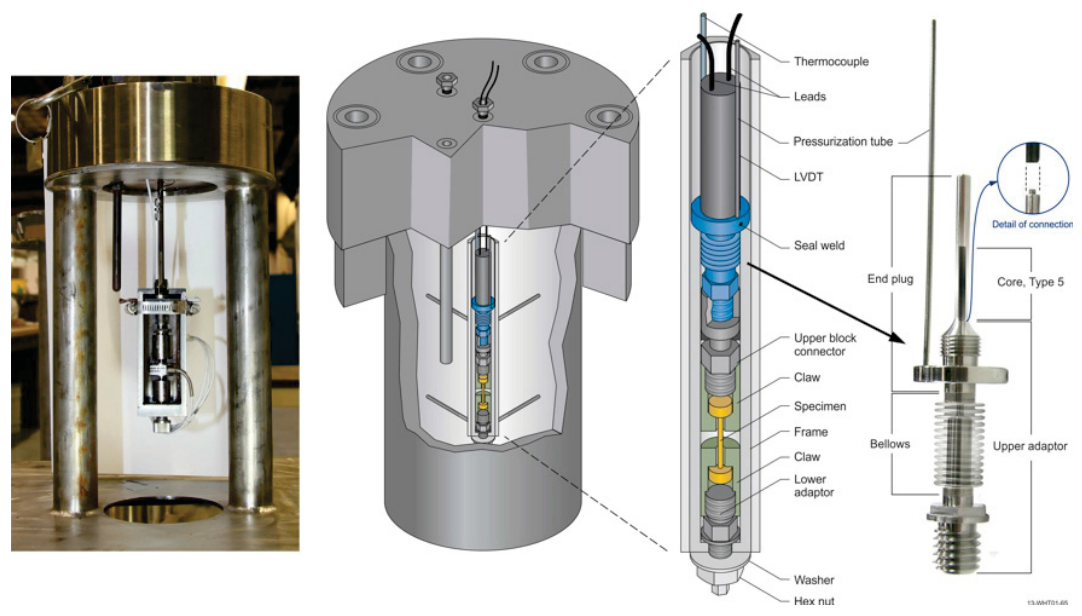

Figure 54. New variable load creep test rig now available.
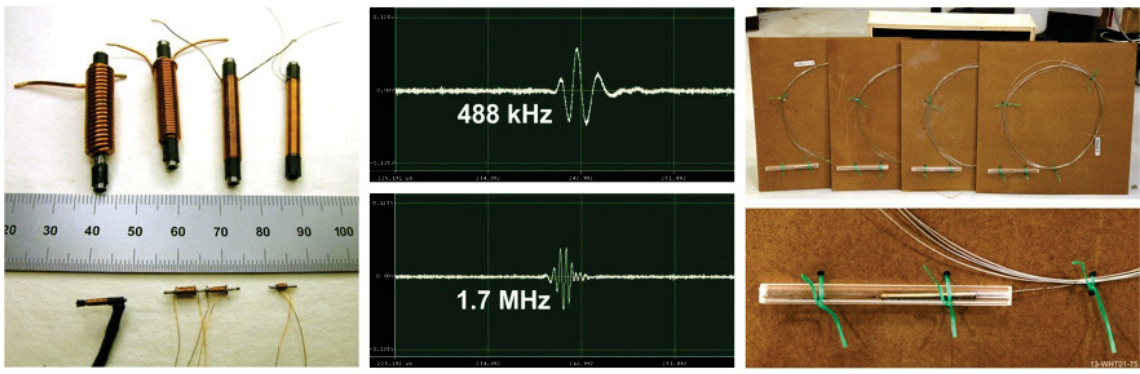

Figure 55. INL-developed magnetostrictive transducer design. 


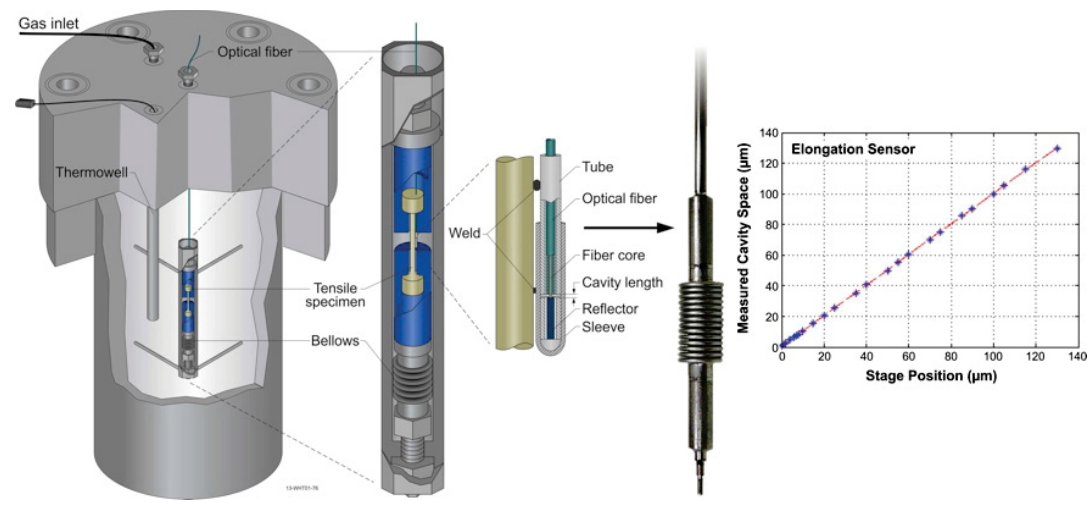

Figure 56. Laboratory evaluations initiated for enhancing fiber optics based elongation probe.

\section{REFERENCE}

1. J. Rempe, et al, In-pile Instrumentation to Support Fuel Cycle Research and Development -FY13 Status Report, FCRD-FUEL-2013-000237, September 2013.

\section{PATENTS/AWARDS}

"Fiber Optic Elongation/Displacement Sensor," IDR \#BA-725, submitted February 29, 2012. Inventors: Robert S. Schley, Joy L. Rempe, and Darrell L. Knudson.

"High Frequency Magnetostrictive Transducer for Waveguide Applications, IDR \#BA-767, submitted August 8, 2012; elected by BEA for patent filing August 1, 2013, Inventors: Joshua Daw, Steven Cheney Taylor, Joy Lynn Rempe, Darrell L. Knudson, and Steven Curtis Wilkins.

HTTL Doctoral Student, Joshua Daw, First Place, Fuel Cycle Research Innovations competition for paper, "Hot Wire Needle Probe for In-Reactor Thermal Conductivity Measurement" (IEEE Sensors, August, 2012).

\subsection{Crosscutting Technologies - Key Publications}

B.G. Kim, J. Rempe, D. Knudson, K. Condie, and B. Sencer, "An In-situ Creep Testing Capability for the Advanced Test Reactor,” Nuclear Technology, 179, 3, September 2012, pp. 413-428.

C. Morris, M. Bourke, D. Byler, C. Chen, G Hogan, J. Hunter, K. Kwiatkowski, F. Mariam, K.J. McClellan, F. Merrill, D. Morley, A. Saunders, "Qualitative Comparison of Bremsstrahlung X-rays and 800 MeV Protons for Tomography of Urania Fuel Pellets," Rev. Sci. Instr., 84[2], pp. 023902-1-7 (2013).

C. Xing, C, Jensen, Z. Hua, H. Ban D. H. Hurley, M. Khafizov, R. J. Kennedy, "Parametric Study of the Frequency-Domain Thermoreflectance Technique”, Journal of Applied Physics, 112 (2012).

D.H. Hurley, M. Khafizov, J. R. Kennedy, E. Burgett, “Mechanical Properties of Nuclear Fuel Surrogates Using Picosecond Laser Ultrasonics" 2013 International Congress on Ultrasonics (ICU 2013), G.W. Siong, L.S. Piang, K.B. Cheong eds., May 2-5, 2013.

I.O. Usov, R.M. Dickerson, P.O. Dickerson, M.E. Hawley, D.D. Byler, K.J. McClellan, "Thin uranium dioxide films with embedded xenon," J. Nuc. Mater., 437, pp.1-5 (2013). 
J. Crapps, D. S. DeCroix' J. D. Galloway, D. A. Korzekwa, R. Aikin, R. Fielding, R. Kennedy, C. Unal, "Separate effects identification via casting process modeling for experimental measurement of U-Pu-Zr alloys, Journal of Nuclear Materials, in print, 2013.

J. Daw, J. Rempe, D. Knudson, and S. C. Wilkins, "Hot Wire Needle Probe for In-Pile Thermal Conductivity Detection, IEEE Sensors Journal,12, Issue 8, August 2012, pp. 2554-2560.

J. Daw, J. Rempe, J. Palmer, P. Ramuhalli, R. Montgomery, H-T. Chien, B. Tittmann, B. Reinhardt, and G. Kohse, "Irradiation Testing of Ultrasonic Transducers," invited paper for ANIMMA 2013 Special Edition, IEEE Transactions on Nuclear Science, in process.

J.L. Rempe, D. L. Knudson, J. E. Daw, T. Unruh, B.M. Chase, K. Davis, A. J. Palmer, and R. S. Schley, "Advanced In-pile Instrumentation for Material and Test Reactors," invited paper for ANIMMA 2013 Special Edition, IEEE Transactions on Nuclear Science, in process.

J.L. Rempe, D. Knudson, J. Daw, T. Unruh, B. Chase, and K. Davis, "Enhanced In-pile Instrumentation at the Advanced Test Reactor," invited paper for ANIMMA 2011 Special Edition, IEEE Transactions on Nuclear Science,59, Issue 4, Part:2, August 2012, pp. 1214 -1223.

\section{CONFERENCE PROCEEDINGS}

J.E. Daw, J. Rempe, J. Palmer, P. Ramuhalli, R. Montgomery, H-T. Chien, B. Tittmann, B. Reinhardt, and G. Kohse, "Irradiation Testing of Ultrasonic Transducers," 2013 Conference on Advancements in Nuclear Instrumentation, Measurements Methods (ANIMMA 2013), June 2327, 2013, Marseilles, France.

J.E. Daw, J. L. Rempe, and J. C. Crepeau, "Update on Progress in Ultrasonic Thermometry Development," 8th International Topical Meeting on Nuclear Plant Instrumentation, Control, and Human Machine Interface Technologies (NPIC\&HMIT 2012), San Diego, CA, July 22-26, 2012.

J.L. Rempe, D. L. Knudson, J. E. Daw, T. Unruh, B.M. Chase, K. Davis, A. J. Palmer, and R. S. Schley, "Advanced In-pile Instrumentation for Material and Test Reactors," 2013 Conference on Advancements in Nuclear Instrumentation, Measurements Methods (ANIMMA 2013), June 2327, 2013, Marseilles, France.

J.L. Rempe, D. Knudson, J. Daw, T. Unruh, B. Chase, K. Davis, R. Schley, and S. Taylor, " New Sensors for Irradiation Testing at Materials and Test Reactors," IAEA Technical Meeting on In-Pile

J.L. Rempe, D. Knudson, J. Daw, T. Unruh, B. Chase, K. Davis, and R. Schley, "Enhanced Instrumentation for Materials and Test Reactors," 8th International Topical Meeting on Nuclear Plant Instrumentation, Control, and Human Machine Interface Technologies (NPIC\&HMIT 2012), San Diego, CA, July 22-26, 2012.

R. Fielding, J. Crapps, C. Unal, R. Kennedy, "Metal Fuel Casting Experiments and Simulations," Submitted to International Conference on Fast Reactors and Related Fuel Cycles: Safe Technologies and Sustainable Scenarios (FR13), March 4-7 2013, Paris France.

"Testing and Instrumentation for Development of Generation-IV Fuels and Materials," 21-24 August 2012, Halden, Norway. 
KEY LEVEL 2 MILESTONES

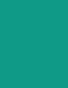

KEV LEVEL 2 MILESTONES

KEY LEVEL 2 MILESTONES 


\section{AFC FY 2013 LEVEL 2 MILESTONES}

\begin{tabular}{|c|c|c|c|}
\hline Site & Id No. & MS Title & Finish \\
\hline INL & $\begin{array}{c}\text { M2FT- } \\
\text { 13IN0201012 }\end{array}$ & Issue AFC 2013 Accomplishments Report & $11 / 01 / 2013$ \\
\hline INL & $\begin{array}{c}\text { M2FT- } \\
\text { 13IN0201013 }\end{array}$ & Conduct National ATF Metrics Workshop & $10 / 1512012$ \\
\hline INL & $\begin{array}{c}\text { M2FT- } \\
\text { 13IN0201014 }\end{array}$ & Conduct International ATF Workshop & $12 / 10 / 2012$ \\
\hline INL & $\begin{array}{c}\text { M2FT- } \\
\text { 13IN0201016 }\end{array}$ & Issue Advanced Fuels 2012 Accomplishments Report & $11 / 28 / 2012$ \\
\hline INL & $\begin{array}{c}\text { M2FT- } \\
\text { 13IN0202011 }\end{array}$ & ATF-1 Experiment ATR Design Acceptance & 9/25/2013 \\
\hline INL & $\begin{array}{l}\text { M2FT- } \\
\text { 13IN0202031 }\end{array}$ & $\begin{array}{l}\text { Deliver Report documenting fabrication of high density fuel } \\
\text { specimens that support development of accident tolerant } \\
\text { fuels }\end{array}$ & 9/12/2013 \\
\hline LANL & $\begin{array}{c}\text { M2FT- } \\
\text { 13LA0202061 }\end{array}$ & $\begin{array}{l}\text { Assessment of advanced cladding effects on LWR fuel } \\
\text { thermochemistry under off-normal and accident conditions }\end{array}$ & $9 / 13 / 2013$ \\
\hline LANL & $\begin{array}{c}\text { M2FT- } \\
\text { 13LA0202063 }\end{array}$ & $\begin{array}{l}\text { Demonstration of evolutionary enhancements to UO2 fuel } \\
\text { performance }\end{array}$ & 9/1/2013 \\
\hline ORNL & $\begin{array}{c}\text { M2FT- } \\
\text { 13OR0202071 }\end{array}$ & $\begin{array}{l}\text { Complete experiments and modeling of urania-ceria system } \\
\text { and submit paper for publication }\end{array}$ & $12 / 21 / 2012$ \\
\hline LANL & $\begin{array}{c}\text { M2FT- } \\
\text { 13LA0202081 }\end{array}$ & $\begin{array}{l}\text { Issue report on assessment of advanced NDE and path } \\
\text { forward for AFC- } 2 \text { C testing }\end{array}$ & $2 / 25 / 2013$ \\
\hline LANL & $\begin{array}{l}\text { M2FT- } \\
\text { 13LA0202082 }\end{array}$ & $\begin{array}{l}\text { Complete dry run using clad dUO2 rodlets with } \\
\text { structures/defects tailored to define current advanced NDE } \\
\text { capabilities }\end{array}$ & $12 / 21 / 2013$ \\
\hline ORNL & $\begin{array}{c}\text { M2FT- } \\
\text { 13OR0202132 }\end{array}$ & $\begin{array}{l}\text { Issue report documenting joint LANL and ORNL Advanced } \\
\text { LWR cladding materials LOCA testing }\end{array}$ & $10 / 31 / 2013$ \\
\hline ORNL & $\begin{array}{c}\text { M2FT- } \\
\text { 13OR0202152 }\end{array}$ & $\begin{array}{l}\text { Provide report on development and characterization of high } \\
\text { toughness nanostructured ferritic alloy for cladding }\end{array}$ & $8 / 30 / 2013$ \\
\hline ORNL & $\begin{array}{l}\text { M2FT- } \\
\text { 13OR0202191 }\end{array}$ & $\begin{array}{l}\text { Report on modeling and thermochemical and } \\
\text { thermostructural evolution of LWR engineered fuel }\end{array}$ & 9/20/2013 \\
\hline ORNL & $\begin{array}{c}\text { M2FT- } \\
\text { 13OR0202201 }\end{array}$ & $\begin{array}{l}\text { Compilation of Properties and Microstructure of Optimized } \\
\text { FCM Fuel }\end{array}$ & $9 / 13 / 2013$ \\
\hline ORNL & $\begin{array}{l}\text { M2FT- } \\
\text { 13OR0202211 }\end{array}$ & $\begin{array}{l}\text { Issue final PIE Report on Matrix Stability and Pellet Clad } \\
\text { Interaction of FCM-E Series Capsules. }\end{array}$ & $8 / 13 / 2013$ \\
\hline ORNL & $\begin{array}{l}\text { M2FT- } \\
\text { 13OR0202221 }\end{array}$ & $\begin{array}{l}\text { Report Documenting Production Process, Thermophysical } \\
\text { Properties, and QA Process to be Applied to First Irradiation } \\
\text { Batch of FCM Fuels }\end{array}$ & $7 / 26 / 2013$ \\
\hline ORNL & $\begin{array}{c}\text { M2FT- } \\
\text { 13OR0202231 }\end{array}$ & $\begin{array}{l}\text { Issue progress report documenting results of UN kernel } \\
\text { fabrication }\end{array}$ & 8/8/2013 \\
\hline ORNL & $\begin{array}{c}\text { M2FT- } \\
\text { 13OR0202241 }\end{array}$ & $\begin{array}{l}\text { Complete in-cell installation of High-Temperature capability } \\
\text { for Severe Accident Test Station. }\end{array}$ & $11 / 28 / 2013$ \\
\hline ORNL & $\begin{array}{l}\text { M2FT- } \\
\text { 13OR0202242 }\end{array}$ & $\begin{array}{l}\text { Complete design and construction of (ex-cell) LOCA quench } \\
\text { furnace }\end{array}$ & $6 / 13 / 2013$ \\
\hline INL & $\begin{array}{c}\text { M2FT- } \\
\text { 13IN0203031 } \\
\end{array}$ & $\begin{array}{l}\text { Initiate casting of minor actinide bearing fuel samples in } \\
\text { GACS }\end{array}$ & $8 / 13 / 2013$ \\
\hline INL & $\begin{array}{c}\text { M2FT- } \\
\text { 13IN0203032 }\end{array}$ & Install GACS furnace in casting laboratory glove box & $2 / 27 / 2013$ \\
\hline INL & $\begin{array}{c}\text { M2FT- } \\
\text { 13IN0203053 }\end{array}$ & $\begin{array}{l}\text { Initiate pure Am metal production for fuel research and } \\
\text { Development }\end{array}$ & $1 / 31 / 2013$ \\
\hline INL & M2FT- & Ready to Insert AFC Outboard-A Year 2 Adv. Metallic Fuel & $9 / 24 / 2013$ \\
\hline
\end{tabular}




\begin{tabular}{|c|c|c|c|}
\hline Site & Id No. & MS Title & Finish \\
\hline & $13 \mathrm{IN} 0203081$ & Experiments (AFC-4A,4B) in ATR & \\
\hline INL & $\begin{array}{l}\text { M2FT- } \\
\text { 13IN0203091 }\end{array}$ & Issue PIE Report on FFTF Legacy Metallic Fuels & $4 / 30 / 2013$ \\
\hline INL & $\begin{array}{l}\text { M2FT- } \\
\text { 13IN0203092 }\end{array}$ & Issue PIE Report on EBR-II Legacy Metallic Fuels & $6 / 29 / 2013$ \\
\hline INL & $\begin{array}{l}\text { M2FT- } \\
\text { 13IN0203093 }\end{array}$ & $\begin{array}{l}\text { Complete dry run with TN-106 complete, HFEF ready to } \\
\text { receive FUTURIX-FTA shipment }\end{array}$ & $12 / 31 / 2013$ \\
\hline ORNL & $\begin{array}{c}\text { M2FT- } \\
\text { 13OR0203111 }\end{array}$ & $\begin{array}{l}\text { Complete fabrication of three rabbit capsules containing } \\
\text { metallic fuels for irradiation in HFIR }\end{array}$ & $9 / 27 / 2013$ \\
\hline LANL & $\begin{array}{c}\text { M2FT- } \\
\text { 13LA0203122 }\end{array}$ & $\begin{array}{l}\text { Issue summary report documenting fuel performance } \\
\text { modeling results for selected rodlets from AFC irradiation } \\
\text { experiments. }\end{array}$ & $9 / 12 / 2013$ \\
\hline LANL & $\begin{array}{c}\text { M2FT- } \\
\text { 13LA0203133 }\end{array}$ & $\begin{array}{l}\text { Prepare mechanical test specimens from ACO-3 duct for re- } \\
\text { irradiation in BOR-60 }\end{array}$ & $11 / 9 / 2012$ \\
\hline LANL & $\begin{array}{c}\text { M2FT- } \\
\text { 13LA0203151 }\end{array}$ & Fabricate ODS Steel tubing for BOR-60 Irradiation & $6 / 1 / 2013$ \\
\hline INL & $\begin{array}{c}\text { M2FT- } \\
13 \mathrm{IN} 0204011\end{array}$ & Issue a Conceptual (Draft) Transient Testing Plan & $8 / 30 / 2013$ \\
\hline INL & $\begin{array}{c}\text { M2FT- } \\
13 I N 0204031\end{array}$ & $\begin{array}{l}\text { Issue Summary Report on Advanced Sensor Development; } \\
\text { recommend technology for near-term deployment in SET-1 } \\
\text { and identify remaining tasks }\end{array}$ & 9/10/2013 \\
\hline INL & $\begin{array}{c}\text { M2FT- } \\
\text { 13IN0204061 }\end{array}$ & $\begin{array}{l}\text { Design and begin construction of sample loading and heating } \\
\text { apparatus for measurement of mechanical and thermal } \\
\text { properties }\end{array}$ & $9 / 13 / 2013$ \\
\hline
\end{tabular}

\subsection{KEY Milestone Reports}

A.T. Nelson and K. Suzuki, "Assessment of Advanced Cladding Effects on LWR Fuel Evolution during Off-Normal Conditions, M2FT-13LA0202061."

A.T. Nelson, R.M. Leckie and E.P. Luther, J.T. White, J.T. Dunwoody, and P. Peralta, "Evolutionary Enhancements to $\mathrm{UO}_{2}$ Fuel Performance, M2FT-13LA0202063."

B. Mihaila, and E.P. Luther, "Progress report on MSC-DFEM (Densification-Based Finite-Element Model) for the Sintering of Ceramic Nuclear Fuels, M4FT-13LA0204093."

J.A. Valdez and D.D. Byler, "Report on synthesis of high density ceramic composite materials with microstructural and chemical characterization, M3FT-13LA0202088."

J.L. Rempe, H. MacLean, R. Schley, D. Hurley, J. Daw, S. Taylor, J. Smith, J. Svoboda, D. Kotter, D. Knudson, S. C. Wilkins, M. Guers, L. Bond, L. Ott, J. McDuffee, E. Parma, and G. Rochau, New InPile Instrumentation to Support Fuel Cycle Research and Development, FCRD-FUEL-2011-000033 (also issued as INL/EXT-10-19149), January 2011.

J.L. Rempe, J. Daw, D. Knudson, R. Schley, L. Bond, J. Coble, M. Good, and R. Meyer, In-pile Instrumentation to Support Fuel Cycle Research and Development - FY11 Status Report, FCRDFUEL-2011-000307 (also issued as INL/EXT-11-23119), September 2011.

J.L. Rempe, J. Daw, D. Knudson, R. Schley, T. Unruh, and B. Chase, In-pile Instrumentation to Support Fuel Cycle Research and Development -FY12 Status Report, FCRD-FUEL-2012-000282, September 2012. 
J.L. Rempe, J. Daw, R. Schley, K. Davis, D. Knudson, T. Unruh, and B. Chase, and J. Palmer, In-pile Instrumentation to Support Fuel Cycle Research and Development -FY13 Status Report, FCRDFUEL-2013-000237, September 2013.

J.T. White and A.T. Nelson, 'Thermophysical Properties of Advanced Fuels Progress Report, M3FT13LA0202068."

J.T. White and A.T. Nelson, "Performance of Advanced Ceramic LWR Fuel Candidates, M3FT13LA0202069."

K. Suzuki, and A.T. Nelson, "Characterization of Oxidation of $\mathrm{UO}_{2}$ under Off-Normal Conditions, M3FT-13LA0202066."

R.M. Leckie and E.P. Luther, “Evolutionary UO UO $_{2}$ Progress Report, M3FT-13LA0202067.”

S.C. Vogel, D.D. Byler, K.J. McClellan, F. Mariam, M.A.M. Bourke, M. Okuniewski, "Assessment of advanced NDE techniques and the path forward to evaluating an AFC-2C irradiated fuel pin, M2FT-13LA0202081."

S.L. Voit, B. Slone, and T. Besmann, "Thermochemical experiment and modeling in the U-Ce-O system, M2FT-130R0202071." 